Published in "Bulletin of the Peabody Museum of Natural History

57(1): 57-95, 2016"

which should be cited to refer to this work.

\title{
A Review of the Fossil Record of Turtles of the Clade Pan-Kinosternoidea
}

\author{
Walter G. Joyce ${ }^{1}$ and Jason R. Bourque ${ }^{2}$ \\ ${ }^{1}$ Corresponding author: Department of Geosciences, University of Fribourg, 1700 Fribourg, Switzerland \\ —email: walter.joyce@unifr.ch \\ ${ }^{2}$ Florida Museum of Natural History, University of Florida, Gainesville, FL 32611 USA \\ -email: jbourque@flmnh.ufl.edu
}

\begin{abstract}
Turtles of the total clade Pan-Kinosternoidea have a relatively poor fossil record that extends back to the Late Cretaceous (Campanian). The clade is found only in North America during its early history, but dispersed to Central America no later than the Miocene and to South America no later than the Pleistocene. Ancestral pan-kinosternoids were likely aquatic, bottom-walking omnivores or carnivores that preferred low-energy freshwater habitats. The Pan-Dermatemys lineage is often recovered in more fluvial habitats, and some are specialized to feed on aquatic vegetation. Alternatively, many representatives of Kinosternon evolved specializations (e.g., plastral lobe kinesis) that allowed them to successfully inhabit and disperse across more terrestrial habitats such as savannas and floodplains. A taxonomic review of the group concludes that of 42 named taxa, 27 are nomina valida (including two species of the controversial taxon Planetochelys), 14 are nomina invalida and only one a nomen dubium.
\end{abstract}

KEYWORDS

Phylogeny, biogeography, paleoecology, Kinosternoidea, Kinosternidae, Dermatemys mawii

\section{Introduction}

The term Pan-Kinosternoidea refers to the total clade of Kinosternoidea, which originates from the common ancestor of the mud turtle Kinosternon scorpioides (Linnaeus, 1766), the Mexican musk turtle (or Guao) Staurotypus triporcatus (Wiegmann, 1828) and the Central American river turtle (or Hicatee) Dermatemys mawii Gray, 1847. The two primary crown clades within Kinosternoidea are Kinosternidae and D. mawii, and their total clades are referred to as Pan-Kinosternidae and Pan-Dermatemys (Joyce et al. 2004). We herein informally name representatives of the latter clade "pan-dermatemydids."

The increasingly more inclusive sister group relationship between kinosternines and staurotypines, between kinosternids and dermatemydids and between kinosternoids and chelydrids has only been recognized relatively recently, although parts of these were recognized throughout the history of research. The first meaningful global classifications of turtles proposed during the second half of the 19th century surprisingly resemble the current consensus, although notable differences persist. Gray (1869) grouped chelydrids, staurotypines and Sternotherus into the paraphyletic "Crucisterna" and all Kinosternon into "Kinosterna" and then united these two groups into the paraphyletic "Chelydradae," which essentially includes all then-known chelydroids, with the notable exception of Dermatemys mawii. Subsequently, Boulenger (1889) provided a close variation of this classification that recognizes chelydrids and kinosternines as two natural groups, but furthermore grouped staurotypines and D. mawii into an intermediate "dermatemydid" family. Siebenrock (1909) later united D. mawii with kinosternids into his "Kinosternidae," but this taxon also includes the aberrant Asian big-headed turtle Platysternon megacephalum Gray, 1831. The modern consensus for classifying these turtles was first recognized by Baur (1893), who united chelydrids, dermatemydids, staurotypines and kinosternines into "Chelydroidea," but this arrangement was not widely recognized, 
perhaps because Baur (1893) died soon after and was not able to further publish his insights in additional publications.

Hay (1908a) provided an extensive classification that was the first to include all fossil and living turtles. The arrangement that Hay (1908a) proposed greatly resembles that of Boulenger (1889) by recognizing chelydrids and kinosternines, but greatly expanded the concept of "Dermatemydidae" through the inclusion of an eclectic assortment of fossil turtles, in particular adocids, nanhsiungchelyids, carettochelyids and the pleurosternid Compsemys. This polyphyletic wastebasket taxon was primarily united in Hay's (1908a) diagnosis by a complete row of inframarginal scutes, a character now considered to be symplesiomorphic (Meylan and Gaffney 1989), and all other characters are noted to occur only sometimes. The polyphyletic nature of "Dermatemydidae" was later further circumscribed to include lindholmemydids, "sinochelyids" and solemydids (e.g., Romer 1956; Kuhn 1964; Mlynarski 1976; Carroll 1988). The close relationships of the remaining chelydroids was nevertheless recognized in these classifications (e.g., Williams 1952; Kuhn 1964; Mlynarski 1976), though sometimes still to the inclusion of Platysternon megacephalum (Romer 1956).

The close relationship of Dermatemys mawii with kinosternids was highlighted in a series of morphological studies (e.g., Williams 1950; McDowell 1961; Zug 1966; Albrecht 1967), but this did not result in a change in the prevailing classifications. Using cranial characters and cladistic arguments, Gaffney (1975) finally united D. mawii and Kinosternidae to the exclusion of the broad set of fossil taxa listed above, but furthermore grouped these with Trionychia to form the clade "Trionychoidea." The clade consisting of D. mawii and Kinosternidae was later named "Kinosternoidae" (Gaffney and Meylan 1988), but subsequently renamed "Kinosternoidea" (Joyce et al. 2004).

The monophyly of Kinosternoidea was more recently corroborated by a series of increasingly complete studies using molecular data (e.g., Shaffer et al. 1997; Krenz et al. 2005; Barley et al. 2010; Crawford et al. 2015), but these studies also highlighted that kinosternoids are not closely related to trionychians, but rather to chelydrids, as had been proposed throughout the 19th century. Although numerous morphological characters exist that could unite this highly inclusive clade, named Chelydroidea following Baur (1893) (Knauss et al. 2011), current morphological studies still fail to retrieve this clade (e.g., Joyce 2007; Anquetin 2012; Sterli et al. 2013; Rabi et al. 2014). Nevertheless, the fossil record is more consistent with the molecular arrangement in that all pantrionychian clades can be traced back to the Early Cretaceous of Asia, whereas all chelydroid clades only emerged during the Late Cretaceous of North America (Crawford et al. 2015), and because early representatives of the chelydroid lineage are difficult to distinguish from one another. We therefore speculate that it is only a matter of time until new fossil finds will support the emerging molecular consensus.

For institutional abbreviations see Appendix 1. Named pan-kinosternoid genera are listed in Appendix 2.

\section{Skeletal Morphology}

\section{Cranium}

Bienz (1895) described the cranial morphology of Dermatemys mawii in detail, and McDowell (1964), Meylan and Gaffney (1989) and Legler and Vogt (2013) provided additional figures for that taxon. Among kinosternids, we are aware of original cranial figures of decent quality for Claudius angustatus (Gaffney 1979), Kinosternon leucostomum (Boulenger 1889; Legler and Vogt 2013), K. scorpioides (Pritchard and Trebbau 1984; Legler and Vogt 2013), K. subrubrum (Gaffney 1979), Staurotypus salvinii (Gray 1869; Boulenger 1889; Williams 1952), S. triporcatus (Legler and Vogt 2013) and Sternotherus odoratus (Gaffney 1979; Bever 2009). Of these, Bienz (1895), Gaffney (1979) and Bever (2009) provide the most meaningful insights into the cranial anatomy of the group. Among unambiguous fossil pan-kinosternoids, cranial material has been reported for the Late Cretaceous (Maastrichtian) Emarginachelys cretacea (Whetstone 1978), the early Eocene Baptemys garmanii (Estes 1988) and Baptemys wyomingensis (Hay 1908a), the late Eocene Xenochelys formosa (Williams 1952), the late Oligocene Xenochelys floridensis (Bourque 2013), and the middle Miocene Kinosternon skullridgescens (Bourque 2012b), Kinosternon pojoaque (Bourque 2012a) and Kinosternon rincon (Bourque, in press).

The skulls of pan-kinosternoids are generally broad and triangular in shape, the eyes are mostly oriented laterally and the interorbital 
area is broad. With few exceptions (e.g., some Kinosternon such as K. flavescens), extant kinosternoids have a protruding nose and this is also apparent in the skull in lateral view. The upper temporal emargination is typically deep, but the lower temporal emargination only shallow (Figure 1).

The prefrontals are large, cover much of the interorbital area, have broad midline contact with one another and form a broad descending process that contacts the vomer and palatines distally and defines a narrow keyhole fissura ethmoidalis (see Figure 1). The frontals are typically reduced in size relative to the prefrontals and either only contribute to the orbit along a narrow process, as in Emarginachelys cretacea and Dermatemys mawii (Figure 1A), or not at all, as in kinosternids (Figure $1 \mathrm{~B}, \mathrm{C}$ ). The parietals are large elements that contribute little to the dorsal skull roof and only contact the postorbitals laterally. The parietals form broad descending processes that contact the palatines, pterygoids and epipterygoids ventrally, but do not contribute directly to the otic trochlear processes. The postorbitals are relatively small bones that are broadly overlain by the postorbitals, but always contact the squamosals posteriorly.

The paired premaxillae, together with the vomer, hinder medial contact of the maxillae in ventral view, even in taxa with extremely deep triturating surfaces (see Figure 1). The maxillae are large elements that symplesiomorphically lack a posterior contact with the quadratojugal in Emarginachelys cretacea or Dermatemys mawii (see Figure 1A), but often broadly contact this element in kinosternids (see Figure 1B, C). The jugals broadly overlap the postorbitals, but never contribute to the upper temporal emargination. The quadratojugals are enlarged elements that narrowly contact the postorbitals anteriorly and the squamosals posteriorly, and broadly frame the cavum tympani. The squamosals contact the quadratojugals anteriorly and define the typically voluminous cavum postoticum.

The broad secondary palate of Dermatemys mawii is formed by only the maxilla and consists of a serrated lingual ridge and several accessory ridges (see Figure 1A). By contrast, the expansive palate of many kinosternids often shows a broad contribution from the palatine, but lacks any accessory ridges or teeth (see Figure 1B, C). The vomer is an unpaired element that clearly contacts the prefrontal anteriorly and completely separates the maxillae and palatines from paired contact along the midline. The foramina palatinum posterius are present, but typically highly reduced in size. An ascending process of the palatine contributes to the lateral braincase wall. This process ranges in size from small in $D$. mawii, to intermediate in kinosternines, to enormous in staurotypines. The pterygoids are large elements that contact one another along the midline, floor the otic area and broadly contact the basioccipital posteriorly. The external processes are minute and lack a vertical flange. The basisphenoid contributes little to the ventral surface of the skull.

The quadrates form enlarged cavum tympani and fully define the anterior limits of the voluminous antrum postoticum. The incisura columella auris is a deep notch that remains open in all kinosternoids. The trochlear process is formed by the prootic and quadrate and overhangs the enclosed trigeminal foramen. Although the trochlear process is indistinct in Emarginachelys cretacea and Dermatemys mawii (see Figure 1A), it greatly protrudes into the temporal fossa in kinosternids (see Figure 1B, C). The stapedial foramen has a regular size in E. cretacea, but is greatly reduced in kinosternids and fully lost in $D$. mawii (see Figure 1). The supraoccipital forms an elongate crista that protrudes posteriorly well beyond the posterior margin of the skull.

The pterygoid forms the floor of a groove into which the internal carotid artery enters at the back of the skull. The posterior jugular foramen is well defined, but only sometimes fully enclosed by contact of the exoccipital with the opisthotic. The remainder of the fenestra postotica, however, remains wide open. The basioccipital and exoccipitals enclose two pairs of hypoglossal foramina. The basioccipital is a large element in Dermatemys mawii (see Figure 1A), but relatively small in kinosternids (see Figure 1B, C).

The mandibles of kinosternoids are generally low and lack splenials and distinct retroarticular processes. The triturating surface mirrors that of the upper triturating surfaces and is therefore highly variable, ranging from very narrow to extremely broad in kinosternids, to highly ornamented with accessory ridges in Dermatemys mawii. The breadth of the triturating surfaces is typically correlated with head to body size and diet. 

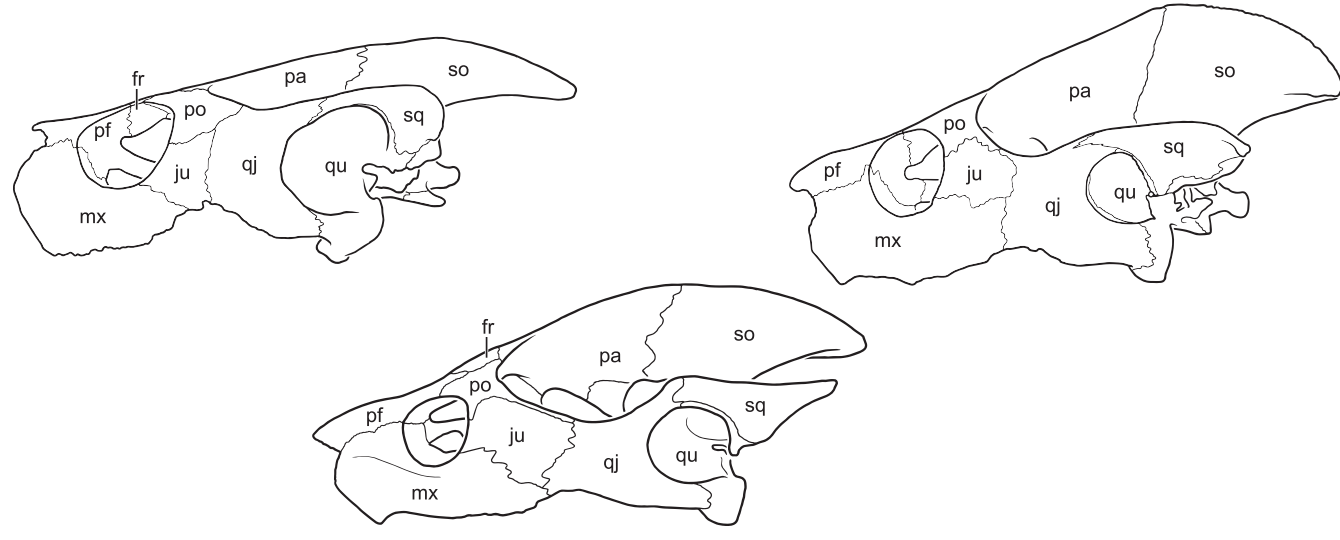

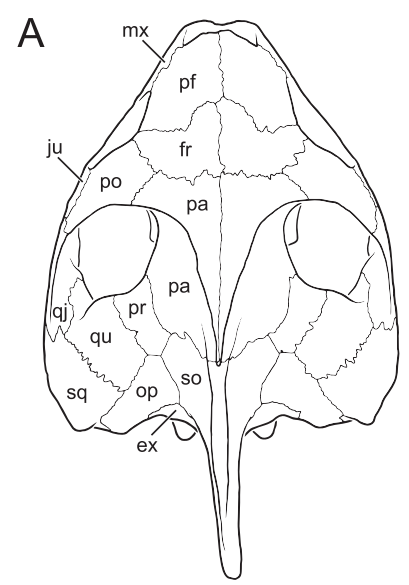

Dermatemys mawii
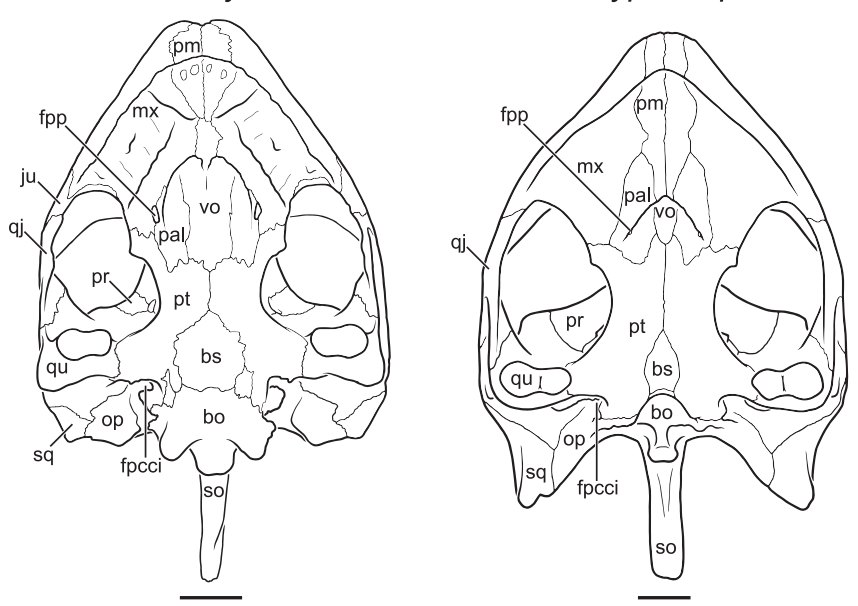

C

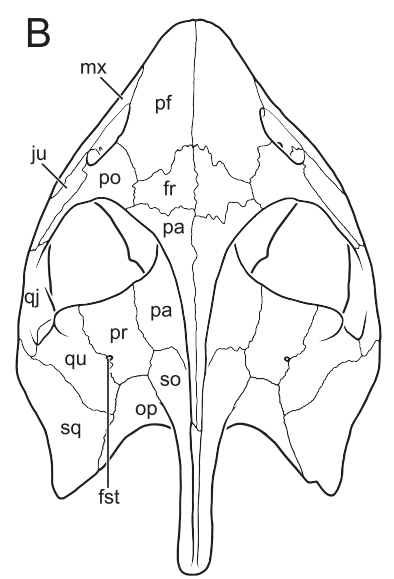

Staurotypus triporcatus
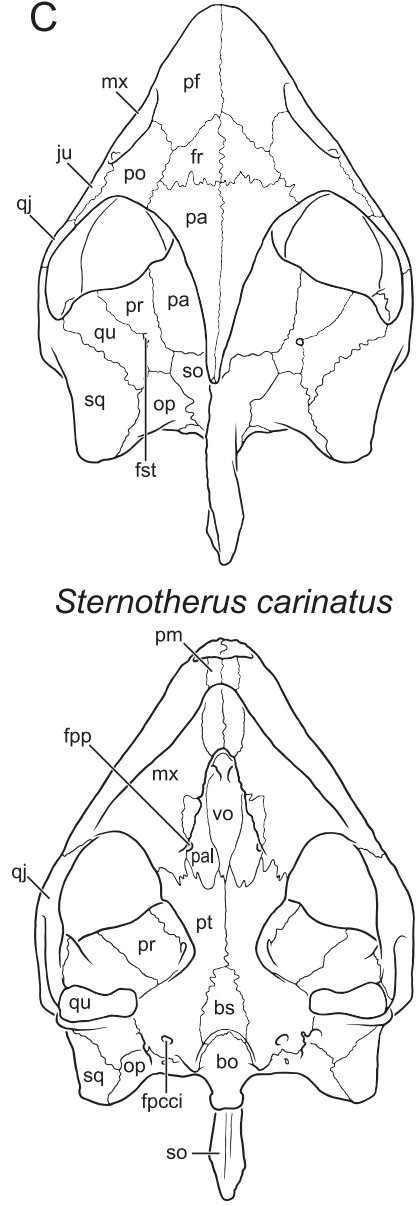

ternotherus carinatus

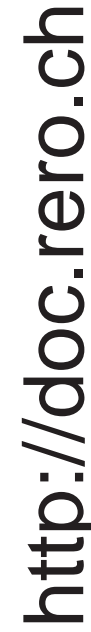

Figure 1. Cranial morphology of Pan-Kinosternoidea as exemplified by three species. A, Dermatemys mawii (USNM 66669). B, Staurotypus triporcatus (UF 3472). C, Sternotherus carinatus (USNM 59959). Abbreviations: bo, basioccipital; bs, basisphenoid; ex, exoccipital; fpcci, foramen posterius canalis carotici interni; fpp, foramen palatinum posterius; fr, frontal; fst, foramen stapedio-temporale; ju, jugal; $\mathrm{mx}$, maxilla; op, opisthotic; pa, parietal; pal, palatine; pf, prefrontal; pm, premaxilla; po, postorbital; pr, prootic; pt, pterygoid; qj, quadratojugal; qu, quadrate; so, supraoccipital; sq, squamosal; vo, vomer. Scale bars approximate $1 \mathrm{~cm}$. 
A

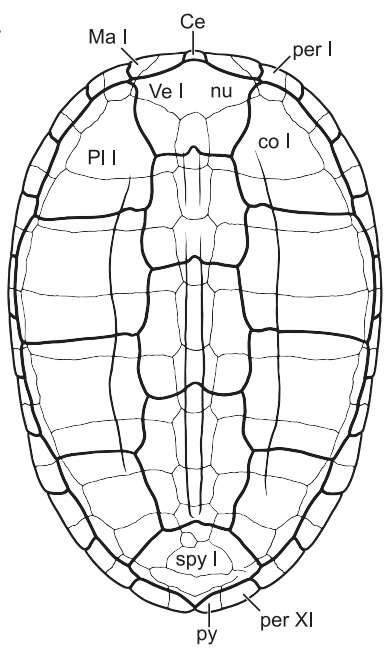

Baptemys nanus

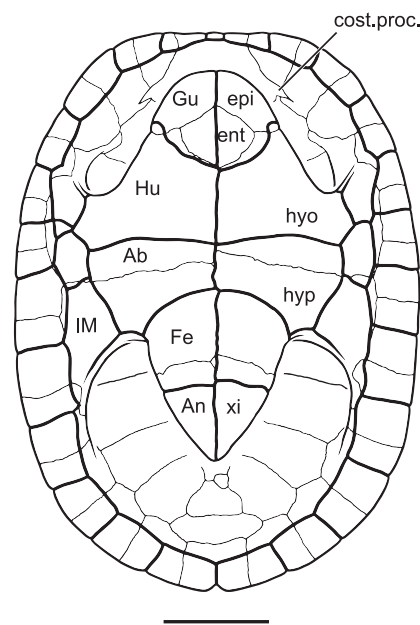

B

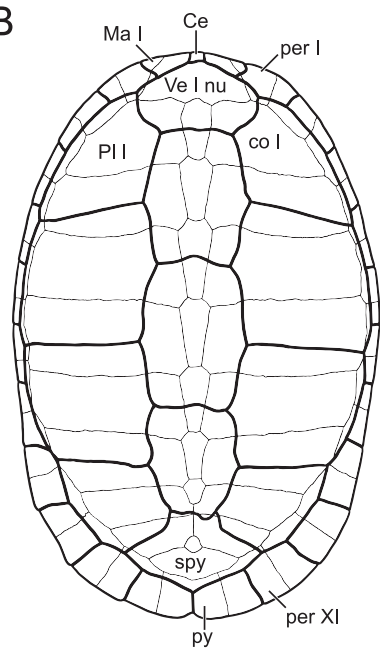

Dermatemys mawii

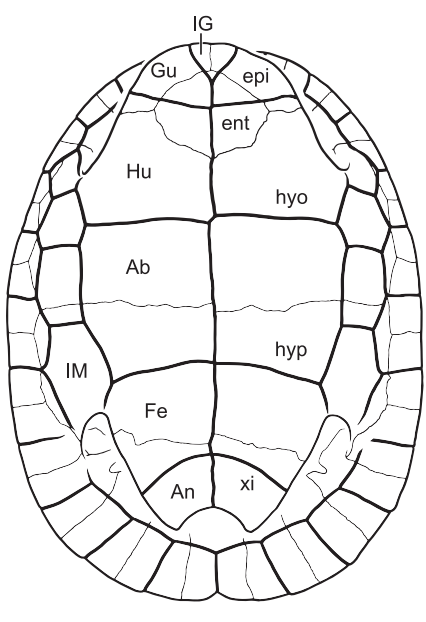

C

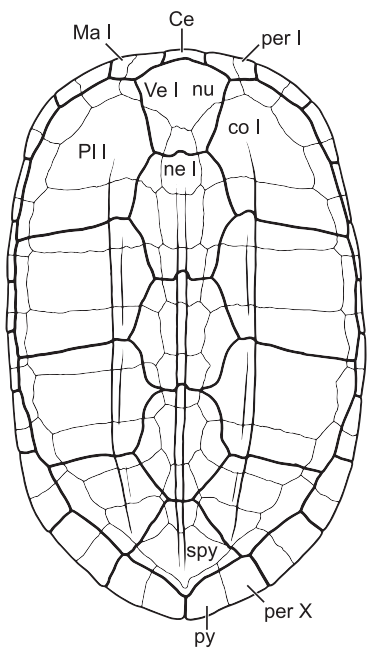

Staurotypus salvinii

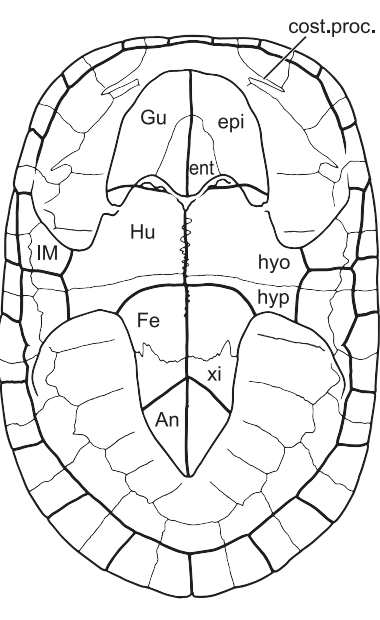

FIGURE 2. Shell morphology of Pan-Kinosternoidea. A, Baptemys nanus (redrawn and idealized from Bourque et al. 2014). B, Dermatemys mawii (USNM 66669). C, Staurotypus salvinii (UF 165992). Abbreviations: Ab, abdominal scute; An, anal scute; Ce, cervical scute; co, costal; cost. proc., costiform process; ent, entoplastron; epi, epiplastron; Fe, femoral scute; $\mathrm{Gu}$, gular scute; Hu, humeral scute; hyo, hyoplastron; hyp, hypoplastron; IG, intergular scute; IM, inframarginal scute; Ma, marginal scute; ne, neural; nu, nuchal; per, peripheral; Pl, pleural scute; py, pygal; spy, suprapygal; Ve, vertebral scute; xi, xiphiplastron. Scale bars approximate $5 \mathrm{~cm}$.

\section{Shell}

We are only aware of few illustrations of the complete shell of extant kinosternoids, in particular those of Dermatemys mawii (Boulenger 1889), Kinosternon flavescens (Joyce 2007), K. leucostomum (Boulenger 1889), K. scorpioides (Pritchard and Trebbau 1984) and Staurotypus salvinii (Boulenger 1889). Given that the vast majority of named fossil pan-kinosternoids are based on relatively complete shell material, we here refrain from listing all illustrations of fossil pan-kinoster- noids and refer the reader to the Systematic Paleontology below.

The shells of pan-kinosternoids are typically oval and often intermediately to highly domed, with some exceptions such as Claudius angustatus which has a relatively flat carapace. The shell of basal pan-kinosternoids was tricarinate (e.g., Figure $2 \mathrm{~A}, \mathrm{C}$ ). This morphology was later amplified among representatives of the fossil Hoplochelys and the extant Staurotypus, but strongly suppressed or lost in adult Dermatemys mawii (Figure 2B) and 
A

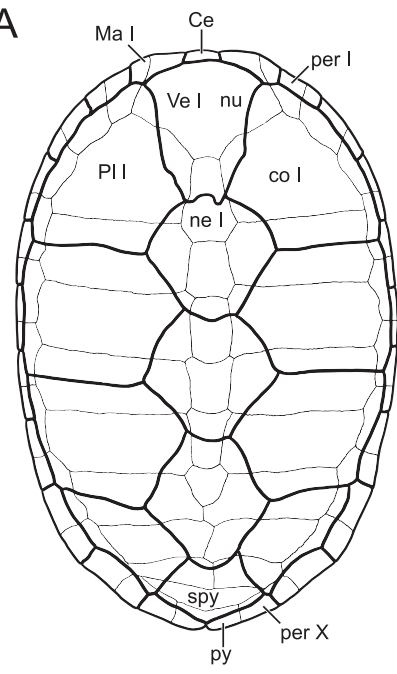

Xenochelys lostcabinensis

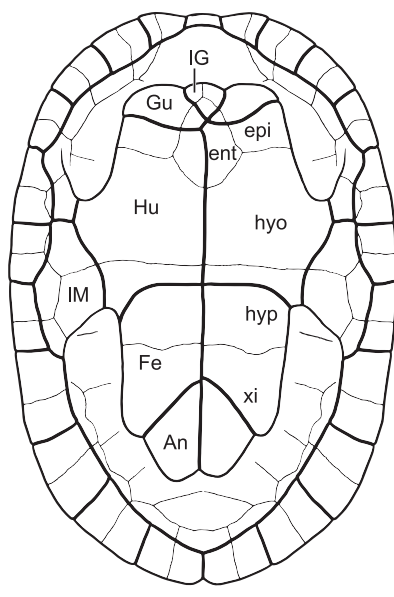

B

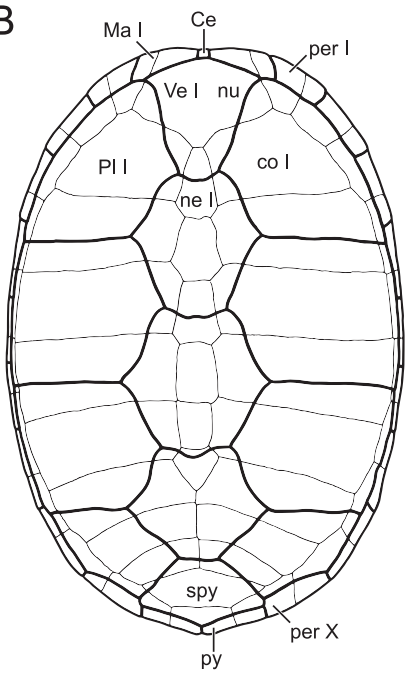

Kinosternon bauri

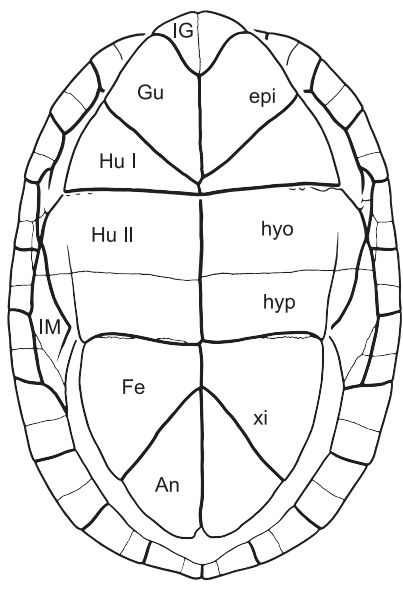

C

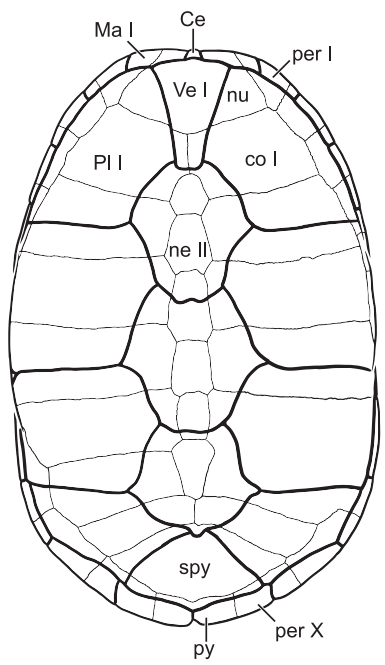

Sternotherus odoratus

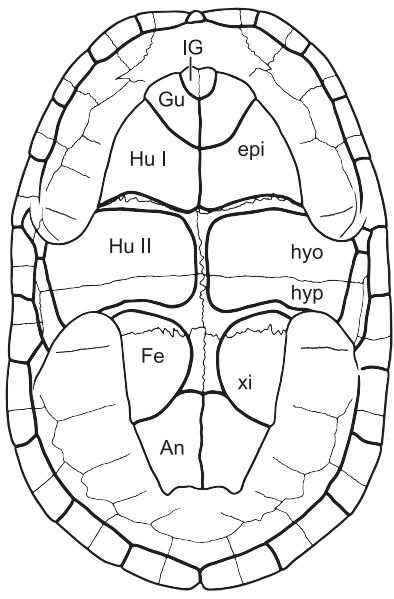

Figure 3. Shell morphology of Pan-Kinosterninae. A, Xenochelys lostcabinensis (redrawn from Hutchison 1991). B, Kinosternon baurii (UF 165988). C, Sternotherus odoratus (UF 135153). Abbreviations: An, anal scute; Ce, cervical scute; co, costal; ent, entoplastron; epi, epiplastron; Fe, femoral scute; $\mathrm{Gu}$, gular scute; $\mathrm{Hu}$, humeral scute; hyo, hyoplastron; hyp, hypoplastron; IG, intergular scute; IM, inframarginal scute; Ma, marginal scute; ne, neural; nu, nuchal; per, peripheral; Pl, pleural scute; py, pygal; spy, suprapygal; Ve, vertebral scute; xi, xiphiplastron. Scale bars approximate $5 \mathrm{~cm}$.

some kinosternines (Figure 3). The surface of the shell is typically smooth in adults. The carapace of basal pan-kinosternoids consists of a nuchal, a continuous row of 8 neurals, 8 pairs of costals, 11 pairs of peripherals, 2 suprapygals, and a pygal (Figure 2A, B). Kinosternids possess only 10 pairs of peripherals, kinosternines only a single suprapygal (Figures 2C, 3), and a reduction of the neural series and associated midline contact of some posterior costals is apparent in the pan-dermatemydid (see Figure 2B) and kinosternine lineages (see Figure 3).
The nuchal exhibits a pair of well-formed costiform processes that at most insert distally into peripheral II (Figures 2, 3) and appear to be homologous with those of pan-chelydrids (Knauss et al. 2011). In some specimens of $D$. mawii, the costiform process inserts deeply into the peripheral and therefore appears to be absent in ventral view. A single cervical, five vertebrals and four pairs of pleurals cover the carapace of all pan-kinosternoids. The carapace of basal pan-kinosternoids has 12 pairs of marginals (see Figure 2A, B), but is reduced to 11 pairs in 
kinosternids with 10 pairs of peripherals (see Figures $2 \mathrm{C}, 3$ ). The anterior peripherals are incised on their visceral side by a groove of varying length that houses elongate axillary musk ducts. The carapace of kinosternines may have inguinal musk duct foramina adjacent to the inguinal buttresses, whereas Kinosternon subrubrum and Kinosternon baurii additionally have caudal musk duct pores above the tail on peripheral $\mathrm{X}$ between marginals X-XI (Bourque 2012b).

The plastron of pan-kinosternoids ranges from being extremely reduced and cruciform to extremely broad (see Figures 2, 3). The extremely reduced plastron of Claudius angustatus possesses poorly developed buttresses that lack well-formed bony sutural contact with the carapace, contacts only peripherals $\mathrm{V}$ and VI laterally and lacks inframarginals. By contrast, the plastron of Dermatemys mawii is very broad, has extensive axillary buttresses that terminate distally on the costals, contacts peripherals II-VIII and is covered by four to five large inframarginals (see Figure 2B). The plastron of pan-kinosternoids basally consists of an entoplastron and a pair each of epi-, hyo-, hypoand xiphiplastra and is greatly thickened. However, the entoplastron was lost in the kinosternine lineage, which is highly unusual among turtles. Plastral lobe (and sometimes midline) kinesis is present in many pan-kinosternoids, and most Kinosternon show well-developed anterior and posterior plastral hinges that allow fully encapsulating the extremities for protection. The forelobe hinge is situated between the epiplastra and hyoplastra, and the hindlobe hinge between the hypoplastra and xiphiplastra (Bramble et al. 1984).

The plastron of cryptodires, particularly pankinosternoids, is covered by an array of plastral scales that have historically been difficult to interpret. Using a set of clearly stated assumptions, Hutchison and Bramble (1981) elegantly tackled this problem and proposed a system of primary homology statements that has been accepted and tested by subsequent phylogenetic analyses (e.g., Hutchison 1991; Joyce 2007; Knauss et al. 2011). Hutchison and Bramble (1981) furthermore proposed a unifying nomenclatural system for the plastral scales of turtles, which is unfortunately not always utilized consistently in the turtle community, but is implemented here.

The plastron of the ancestral pan-kinosternoid appears to have been covered by paired gulars, humerals, abdominals, femorals and anals, but to have symplesiomorphically lacked extragulars and pectorals. The abdominals symplesiomorphically lacked midline contact, but whereas this contact was reacquired in the pan-dermatemydid lineage, the abdominals were fully lost in the pan-kinosternid lineage. The humeral is secondarily split into an anterior and posterior humeral in the pankinosternine lineage in concert with the acquisition of full anterior plastral lobe kinesis. Finally, a new unpaired scute, the intergular, developed secondarily along the anterior margin of pan-dermatemydids and pan-kinosternines together with the expansion of the plastron. In Sternotherus carinatus and some Sternotherus minor the intergular is secondarily lost. Additionally, in some Sternotherus and Kinosternon the plastral scutes are reduced and expansive gaps of skin are present along the interplastral scute seams, particularly along the midline and in males (Figure 3C).

\section{Postcranium}

We are not aware of any publications that document the nonshell postcranial anatomy of any extant or fossil pan-kinosternoid in any detail, with the exception of Emarginachelys cretacea (Whetstone 1978) and Baptemys wyomingensis (Hay 1908a). The holotypes of the fossil kinosternines Kinosternon skullridgescens, Kinosternon pojoaque and Kinosternon rincon are preserved with numerous nonshell postcranials intact; however, these were not described in any detail in Bourque (2012a, 2012b, in press). We are unaware of any additional fossil taxa with substantial associated nonshell postcranials.

The vast majority of pan-kinosternoids possesses a cervical formula of $(2((3)) 4)) 5)) 6\}\} 7\}\} 8)$, with the exception of Dermatemys mawii, which typically expresses (2))3))4))5))6\}\}7\}\}8) (Williams 1950). The ventral processes are well developed, as in most durocryptodires, but the ventral process of cervical VIII is split lengthwise in kinosternids (Hutchison 1991). The tail is relatively short, lacks chevrons, and all caudals are procoelous.

The pectoral girdle of pan-kinosternoids displays the triradiate morphology typical of all turtles, but representatives of the pan-dermatemydid lineage possess an unusual process at the base of the scapular process. The anterior rim of the ilium of all pan-kinosternoids is adorned by an anteri- 
orly protruding process, the thelial process, which serves as the attachment site for the iliotibialis muscle, but this process is nonhomologous with a less-pronounced process in trionychid turtles (Zug 1971; Joyce 2007). The ilium exhibits a notable posterior kink at the level of the thelial process and lacks the distal fanning typical of other turtles. The acetabulum is not round, but rather exhibits a distinct posterior notch. The manus has five claws and are relatively short to intermediate in length, depending on habitat preferences (Joyce and Gauthier 2004). The pes corresponds in length to the hands, but only has four claws.

\section{Phylogenetic Relationships}

The shells of kinosternoid turtles exhibit an abundance of distinct characters, and it has therefore been possible to reconstruct the phylogeny of the group with confidence. The pioneering studies of Hutchison and Bramble (1981) and Hutchison (1991) synthesized the basal framework of kinosternoid evolution through the fossil record, and later studies have been able to add little more. These studies formed the basis for later analyses, in particular Knauss et al. (2011) and Bourque et al. (2014) and also informed global studies of turtle relationships (e.g., Joyce 2007; Anquetin 2012; Joyce et al. 2013; Sterli et al. 2013; Rabi et al. 2014). Iverson (1991) in parallel provided a detailed morphological analysis that attempts to resolve the phylogenetic relationship of all extant kinosternids at the species level. Although Iverson (1991) retrieved a paraphyletic Sternotherus, subsequent studies built upon this initial character/taxon matrix (Bourque 2012a, 2012b, in press; Bourque and Schubert 2014) retrieve Sternotherus and Kinosternon as monophyletic.

The most important comprehensive studies utilizing molecular data include Rogers (1972), Seidel et al. (1986), Iverson (1991, 1998), Iverson et al. (2013) and Spinks et al. (2014). Although these analyses generally confirm the monophyly of Kinosternidae and Kinosterninae, some fail to produce a monophyletic Kinosternon or Sternotherus (e.g., Rogers 1972; Seidel et al. 1986; Iverson 1991; Iverson et al. 2013). However, it appears that better sampling and more refined tree-finding techniques retrieve the traditional arrangement (e.g., Iverson 1998; Spinks et al. 2014).
Although the recognition of a monophyletic Kinosternoidea is a relatively recent development (see Introduction), there is strong agreement regarding the list of fossil turtles that are associated with this crown clade (Hutchison 1991; Knauss et al. 2011; Bourque et al. 2014). However, the turtles populating the stem are more controversial. The Late Cretaceous (Maastrichtian) Emarginachelys cretacea was originally described as a pan-chelydrid, but has repeatedly been addressed as a pan-kinosternoid, though without explicit justification (e.g., Meylan and Gaffney 1989; Holroyd and Hutchison 2002; Holroyd et al. 2014). We here agree with this assessment, using a list of synapomorphies diagnostic for this clade. The Late Cretaceous (Maastrichtian) to Paleocene Tullochelys montana was similarly described as a pan-chelydrid (Hutchison 2013), but we believe this to be a pan-kinosternoid as well. We provide explicit justifications for the inclusion of both taxa in Pan-Kinosternoidea below (see Systematic Paleontology).

We here finally add two additional, controversial fossil turtles to this list of species being discussed herein, Planetochelys savoiei and P. dithyros. These two Paleogene turtles are known from relatively complete remains from Virginia and Wyoming, respectively, and at first sight greatly resemble testudinoid box turtles such as the extant North American Terrapene or the Asian Cuora in having a domed carapace and fully developed midplastral hinge. Planetochelys was originally assigned to the Asian family Sinemydidae (Weems 1988), but Hutchison (2013) convincingly dismissed this claim and suggested affinities with "Trionychoidea" instead on the basis of the presence of costiform processes, presence of extragulars and a broad plastron. This most recent assessment is somewhat dubious, as increasing amounts of molecular evidence are casting doubt on the existence of a trionychoid clade (see Introduction above). We note that extragulars found in some specimens of Planetochelys appear to be scute anomalies, not regularly formed features, and that a broad plastron is homoplastically acquired in many groups of turtles. The sole character to remain is therefore the costiform process, which recent studies have shown to be a unique synapomorphy of the clade Chelydroidea. Until more character evidence is accrued, it might be prudent to refer Planetochelys to Pan-Chelydroidea, as it reasonably could be situated along 
the stem lineage of Chelydroidea, Chelydridae or Kinosternoidea. However, using temporal considerations, we herein assign Planetochelys to the total group of Kinosternoidea.

The phylogenetic hypothesis presented (Figures 4-6) herein is a consensus of recent studies (Hutchison 1991; Knauss et al. 2011; Bourque 2012a, 2012b, in press; Bourque and Schubert 2014; Bourque et al. 2014). Fossil taxa that have not yet been included in phylogenetic studies were added through the use of diagnostic characters. Only a selection of characters is mapped onto the tree. The diagnoses of all taxa similarly list only the most conspicuous characters. For a complete list of phylogenetically informative characters and more rigorous taxon diagnoses, we ask the reader to refer to the appropriate literature. We here utilize two genera currently thought to be paraphyletic (i.e., Baptemys and Xenochelys), because we find it useful to group species of similar evolutionary development into such taxonomic units and because we find the creation of countless monotypic genera of little added value. However, as these taxa are thought to be paraphyletic, we do not provide formal diagnoses for them or treat them as evolutionary units.

\section{Paleoecology}

The ancestral pan-kinosternoid can be hypothesized as a highly aquatic, bottom-walking turtle that preferred low-energy freshwater aquatic habitats, such as ponds, oxbow lakes and swamps, as this is the predominant habitat preference among extant chelydrids and kinosternoids (Zug 1971; Ernst and Barbour 1989). The fossil record confirms this assertion, as Late Cretaceous kinosternoids are generally associated with chelydrids, plastomenids or Compsemys victa in low-energy environments, in contrast to baenids and trionychines, which are typically found in highenergy channel deposits (Joyce and Lyson 2011, 2015; Lyson and Joyce 2011). In concert with increasing aridity during the Neogene, representatives of Kinosternon secondarily adapted to more terrestrial habitat preference. Extant representatives of the clade readily venture over land for extended periods of time. These turtles nevertheless require habitats that maintain water for at least some time of the year. The ancestral pankinosternoid can furthermore be inferred to have been an omnivore with strong preference for animal protein as this, once again, is the predominant diet of extant chelydrids and pan-kinosternoids. An exception to this is the extant Dermatemys mawii, which is an aquatic herbivore (Ernst and Barbour 1989). Although the skull remains poorly described (Hay 1908a), it is apparent that Baptemys wyomingensis had broad triturating surfaces that were adorned with numerous accessory ridges that correspond closely to its extant sister taxon D. mawii. It is therefore reasonable to infer that the pan-dermatemydid lineage acquired its unusual diet no later than the Eocene.

In contrast to the vast majority of other lineages, pan-kinosternoids retain their cruciform plastron for much of their evolutionary history, although this leaves much of their underside unprotected. This trend quickly reverses in the pandermatemydid lineage during the Eocene, with the acquisition of a broad plastron that convergently resembles that of extant pleurodires or testudinoids in its gestalt. The expansion of the plastron coincides with the acquisition of a herbivorous diet, and we speculate that this may not be accidental. The reduced cruciform plastron is lost in most Kinosternon through expansion of the plastral lobes and development of anterior and posterior hinges, and it seems plausible that these are adaptations for use of more terrestrial habitats (Bramble et al. 1984).

\section{Paleobiogeography}

The entire pre-Pleistocene fossil record of PanKinosternoidea is restricted to North America (Figure 7; Appendix 4), and it therefore appears certain that the group originated on that continent. The earliest pan-kinosternoids have been reported from the Late Cretaceous (Campanian) of Coahuila, Mexico (Rodriguez-de la Rosa and Cevallos-Ferriz 1998; Brinkman and Rodriguez de la Rosa 2006), and New Mexico (Sullivan et al. 2013) and Utah, USA (Hutchison et al. 2013). The majority of these remains are isolated shell bones of small smooth-shelled pan-kinosternids, but rare finds attributable to Hoplochelys are present as well, thereby revealing that the two primary lineages of crown Kinosternoidea were established by the Campanian (Joyce et al. 2013). Pan-kinosternoid remains are notably missing from wellexposed Campanian deposits in southern Alberta, indicating a preference for subtropical latitudes 


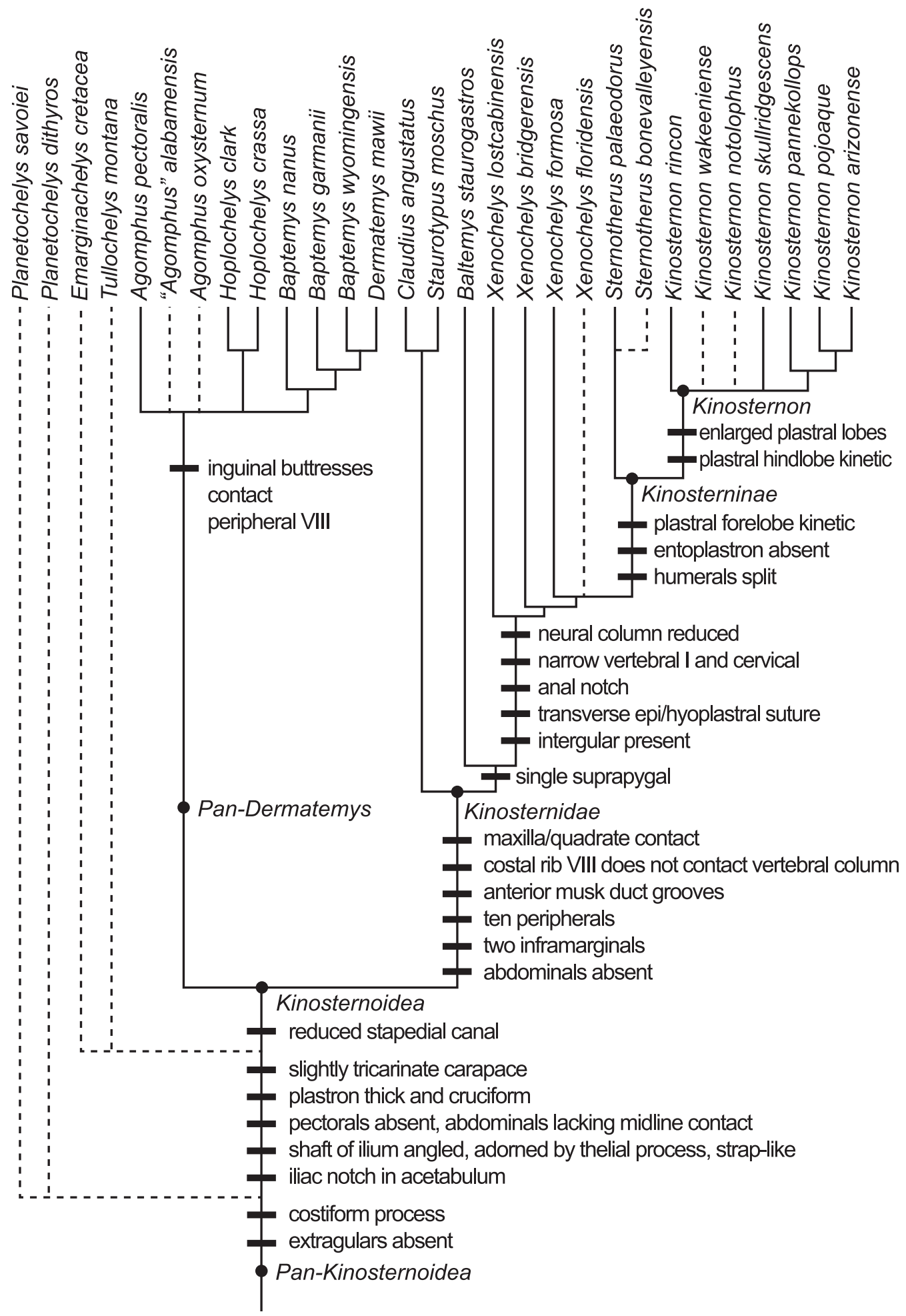

FIGURE 4. A phylogenetic hypothesis of valid pan-kinosternoid taxa, with diagnostic characters for the most important clades, including select extant taxa for reference. The topology is a composite of Knauss et al. (2011), Bourque (2012a, 2012b, in press), Bourque et al. (2014), and Bourque and Schubert (2014). Dashed lines highlight taxa that were not included in these analyses and that were secondarily inserted using diagnostic characteristics. 


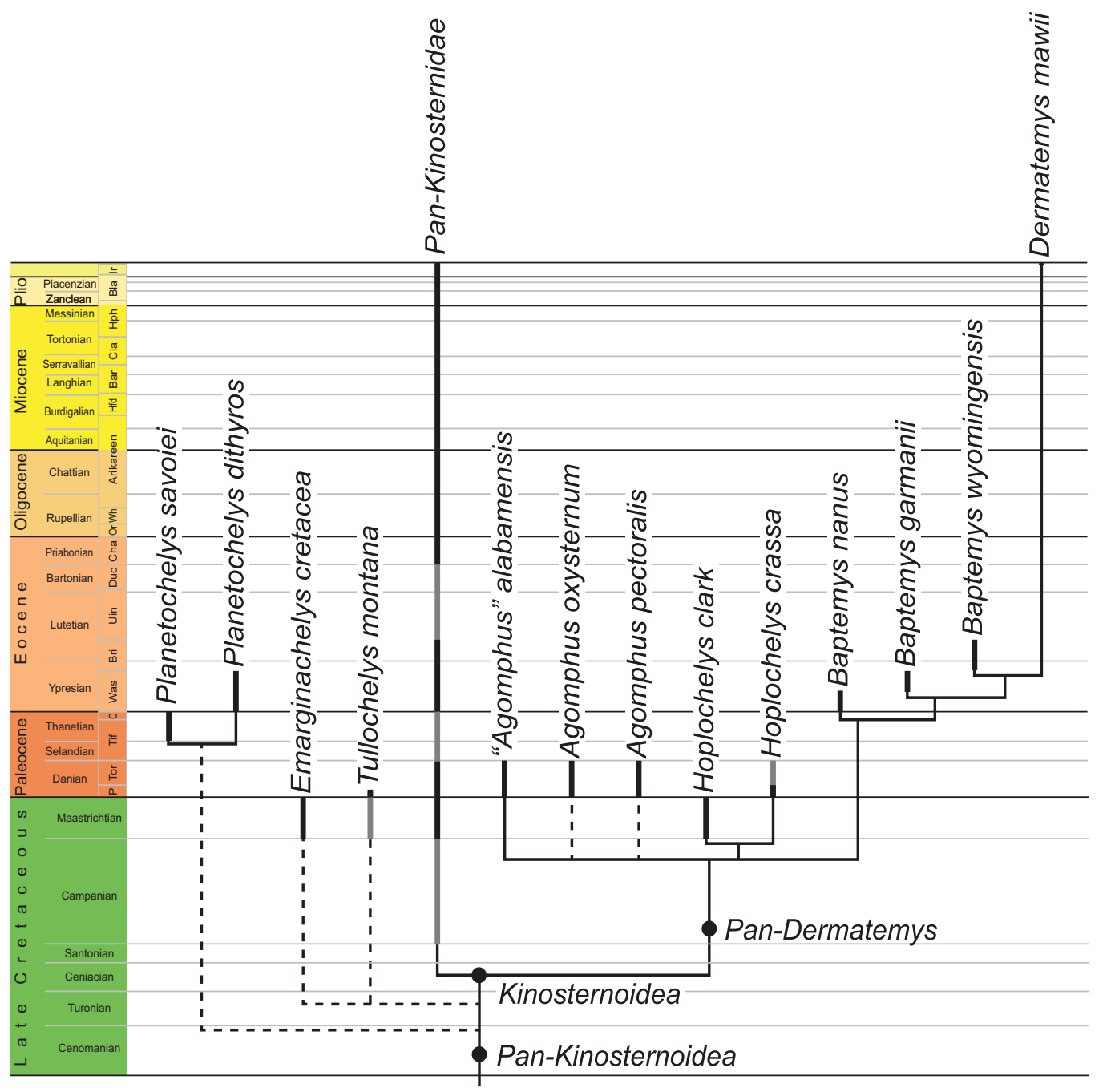

FIGURE 5. The stratigraphic and biogeographic distribution of valid pan-kinosternoid taxa to the exclusion of Kinosternidae, including select extant taxa for reference. Black lines indicate temporal distribution based on type material. Gray lines indicate temporal distribution based on referred material.

(Brinkman 2003). However, by the late Maastrichtian, both primary kinosternoid lineages are reported from the northern deposits of Montana, North Dakota and Wyoming, USA, including Emarginachelys cretacea, Hoplochelys clark and Tullochelys montana, though they remain rare (Whetstone 1978; Holroyd and Hutchison 2002; Knauss et al. 2011; Hutchison 2013).

Directly following the Cretaceous/Tertiary (K/T) extinction event, only Tullochelys montana is reported from the northern basins (Hutchison 2013; see Figure 7). We agree with Hutchison and Holroyd (2003) that the early Paleocene "Agom- phus caelata" Hay 1908b from the early Paleocene of Montana is not a pan-kinosternoid, but rather a pan-chelydrid (Joyce 2016).

An extremely rich fauna attributable to the pan-dermatemydid Hoplochelys crassa has been recovered from the early Paleocene of the San Juan Basin, New Mexico (see Figure 7), but pankinosternids are lacking from these deposits (Cope 1888; Hay 1908a, 1911; Gilmore 1919b). Isolated fragments attributable to Hoplochelys have otherwise been reported from the early Paleocene of Colorado (Hutchison and Holroyd 2003) and Texas (Tomlinson 1997). 


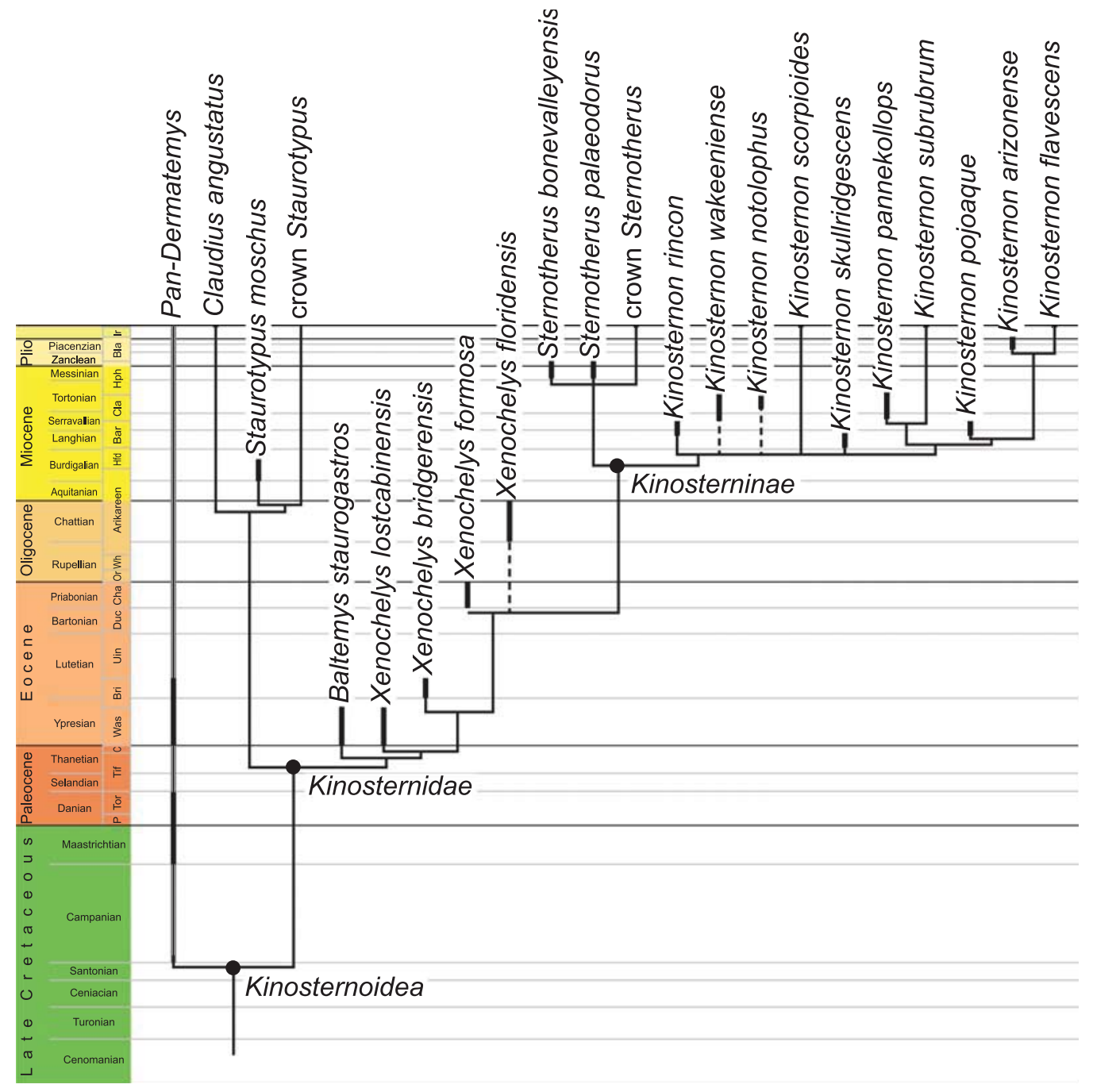

FIGURE 6. The stratigraphic and biogeographic distribution of valid kinosternid taxa. Black lines indicate temporal distribution based on type material, including select extant taxa for reference. Gray lines indicate temporal distribution based on referred material.

A number of historic quarries yielded contemporaneous finds of Agomphus pectoralis in New Jersey (Cope 1868, 1869/70; Wieland 1905; see Figure 7), but the morphology of this taxon is still poorly understood and its phylogenetic affinities therefore uncertain. We agree with Hutchison and Weems (1998) that Emys firmus Leidy, 1856 represents an adocid, not a representative of Agomphus, and this taxon will therefore be discussed elsewhere. Outcrops in Alabama, Georgia and Virginia have yielded "Agomphus" alabamensis (Gilmore 1919a), Agomphus oxysternum (Cope 1877) and the potential pan-kinosternoid Plane- tochelys savoiei, but these taxa are in need of better description and/or character analysis to rigorously assess their validity and phylogenetic affinities (see Systematic Paleontology below). A rich Paleocene fauna from South Carolina is unique by including remains of pan-kinosternids, but given the lack of detailed descriptions for other taxa, we find it difficult to reconstruct most of the taxonomic attributions of Hutchison and Weems (1998) beyond Pan-Kinosternoidea and Agomphus indet.

Abundant remains from early to middle Eocene exposures throughout Wyoming have provided rich insights into the evolution of pan- 


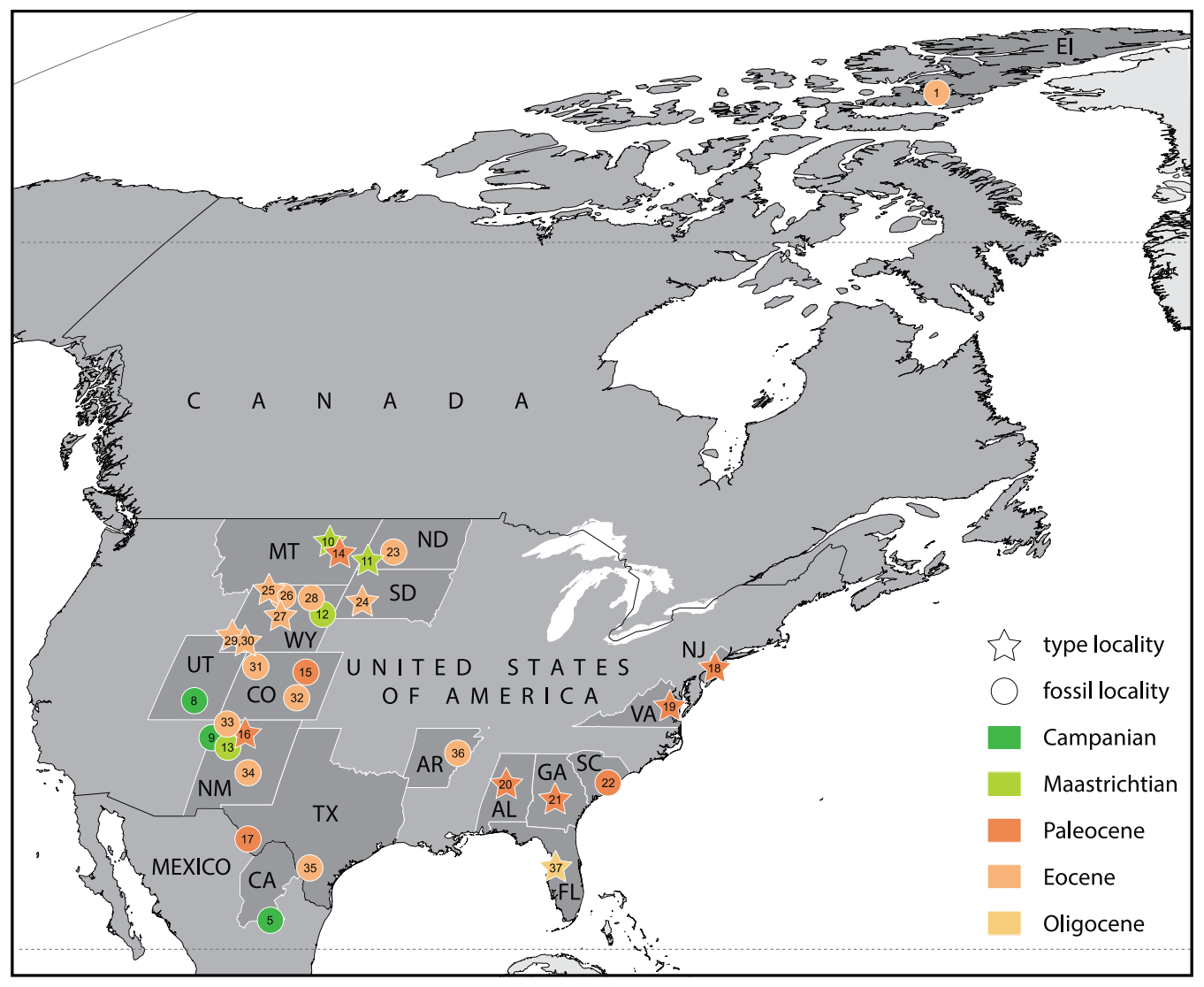

FIGURE 7. The geographic distribution of figured pan-kinosternoids from the Cretaceous and Paleogene. Stars mark the type localities of valid taxa. Locality numbers are cross-listed in Appendix 3. Abbreviations: AL, Alabama; AR, Arkansas; CA, Coahuila; CO, Colorado; EI, Ellesmere Island; FL, Florida; GA, Georgia; MT, Montana; ND, North Dakota; NJ, New Jersey; NM, New Mexico; SC, South Carolina; SD, South Dakota; TX, Texas; UT, Utah; VA, Virginia; WY, Wyoming.

kinosternoid turtles (see Figure 7). The pan-dermatemydid lineage is represented by Baptemys nanus, B. garmanii and B. wyomingensis (Cope 1872, 1873; Leidy 1869; Hay 1908a; West and Hutchison 1981; Zonneveld et al. 2000; Holroyd et al. 2001; Bourque et al. 2014), and these three temporally nonoverlapping species may well represent an anagenetic lineage consisting of chronotaxa. Additional material referable to this lineage has otherwise been reported from the early Eocene of New Mexico, North Dakota and throughout Wyoming (Cope 1875; Estes 1988; Lucas et al. 1989; Bourque et al. 2014). We cannot confirm reports of Baptemys from Texas (Westgate 1989) as no specimens have been figured or referred.

Early to middle Eocene sediments securely document the kinosternid stem lineage in the form of Baltemys staurogastros from the early Eocene of Wyoming and Colorado (Hutchison 1991; Lichtig and Lucas 2015), Xenochelys lostcabinensis from the early Eocene of Wyoming (Hutchison 1991) and X. formosa from the late Eocene of South Dakota (Hay 1906; Williams 1952; see Figure 7). Fragmentary remains attributable to Baptemys, Xenochelys or Pan-Kinosterninae have otherwise been reported from the Eocene of Arkansas, Colorado, New Mexico, South Dakota, Texas, Wyoming and as far north as Ellesmere Island, Canada (Hutchison 1991; Holroyd et al. 2001). Early Eocene sediments in Wyoming preserve the earliest western records of the enigmatic turtle Planetochelys dithyros (Hutchison 2013). We here readily highlight that the phylogenetic affinities of these taxa are 


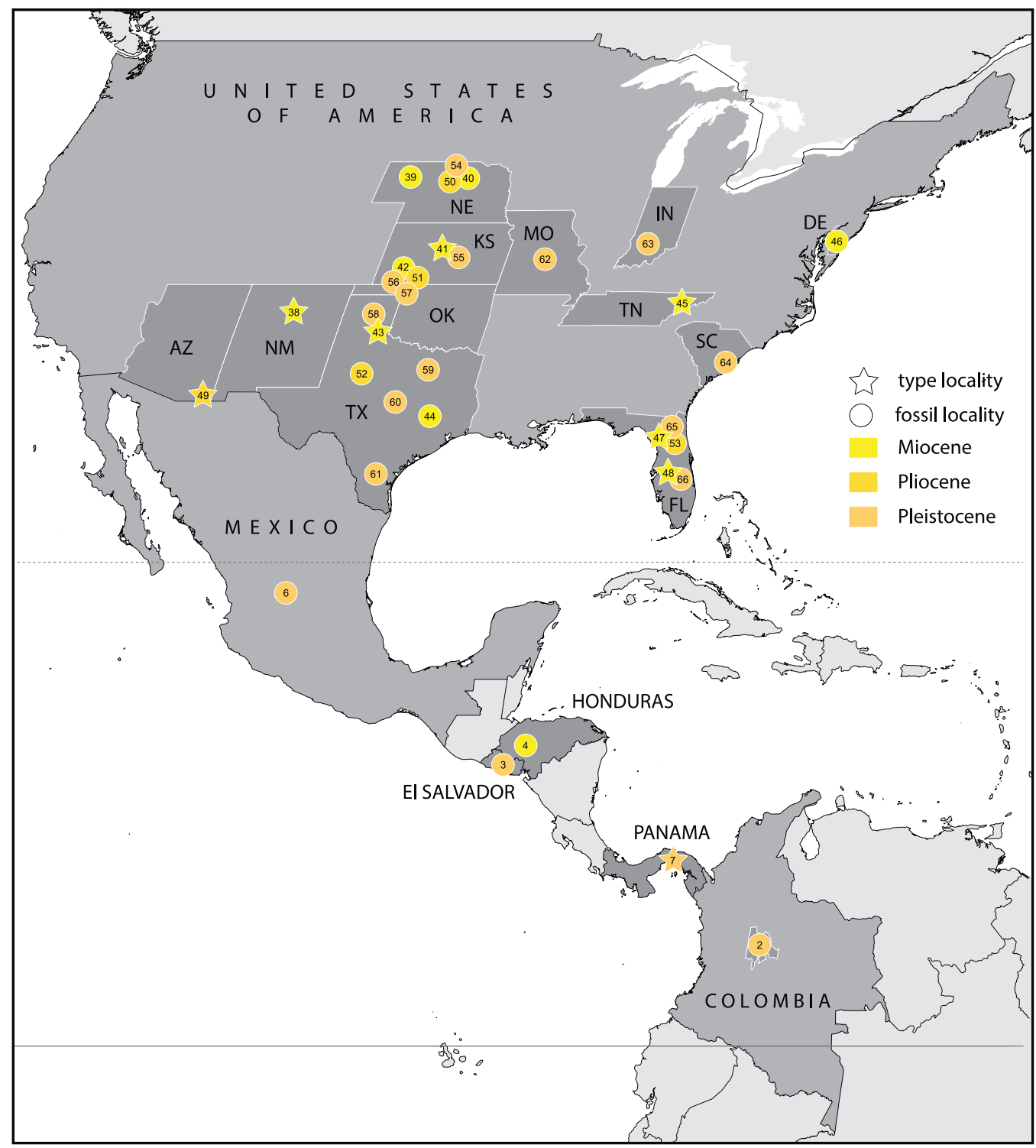

FIGURE 8. The geographic distribution of pan-kinosternoids from the Neogene. Stars mark the type localities of valid taxa. Locality numbers are cross-listed in Appendix 3. Abbreviations: AZ, Arizona; DE, Delaware; FL, Florida; IN, Indiana; KS, Kansas; MO, Missouri; NE, Nebraska; NM, New Mexico; OK, Oklahoma; SC, South Carolina; TN, Tennessee; TX, Texas.

controversial, but characters reminiscent of pankinosternoids compel us to discuss them here (see Systematic Paleontology below).

Following a trend typical for so many other groups of North American turtles during the Arikareean North American Land Mammal Age (NALMA) (Hutchison 1996), pan-kinosternoids almost vanish from the North American fossil record, with the exception of the fragmentary record of Xenochelys floridensis from the late Oligocene of Florida (Bourque 2013; see Figure 7).

The Neogene record of the pan-dermatemydid lineage consists only of fragmentary remains from the early Miocene of Texas (Albright 1994; Figure 8). The Neogene pan-kinosternid record had historically been similarly poor, but recent studies have shed some light on this lineage, based primarily on specimens that languished in 
museum drawers for decades. In particular, Miocene sediments have yielded the remains of Kinosternon pojoaque (Bourque 2012a), K. skullridgescens (Bourque 2012b) and $K$. rincon (Bourque, in press) from New Mexico, K. wakeeniense from Kansas and Nebraska (Bourque, in press), K. pannekollops from Texas (Bourque, in press), Sternotherus palaeodorus from Tennessee (Bourque and Schubert 2014) and K. notolophus and S. bonevalleyensis from Florida (Bourque and Schubert 2014; Bourque, in press). Pliocene sediments have yielded Kinosternon arizonense from Arizona (Gilmore 1923). Phylogenetic analyses firmly place all within the crown of Kinosterninae, often close to extant taxa or small species groups (Bourque 2012a, 2012b, in press; Bourque and Schubert 2014). A number of Miocene to Pliocene remains have previously been referred to extant taxa, in particular K. flavescens (e.g., Fichter 1969; Rogers 1976; Holman and Schloeder 1991; Parmley 1992), but these universally have not been demonstrated to have apomorphic traits and were likely assigned using geographic considerations. Given that the two primary kinosternine lineages (Kinosternon and Sternotherus) are apparent by the Miocene, we here refer all fragmentary remains from Delaware (Holman 1998), Kansas (Fichter 1969), Florida (Becker 1985; Bryant 1991; Bourque 2013, in press), Nebraska (Hutchison 1991; Holman and Schloeder 1991; Parmley 1992) and Texas (Rogers 1976) to Kinosternon indet. or Sternotherus indet. We cannot confirm the plausible presence of Kinosternon indet. from the Pliocene of Michoacán, Mexico (Brattstrom 1955b), as no material has been figured or described.

Fragmentary kinosternine remains have been reported from the Pleistocene of Aguascalientes, Mexico (Mooser 1980), Indiana (Holman and Richard 1993), Florida (Weigel 1962; Meylan 1995; Bourque 2013), Kansas (Holman 1972, 1987; Preston 1979), Missouri (Parmalee and Oesch 1972), Nebraska (Fichter 1969), Oklahoma (Preston 1979), South Carolina (Bentley and Knight 1998) and Texas (Holman 1963; Johnson 1974; Preston 1979; Holman and Winkler 1987; see Figure 8). Although attribution of this material to currently existing taxa may often yield reasonable results, we here refer all of these once again to Kinosternon indet. and Sternotherus indet. pending more detailed morphological analysis.
The invasion of Central and South America by kinosternines is documented by isolated finds of Staurotypus moschus from the early Miocene of Panama (Cadena et al. 2012), Kinosternon indet. from the late Miocene of Honduras (Bourque 2012b) and of Kinosternon indet. from the Pleistocene of El Salvador (Cisneros 2005) and Colombia (Cadena et al. 2007; see Figure 8). About 26 species of kinosternid turtles currently inhabit North and South America, ranging from southern Canada to northern Argentina, from desert to wet tropical and wet temperate regions.

\section{Systematic Paleontology}

\section{Valid Taxa}

See Appendix 4 for the hierarchical taxonomy of Pan-Kinosternoidea as described in this work.

Pan-Kinosternoidea Joyce et al., 2004

Phylogenetic definition. Following Joyce et al. (2004), the term Pan-Kinosternoidea is herein referred to the total clade of Kinosternoidea (see below).

Diagnosis. Representatives of Pan-Kinosternoidea are currently diagnosed relative to other turtles by the symplesiomorphic presence of a slightly tricarinate carapace, costiform processes, a cruciform plastron, the lack of extragulars and pectorals, and midline contact of the abdominals, and the derived presence of a thickened plastron, a thelial process, an iliac notch, an angled ilial shaft and the lack of a distal iliac fan.

\section{Emarginachelys cretacea Whetstone, 1978}

Taxonomic history. Emarginachelys cretacea Whetstone, 1978 (new species); Emarginochelys cretacea Holroyd and Hutchison, 2002 (genus name misspelled).

Type material. KU VP23488 (holotype), a heavily crushed, nearcomplete skeleton primarily lacking the mandible, various digits and most of the tail (Whetstone 1978, figs. 5-8, 10-18).

Type locality. Traweek Ranch, SW1/4, NW1/4, Section 35, T 21 N, R 37 E, Garfield County, Montana, USA (Figure 7); Hell Creek Formation, Maastrichtian, Late Cretaceous (Whetstone 1978).

Referred material and range. No material is herein referred to this taxon (see Comments below).

Diagnosis. Emarginachelys cretacea can be diagnosed as a pankinosternoid by the full list of characters listed for that clade above and can be distinguished from all crown kinosternoids by the full list of characters listed for that clade below. Emarginachelys cretacea is differentiated from Tullochelys montana by having more elongate costiform processes that almost insert in peripheral III and by lacking an overlap of the anal onto the hypoplastron. 
Comments. Emarginachelys cretacea is based on a heavily fractured, but near-complete skeleton from the Hell Creek Formation of Montana (Whetstone 1978). The validity of this taxon has never been in doubt, but its phylogenetic affiliations remain contentious. Whetstone (1978) originally diagnosed this taxon as a pan-chelydrid on the basis of the presence of a cruciform plastron, long costiform processes, a ligamentous bridge, elongate jugals and narrow pectineal pubic processes. Meylan and Gaffney (1989) later interpreted E. cretacea as the most basal pan-kinosternoid within the clade Trionychoidea, but this analysis is highly suboptimal, as pan-chelydrids were omitted a priori. This result was nevertheless replicated by the global analyses of Shaffer et al. (1997) and Joyce (2007). Given that it is becoming increasingly evident that kinosternids and chelonioids are the successive outgroups of chelydrids (see Phylogenetic Relationships above), it is not surprising that the morphology of all three groups converges further back in time. For instance, of the impressive list of characters that Whetstone (1978) listed to support the placement of E. cretacea as a pan-chelydrid, all should now be viewed as symplesiomorphies as they also occur in kinosternids or/and chelonioids. A substantial list of newly recognized synapomorphies, however, places E. cretacea within Pan-Kinosternoidea, but outside crown Kinosternoidea (see Diagnosis above).

Holroyd and Hutchison (2002) attributed a number of specimens from the Hell Creek Formation of North Dakota to Emarginachelys cretacea, but they did not provide an explicit rationale for diagnosing these fragments relatively to coeval pan-kinosternoids, especially the recently named Hoplochelys clark Knauss et al., 2011. We therefore herein disregard this material until more details are available.

\section{Planetochelys Weems, 1988}

Type species. Planetochelys savoiei Weems, 1988.

Diagnosis. Planetochelys can only be diagnosed as a pan-kinosternoid by the presence of costiform processes, a plesiomorphy inferred to be present in the ancestral chelydroid, and the absence of extragulars, a plesiomorphy found in all durocryptodires. Another character that may hold taxonomic significance is the presence of notably low marginal scutes similar to those seen in kinosternids (D. Brinkman, pers. comm., 2015). Planetochelys differs substantially from other pan-kinosternoids by having pectorals, midline contact of the abdominals and a welldeveloped, flat plastron, characters more typical of testudinoids, and by possessing a fully developed hinge between the hyo- and hypoplastra and having costals I-V insert distally in two peripherals. See Phylogenetic Relationships above for problematic relationships of this taxon.

\section{Planetochelys dithyros Hutchison, 2013}

Taxonomic history. Planetochelys dithyros Hutchison, 2013 (new species).

Type material. UCMP 120000 (holotype), an incomplete skeleton consisting of an incomplete shell, partial skull and mandible and isolated vertebrae and limb bones (Hutchison 2013, figs. 26.4b, 26.5a, b); UCMP 125005 (paratype), nearly complete shell and limb bones; UCMP 130896 (paratype), partial shell.
Type locality. UCMP locality V77050, Sweetwater County, Wyoming, USA (see Figure 7); Wasatch Formation, Wasatchian NALMA, Ypresian, early Eocene (Woodburne 2004). The paratypes originate from early Eocene (Ypresian, Wasatchian NALMA), Willwood Formation, UCMP locality V81045, Big Horn County, Wyoming, USA (Hutchison 2013).

Referred material and range. Early Eocene (Ypresian), Wasatchian NALMA of the Big Horn (including paratypes), Green River and Wind River basins (Hutchison 2013).

Diagnosis. Planetochelys dithyros can be diagnosed as Planetochelys by the full list of characters listed above. Planetochelys dithyros is differentiated relative to $P$. savoiei, among others, by being larger, having wedge-shaped costals III-VI, upturned posterior peripherals and by lacking a lateral carina along the bridge peripherals.

Comments. Planetochelys dithyros is based on a rich collection of remains from early Eocene (Ypresian) sediments throughout Wyoming. This taxon was referred to with various informal names for nearly half a century (see Hutchison 2013 for list of informal synonyms), but no voucher specimens were listed.

The documented morphology of $P$. dithyros is highly apomorphic among turtles from the Eocene of North America, most notably in its convergences with extant box turtles, and the validity of this taxon is therefore uncontroversial. For the problematic attribution of this taxon to Pan-Kinosternoidea, however, see Phylogenetic Relationships above.

\section{Planetochelys savoiei Weems, 1988}

Taxonomic history. Planetochelys savoiei Weems, 1988 (new species).

Type material. USNM 412107 (holotype), the posterior half of a carapace (Weems 1988, figs. 5-8; Hutchison 2013, fig. 26.3).

Type locality. West bank of Aquia Creek, Stafford County, Virginia, USA (Weems 1988; see Figure 7); Piscataway Member, Aquia Formation, Thanetian, late Paleocene (Hutchison 2013).

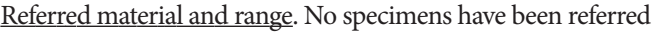
to date.

Diagnosis. Planetochelys savoiei can be diagnosed as Planetochelys by the inferred presence of a plastral hinge and the distal insertion of the anterior costals in two peripherals. Planetochelys savoiei is differentiated relative to $P$. dithyros by being smaller, having less wedge-shaped costals III-VI, flat posterior peripherals and a distinct lateral carina along the bridge peripherals.

Comments. Planetochelys savoiei is based on a well-preserved partial carapace from the late Paleocene of Virginia, USA (Weems 1988). The validity of this taxon is uncontroversial, as the holotype displays an unusual array of unique characters, especially among Eocene turtles. However, given that the type specimen lacks the diagnostic plastron and nuchal region, assessing the phylogenetic relationships of this taxon was historically difficult. Ironically, the finding of more complete remains of the closely related $P$. dithyros, including the nuchal region and plastron, has only added complexity to this 
conundrum. For a more extensive discussion, see Phylogenetic Relationships above.

\section{Tullochelys montana Hutchison, 2013}

Taxonomic history. Tullochelys montana Hutchison, 2013 (new species).

Type material. UCMP 136481 (holotype), a crushed partial skeleton consisting of the posterior two-thirds of the shell and associated with disarticulated limb bones and vertebrae (Hutchison 2013, figs. 26.6a-c, 26.7); UCMP 107791 (paratype), left peripheral I; UCMP 117434 (paratype), articulated left right peripheral XI and suprapygal; UCMP 123314 (paratype), partial carapace; UCMP 129189 (paratype), left peripheral I-II, peripheral fragments, costal I fragment; UCMP 129693 (paratype), fragmentary carapace, most of plastron, limb fragments; UCMP 154567 (paratype), partial shell of a juvenile (Hutchison 2013, fig. 26.6d); UCMP 158704 (paratype), peripheral I-II and partial costal I.

Type locality. UCMP locality V90001, McCone County, Montana, USA (see Figure 7); Hell Creek Formation, Puercan NALMA (Hutchison 2013), Danian, Early Paleocene (Woodburn 2004). The paratypes originate from the Lancian (Maastrichtian) to Puercan (Danian) Hell Creek and Fort Union Formations of Garfield and McCone counties, Montana, USA.

Referred material and range. No material has been referred to date beyond the paratypes.

Diagnosis. Tullochelys montana can be diagnosed as a pan-kinosternoid and differentiated from crown kinosternoids by the full lists of shell characters listed for those clades above and below. Tullochelys montana is differentiated from Emarginachelys cretacea by having shorter costiform processes that only insert in the middle of peripheral II and by exhibiting a broad overlap of the anal onto the hypoplastron.

Comments. Tullochelys montana was recently described as a new species of pan-chelydrid (Hutchison 2013). In contrast to Hutchison (2013), we interpret the presence of short costiform processes (i.e., costiform processes that do not insert in peripheral III), a cruciform plastron, loss of the extragulars and the retention of ventrally exiting musk ducts, as chelydroid symplesiomorphies, not synapomorphies of Pan-Chelydridae, as they broadly occur among pan-kinosternoids as well. However, we agree that the overlap of the anal onto the hypoplastron is a character reminiscent of pan-chelydrids. However, we note the presence of a greatly thickened plastron, a character otherwise restricted to Pan-Kinosternoidea, and a general resemblance with Emarginachelys cretacea, a taxon that exhibits numerous additional synapomorphies of Pan-Kinosternoidea. We therefore tentatively place Tullochelys montana within Pan-Kinosternoidea but await more detailed future analysis, especially more detailed description of the available material.

\section{Kinosternoidea Hutchison and Weems, 1998}

Phylogenetic definition. Following Joyce et al. (2004), the term Kinosternoidea is herein referred to the clade arising from the last common ancestor of Dermatemys mawii Gray, 1847, Staurotypus triporcatus (Wiegmann, 1828) and Kinosternon scorpioides (Linnaeus, 1766). Kinosternoidea is the crown clade of Pan-Kinosternoidea.

Diagnosis. Representatives of Kinosternoidea can be diagnosed as pan-kinosternoids by the full list of characters listed for that clade above. Kinosternoidea is differentiated relative to other pan-kinosternoids by the reduction of the size of the stapedial artery, the presence of an overlap of the hyo-hypoplastral suture by the inguinal, the common presence of an intergular, presence of a medial pectoral process and the presence of an enlarged entoplastron.

Comments. Joyce et al. (2004) were somewhat inconsistent when they referred authorship of Kinosternoidea to Gaffney and Meylan (1988), as these authors did not use this name with that spelling. As far as we can tell, Dobie (1980) was the first to use the name Kinosternoidea, but we disregard this contribution because it is an abstract. Meylan and Gaffney (1989) use this name as well, but this is probably a misspelling, as they otherwise use the term Kinosternoidae in the same publication. The first formal use of the spelling "Kinosternoidea" is therefore that of Hutchison and Weems (1998), and we therefore confer authorship to the latter following the rationale employed by Joyce et al. (2004). Following the rules of the ICZN (1999), incidentally, authorship should be accorded to Agassiz (1857), because he was the first to create a family group taxon typified by Kinosternon (then Cinosternon).

\section{Pan-Dermatemys Joyce et al., 2004}

Phylogenetic definition. Following Joyce et al. (2004), the name Pan-Dermatemys is herein referred to the total-clade that includes Dermatemys mawii Gray, 1847, but no other extant turtle species.

Diagnosis. Representatives of Pan-Dermatemys are currently diagnosed as kinosternoids by the full list of characters listed for that clade above. Pan-Dermatemys is currently diagnosed relative to other kinosternoids by the derived presence of contact of the inguinal buttresses with peripheral VIII.

\section{Agomphus Cope, 1871}

Type species. Emys turgidus Cope, 1869/70.

Diagnosis. Agomphus can be diagnosed as a kinosternoid by the presence of a costiform processes, a thickened, cruciform plastron and the lack of extragulars and as a pan-dermatemydid by the contact of the inguinal buttress with peripheral VIII. Agomphus is currently differentiated from all other pan-dermatemydids by the presence of short axillary buttresses, a highly domed carapace and wide neurals.

\section{“Agomphus" alabamensis Gilmore, 1919a}

Taxonomic history. Agomphus alabamensis Gilmore, 1919a (new species). 
Type material. USNM 8806 (holotype), the anterior half of a shell (Gilmore 1919a, fig. 5, pl. 35).

Type locality. Moscow Landing, Marengo County, Alabama USA (see Figure 7); Midway Formation (Gilmore 1919a), Danian, early Paleocene (Huddlestun et al. 1974).

Referred material and range. We do not refer any specimens to this taxon (see Agomphus pectoralis below for discussion regarding material referred by Hutchison and Weems 1998).

Diagnosis. "Agomphus" alabamensis can be diagnosed as a kinosternoid by the presence of a thickened, cruciform plastron and the lack of extragulars. It furthermore resembles Agomphus and Hoplochelys by being large and high domed. The poor state of preservation and description prohibits rigorously diagnosing this taxon for the moment, but the presence of three low carapacial keels is more reminiscent of Hoplochelys than of Agomphus. We retain this taxon in Agomphus for convenience only.

Comments. "Agomphus" alabamensis is based on a large, partia shell from central Alabama (Gilmore 1919a). The specimen has initially been reported as being Eocene in age (Gilmore 1919a), but more recent insights into the stratigraphy of the southeastern United States revealed the type strata to be early Paleocene (Danian) in age (Huddlestun et al. 1974). This specimen therefore corresponds in age to Hoplochelys crassa from New Mexico and Agomphus pectoralis from New Jersey (see below). The shell is highly worn and in need of additional preparation, but we nevertheless agree with Gilmore (1919a) that the carapace is decorated by three tightly placed sagittal keels. Gilmore (1919a) only compared this specimen to A. pectoralis and failed to see similarities with Hoplochelys crassa, which is particularly strange given that Gilmore (1919b) soon after described numerous new species of Hoplochelys from New Mexico. We note that "A." alabamensis resembles $A$. pectoralis by being extremely highly domed and by having a wide plastron, while at the same time having the three broad midline keels typical of $H$. crassa. Until the type specimen has received additional preparation and description, it will be difficult to resolve this character conflict with confidence. Until this has been achieved, we retain this taxon in Agomphus, but highlight the preliminary nature of this attribution by placing the genus in quotation marks similar to Hutchison and Weems (1998).

\section{Agomphus oxysternum (Cope, 1877)}

Taxonomic history. Amphiemys oxysternum Cope, 1877 (new species); Agomphus oxysternum Hay, 1902 (new combination).

Type material. GSG uncat. (holotype), a partial shell primarily lacking much of the peripheral series (Hay 1908a, fig. 320).

Type locality. Near Flint River, Montezuma, Macon County, Georgia, USA (see Figure 7); Midway Formation (Hay 1908a), Danian, Paleocene (Huddlestun et al. 1974).

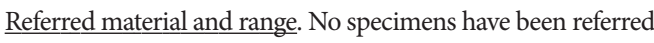
to date.

Diagnosis. Agomphus oxysternum can be diagnosed as a representative of Agomphus by the full list of characters listed for that clade above. A rigorous differentiation is currently not possible relative to Agomphus pectoralis, but the complete absence of keels clearly distinguishes this taxon from "Agomphus" alabamensis (see Comments below).

Comments. Agomphus oxysternum is based on a relatively complete shell from central Georgia (Cope 1877). Given that the Paleocene had not yet been formally defined when this taxon was named, the type locality was originally reported to be Eocene, but has since been shown to be early Paleocene (Danian) in age (Huddlestun et al. 1974). Cope (1877) originally assigned oxysternum to its own genus, Amphiemys, but Baur (1888) noted that Amphiemys is identical to Agomphus and Hay (1902) therefore transferred oxysternum to the latter taxon. Cope (1877) highlighted a number of unusual morphologies to the plastron of this taxon, but Hay (1908a) noted that the plastron actually corresponds to that of $A$. crassa. However, given that the plastron was never figured, we are not able to reproduce either observation. The carapace of A. oxysternum generally resembles that of A. pectoralis, but comparison is made difficult by the fragmentary preservation of all available $A$. pectoralis material. Given that both taxa originate from the early Paleocene (Danian) of the eastern US seaboard, the possibility remains that they are synonymous. However, we here retain both as valid until the morphology of Agomphus has been revised in greater detail.

\section{Agomphus pectoralis (Cope, 1868)}

(= Agomphus masculinus Wieland, $1905=$ Adocus petrosus Cope, $1868=$ Agomphus tardus Wieland, 1905 = Emys turgidus Cope, 1869/70)

Taxonomic history. Pleurosternum pectorale Cope, 1868 (new species, misspelled genus name); Adocus pectoralis Cope, 1869/70 (new combination); Agomphus pectoralis Hay, 1908a (new combination); Agomphus pectoralis $=$ Adocus petrosus $=$ Agomphus masculinus $=$ Agomphus tardus $=$ Emys turgidus Hutchison and Weems, 1998 (senior synonym).

Type material. AMNH 1478 (holotype), right and left hyoplastron (Cope 1869/70, pl. 7.1; Hay 1908a, pl. 37.8, 9).

Type locality. Medford, Burlington County, New Jersey, USA (see Figure 7); Hornerstown Formation, Danian, early Paleocene (Miller 1955; Sugarman et al. 1995).

Referred material and range. Early Paleocene (Danian), Hornerstown Formation of New Jersey, USA (hypodigm of Hutchison and Weems 1998, including type material of Adocus petrosus, Agomphus masculinus, Agomphus tardus and Emys turgidus).

Diagnosis. Agomphus pectoralis can be diagnosed as a representative of Agomphus by the full list of characters listed for that clade above. A rigorous differentiation is currently not possible relative to Agomphus oxysternum (see above), but the complete absence of keels clearly distinguishes this taxon from "Agomphus" alabamensis.

Comments. The marl pits of New Jersey have yielded rich collections of fossil vertebrates, particularly during the 19th century, that span the K/T extinction event (Gallagher 1993). 
However, given that these deposits were accumulated in a nearshore environment, most turtle finds are highly fragmentary and represent marine groups. A total of five turtle taxa were named from New Jersey that closely resemble one another in being medium-sized to small turtles with highly domed thick shells and cruciform plastra. These include Pleurosternon pectorale Cope, 1868, Adocus petrosus Cope, 1868, Emys turgidus Cope, 1869/70, Agomphus masculinus Wieland, 1905 and Agomphus tardus Wieland, 1905. Given that the stratigraphy of the US Atlantic Coast was not fully understood at the beginning of the 19th century, most of these taxa were noted as originating from the "Upper Green Sands" of New Jersey and presumed to be Cretaceous in age (Hay 1908a). The Upper Green Sands have since been renamed as the Hornerstown Formation and have been shown to be early Paleocene (Danian) in age (Sugarman et al. 1995). In his summary of the fossil record of New Jersey, Miller (1955) listed pectorale, turgidus, masculinus and tardus as originating from the Hornerstown Formation, but petrosus as originating from the Campanian Matawan group. However, this must be an error, given that Cope (1868) reported the holotype of petrosus as having been collected from the Upper Green Sands of West Jersey Marl Pits (Hay 1908a). All five taxa listed above were therefore collected within close proximity of one another and in sediments of equivalent age.

The name Agomphus was created by Cope (1871) to highlight the distinct nature of turgidus, but by the time Hay (1908a) revised the fossil turtles of North America, this taxon included a total of six species from the Upper Green Sands of New Jersey. Hutchison and Weems (1998) suggested that the sixth taxon, Emys firmus Leidy, 1856, represents an adocid and that the remaining five are synonymous with each other, as they show only minor morphological differences. Given the incomplete nature of all involved taxa, the tight temporal and geographic proximity, we agree with this taxonomic assessment.

There are some difficulties with establishing the senior synonym among the five New Jersey Agomphus taxa. Cope explicitly described the new taxon petrosus in 1868, and only mentioned the name pectorale in the same publication in an offhand comment. In 1869, Cope (1869/70) then formally designated pectorale as a new taxon, after its first use. The rules of the ICZN (1999) demand little for names published before 1931, including a description, definition or indication, and the intention that the name is valid. Although Cope (1868) only utilized pectorale to compare it with petrosus, some character information can nevertheless be gleaned for pectorale. We therefore conclude that Cope (1868) named both pectorale and petrosus in the same publication. Hay (1908a) was the first to suggest that pectorale and petrosus are synonyms, but for inexplicable reasons he chose pectorale as the senior synonym while acknowledging the nomenclatural problems outlined above. Like Hutchison and Weems (1998), we here follow this historic precedence.

It is plausible that a sixth taxon, Agomphus oxysternum (Cope, 1877), from the Paleocene of Georgia may be synonymous with Agomphus pectoralis as well, as its overall morphology is reported to agree with Agomphus (Hay 1908a) and because it is now understood to be equivalent in age (see Agomphus oxysternum above). However, given that this taxon is based on a relatively complete, though poorly described shell, we maintain this taxon as valid until a better description of all available Agomphus material is produced. Additionally, until the morphology of Agomphus is better understood, we refer all material from the Paleocene of South Carolina (Hutchison and Weems 1998) to Agomphus indet. as well.

\section{Baptemys Leidy, 1870}

Type species. Emys wyomingensis Leidy, 1869.

Comments. Although current phylogenies suggest that Baptemys is paraphyletic in its traditional conception (Bourque et al. 2014), we here retain this taxon because we regard it as useful in referring to early Eocene dermatemydids from the western interior USA that may represent an anagenetic lineage. However, given that this taxon is not monophyletic, we do not provide a diagnosis.

Baptemys garmanii (Cope, 1872)

$(=$ Baptemys tricarinata Hay, 1908a $=$

Dermatemys costilata Cope, 1875)

Taxonomic history. Notomorpha garmanii Cope, 1872 (new species); Notomorpha gravis = Notomorpha garmanii Hay, 1908a (junior synonym); Baptemys garmanii = Baptemys tricarinata $=$ Dermatemys costilata Lucas et al., 1989 (senior synonym and new combination); Baptemys garmanii = Baptemys tricarinata $=$ Dermatemys $\quad$ costilata $=$ Notomorpha gravis Bourque et al., 2014 (senior synonym).

Type material. USNM 4129 (holotype, Bourque et al. 2014), shell fragments (Cope 1884, pl. 23.14-16, labeled as Notomorpha gravis).

Type locality. Near Bear River, $10 \mathrm{~km}$ north of Evanston, Uinta County, Wyoming, USA (see Figure 7); Wasatch Formation (Hay 1908a), Wasatchian NALMA, Ypresian, early Eocene (Woodburne 2004).

Referred material and range. Early Eocene (Ypresian), middle to late Wasatchian NALMA of New Mexico (including type of Dermatemys costilata) and Wyoming (hypodigm of Bourque et al. 2014, including type material of Baptemys tricarinata and Dermatemys costilata).

Diagnosis. Baptemys garmanii can currently be diagnosed as a representative of Kinosternoidea and Pan-Dermatemys by the presence of a tricarinate carapace, short costiform processes, absence of extragulars and contact of the inguinal buttresses with peripheral VIII. Baptemys garmanii differs from Hoplochelys spp. by having a midline contact of the abdominals, from Agomphus spp. by being tricarinate, from $B$. nanus by being much larger, having a more anteriorly situated gular-humeral sulcus on the entoplastron and having a keeled pygal, from $B$. wyomingensis and Dermatemys mawii by the development of three fully developed keels but only three inframarginals and from $D$. mawii by a complete neural column.

Comments. Baptemys garmanii has a tortuous nomenclatural history, which, as is often the case, is based on confusing statements made by Cope $(1872,1884)$. In 1872, Cope reported several new species of turtles from Wasatchian deposits of 
Wyoming, garmanii, gravis and testudinea, which he grouped into the new pleurodiran taxon Notomorpha, but this description does not include any figures. In 1884, Cope reassigned testudinea to Emys, and synonymized garmanii and gravis under the name Notomorpha gravis. Cope (1884) furthermore figured some fragments, in particular an "epiplastron" that must represent the holotype of garmanii, given that no such element was reported for gravis (Cope 1872). Hay (1908a) followed Cope (1884) and also reported this taxon as Notomorpha gravis, while noting that the holotype of gravis had been lost. More recently, Bourque et al. (2014) outlined in detail the nomenclatural history of various Baptemys taxa and declared gravis to be a nomen dubium, because the type was never figured and has long since been lost. However, they incorrectly listed this taxon as a junior synonym of garmanii, which is inconsistent, as gravis has priority over garmanii, because Cope (1884) as the first reviser of the group gave that taxon precedence. We here agree with the conclusion that gravis is a nomen dubium, because the type material is lost and has never been figured and because the characters listed by Cope (1872) are insufficient to diagnose a valid taxon. The Wasatchian species should be called garmanii, but questions remain regarding its generic attribution.

In his description of Notomorpha garmanii, Cope (1872, p. 477) compares the epiplastron of garmanii to the "type of the genus," which can only refer to the first listed Notomorpha testudinea, as this is the only other species of Notomorpha reported to have an epiplastron. Cope (1884) was therefore in error in removing testudinea from Notomorpha and by implicitly designating gravis as the type of this genus. Bourque et al. (2014) were similarly in error in designating garmanii as the type species, although they were correct that the figured portion of the type of garmanii is not a plastron, but rather a nuchal fragment. Notomorpha is therefore clearly typified by testudinea, which is now agreed to be a testudinoid turtle (Hay 1908a; Bourque et al. 2014) and this name therefore has no nomenclatural relevance to kinosternoid turtles. Instead of creating yet another monotypic genus name for this taxon, we here recognize Baptemys as a paraphyletic taxon that includes all currently known Eocene taxa.

Although the holotype of Baptemys garmanii is highly fragmentary, it displays enough characters to compare it with the beautifully preserved holotype of $B$. tricarinata and to distinguish it from all other pan-dermatemydids. The validity of this taxon is therefore uncontroversial.

Baptemys nanus (Bourque et al., 2014), comb. nov.

Taxonomic history. Gomphochelys nanus Bourque et al., 2014 (new species).

Type material. UF 225761 (holotype), a nearly complete shell (Bourque et al. 2014, figs. 3-6, 8a).

Type locality. UF locality WY06111, near Cabin Fork, Washakie County, Wyoming, USA (see Figure 7); Willwood Formation, earliest Wasatchian NALMA, biohorizon Wa 0 (Bourque et al. 2014), Ypresian, early Eocene.

Referred material and range. Early Eocene (Ypresian), earliest Wasatchian NALMA of Washakie County, Wyoming, USA (hypodigm of Bourque et al. 2014).
Diagnosis. Baptemys nanus can be diagnosed as a representative of Kinosternoidea and Pan-Dermatemys by the presence of a tricarinate carapace, short costiform processes, absence of extragulars and contact of the inguinal buttresses with peripheral VIII. Baptemys nanus differs from Hoplochelys spp. by having a midline contact of the abdominals, from Agomphus spp. by being keeled, from B. garmanii, B. wyomingensis and Dermatemys mawii by being smaller in size, having thickened peripherals and a posteriorly situated gular-humeral sulcus on the entoplastron, from $B$. wyomingensis and $D$. mawii by having only three inframarginals and from $D$. mawii by a complete neural column.

Comments. Baptemys nanus was only recently named based on a highly fractured, but nearly complete shell from the earliest Wasatchian of Wyoming (Bourque et al. 2014). A phylogenetic analysis placed all three Eocene species of Baptemys into a paraphyletic grade relative to the extant Dermatemys mawii (Bourque et al. 2014). Given that these species do not show any temporal overlap and that the oldest species show plesiomorphic characters relative to the later species, it appears plausible that they form a single anagenetic lineage. Given that the name Notomorpha cannot be applied to a pan-dermatemydid (see Baptemys garmanii above), we here return to a simplified taxonomy of pandermatemydids by unifying all three named Eocene pandermatemydid species into the paraphyletic genus Baptemys.

Baptemys wyomingensis (Leidy, 1869)

\section{$(=$ Baena ponderosa Hay, 1908a = Baptemys} fluviatilis Hay, 1908a)

Taxonomic history. Emys wyomingensis Leidy, 1869 (new species); Baptemys wyomingensis Leidy, 1870 (new combination); Adocus wyomingensis Cope, 1869/70 (new combination); Dermatemys wyomingensis Cope, 1872 (new combination); Baptemys wyomingensis = Baena ponderosa Hay, 1908a (senior synonym); Baptemys wyomingensis = Baptemys fluviatilis Lucas et al., 1989 (senior synonym); Baptemys wyomingensis = Baena ponderosa $=$ Baptemys fluviatilis Bourque et al., 2014 (senior synonym).

Type material. ANSP 10074 (holotype, Meylan and Gaffney 1989), a nearly complete shell primarily lacking some peripherals and the anterior plastral lobe (Leidy 1873, pl. 12).

Type locality. Near Fort Bridger, Wyoming, USA (Leidy 1869; see Figure 7); Bridger Formation, Bridgerian NALMA (Hay 1908a), Ypresian-Lutetian, Eocene (Woodburne 2004).

Referred material and range. Early Paleocene (Ypresian-Lutetian), Bridgerian NALMA, of the Green River Basin, Wyoming, USA (Hay 1908a; Zonneveld et al. 2000; West and Hutchison 1981; Bourque et al. 2014; including Baena ponderosa of Cope 1873).

Diagnosis. Baptemys wyomingensis can currently be diagnosed as a representative of Kinosternoidea and Pan-Dermatemys by the presence short costiform processes, absence of extragulars and contact of the inguinal buttresses with peripheral VIII. It can furthermore be differentiated from other kinosternoids, 
with the exception of Dermatemys mawii, by a contribution of the frontal to the orbit and the presence of accessory lingual ridges in the palate. Among pan-dermatemydids, B. wyomingensis differs from Hoplochelys spp. by having midline contact of the abdominals, from Agomphus spp., B. nanus and B. garmanii by having four inframarginals and a posteriorly positioned midline keel only that extends onto the pygal and from D. mawii by the development of a complete neural column.

Comments. Baptemys wyomingensis is known from relatively rich material from the Green River Basin of southwestern Wyoming, and this taxon is therefore well diagnosed relative to other representatives of the pan-dermatemydid lineage (Leidy 1869; Cope 1873; Hay 1908a; West and Hutchison 1981; Zonneveld et al. 2000; Bourque et al. 2014). Phylogenetic analysis suggests that the three herein recognized species of Baptemys form a paraphyletic grade relative to Dermatemys mawii, with $B$. wyomingensis being the most derived (Bourque et al. 2014). In many aspects of the cranial and shell morphology, B. wyomingensis already resembles its extant cousin D. mawii, and it is therefore plausible that B. wyomingensis already expressed the deviant ecology of this lineage, by being an aquatic herbivore, in contrast to the highly carnivorous proclivities of many other pan-kinosternoids.

\section{Hoplochelys Hay, 1908a}

Type species. Chelydra crassa Cope, 1888

Diagnosis. Hoplochelys can be diagnosed as a representative of Kinosternoidea and Pan-Dermatemys by the full list of shell characters listed above for those taxa. Hoplochelys can be distinguished from all other pan-dermatemydids by the development of three broad carapacial keels combined with the absence of medially contacting abdominals.

Comments. We recognize two species of Hoplochelys: the late Cretaceous (Maastrichtian) H. clark and the early Paleocene (Danian) H. crassa (see below). Given that these two species can only be distinguished by nuances pertaining to the median keel and the plastral scutes, we herein refer all fragmentary Hoplochelys material reported outside of the type regions of these taxa to Hoplochelys indet. This includes fragments from the Late Cretaceous (Campanian) of Coahuila, Mexico (Rodriguez-de la Rosa and Cevallos-Ferriz 1998; Brinkman and Rodriguez de la Rosa 2006), and the early Paleocene (Danian) of Texas (Tomlinson 1997) and Colorado (Hutchison and Holroyd 2003). We agree with Hutchison and Holroyd (2003) that "Hoplochelys" caelata is a pan-chelydrid.

\section{Hoplochelys clark Knauss et al., 2011}

Taxonomic history. Hoplochelys clark Knauss et al., 2011 (new species).

Type material. PTRM 16173 (holotype), a nearly complete, crushed shell, primarily lacking portions of the nuchal, the left posterior peripherals and the pygal region (Knauss et al. 2011, figs. 2, 3).
Type locality. PTRM site V95018, Slope County, North Dakota, USA (see Figure 7); $21.10 \mathrm{~m}$ below pollen-defined K/T boundary, Hell Creek Formation, Maastrichtian, Late Cretaceous (Knauss et al. 2011).

Referred material and range. Late Cretaceous (Maastrichtian) of Montana and North Dakota, USA (original hypodigm of Knauss et al. 2011)

Diagnosis. Hoplochelys clark can currently be diagnosed as a representative of Kinosternoidea, Pan-Dermatemys and Hoplochelys by the full list of shell characters listed above for those taxa. Hoplochelys clark is currently differentiated from $H$. crassa by the presence of a subdivided median keel and placement of the humeral-femoral sulcus posterior to the hyo-hypoplastral suture.

Comments. Hoplochelys clark was only recently named based on a relatively complete, though crushed shell from the Late Cretaceous (Maastrichtian) of North Dakota (Knauss et al. 2011) and numerous fragments found in the vicinity of the North Dakota-Montana border. Hoplochelys clark closely resembles the slightly younger $H$. crassa from the early Paleocene of New Mexico, but the Late Cretaceous material differs consistently from its southern congener by having a continuous median keel and an overlap of the humeralfemoral sulcus with the hyo-hypoplastral suture. It is plausible that $H$. clark and $H$. crassa are chronospecies (Knauss et al. 2011).

Hoplochelys crassa (Cope, 1888)

(= Hoplochelys bicarinata Hay, $1911=$

Hoplochelys elongata Gilmore, 1919b =

Hoplochelys laqueata Gilmore, 1919b = Hoplochelys paludosa Hay, 1908a = Hoplochelys saliens Hay, 1908a)

Taxonomic history. Chelydra crassa Cope, 1888 (new species); Hoplochelys crassa Hay, 1905 (new combination); Hoplochelys crassa $=$ Hoplochelys bicarinata $=$ Hoplochelys laqueata Hutchison and Holroyd, 2003 (senior synonym); Hoplochelys crassa = Hoplochelys bicarinata $=$ Hoplochelys elongata $=$ Hoplochelys laqueata $=$ Hoplochelys paludosa $=$ Hoplochelys saliens Knauss et al., 2011 (senior synonym and lectotype designation).

Type material. AMNH 6091 (lectotype), currently consisting of the medial portion of two right costals, four peripherals, a partial right hyoplastron and a partial left hypoplastron (Hay 1908a, fig. 325, pl. 38.4-9), herein designated as the lectotype. The paralectotype has been reported lost (Hay 1908a).

Type locality. Inferred to be near Chaco Canyon, San Juan County, New Mexico, USA (Hay 1908a; see Figure 7); Nacimiento Formation, Puercan NALMA (Gilmore 1919b), Danian, early Paleocene (Woodburne 2004).

Referred material and range. Early Paleocene (Danian), Puercan-Torrejonian NALMA of New Mexico, USA (hypodigm of Knauss et al. 2011) 
Diagnosis. Hoplochelys crassa can currently be diagnosed as a representative of Kinosternoidea, Pan-Dermatemys and Hoplochelys by the full list of shell characters listed above for those taxa. Hoplochelys crassa is currently differentiated from $H$. clark by the presence of a continuous median keel and placement of the humeral-femoral sulcus along the hyo-hypoplastral suture.

In contrast to all other deposits, material referable to Hoplochelys appears to be relatively common in the early Paleocene of the San Juan Basin of northwestern New Mexico. Cope (1882) reported two fragmentary specimens from these deposits under the name Dermatemys sp., but later felt that these were a new species of chelydrid, which he named Chelydra crassa. Hay $(1905,1908$ a) later referred crassa to the new taxon Hoplochelys and noted that it is a "dermatemydid," a taxon now recognized to be highly polyphyletic in its traditional meaning. In a series of papers, Hay (1908a, 1911) and Gilmore (1919b) reported more than a dozen, often relatively complete specimens from the Puercan and Torrejon of New Mexico and variously referred these to five newly named taxa or previously named taxa. Hutchison and Holroyd (2003) suggested that crassa, bicarinata and laqueata may be synonymous, but Knauss et al. (2011) went further by suggesting that all five were synonymous, as the primary differences used to separate these appear to be caused by taphonomic crushing. This conclusion was later supported by Holroyd et al. (2014). Knauss et al. (2011) furthermore named H. clark on the basis of material from the Late Cretaceous (Maastrichtian) of North Dakota and Montana, but differences between the two taxa are minute, though consistent. It therefore appears plausible that $H$. clark and $H$. crassa are chronospecies (Knauss et al. 2011). A detailed review of the morphology of $\mathrm{H}$. crassa is long overdue.

\section{Kinosternidae Hay, 1892}

Phylogenetic definition. Following Joyce et al. (2004), the term Kinosternidae is herein referred to the clade arising from the last common ancestor of Staurotypus triporcatus (Wiegmann, 1828), and Kinosternon scorpioides (Linnaeus, 1766). Kinosternidae is the crown clade of Pan-Kinosternidae.

Diagnosis. Kinosternidae is currently diagnosed to be part of Kinosternoidea by the complete list of characters provided above for that clade. Kinosternidae is differentiated from all other kinosternoids by presence of anterior musk grooves, reduction in peripherals to 10 , reduction of marginals to 11 , reduction of the inframarginals to 2, absence of abdominals and absence of a contact between costal rib VIII and its vertebra.

Comments. Given that no single fossil taxon is currently hypothesized to be a stem-kinosternid, we herein do not list Pan-Kinosternidae as a distinct taxon (Joyce et al. 2004), as it would fully overlap with Kinosternidae in its content and diagnosis.

Baltemys staurogastros Hutchison, 1991 (= Baltemys velogastros Lichtig and Lucas, 2015)

Taxonomic history. Baltemys staurogastros Hutchison, 1991 (new species).
Type material. UCMP 127200 (holotype), nearly complete shell (Hutchison 1991, figs. 2a, 3a, b).

Type locality. UCMP locality V81170 (= US Geological Survey locality D-1162), Big Horn County, Wyoming, USA (see Figure 7); Lysitian subage, Willwood Formation, late Wasatchian NALMA (Hutchison 1991), Ypresian, early Eocene (Woodburne 2004).

Referred material and range. Early Eocene (Ypresian), Wasatchian NALMA, Big Horn and Washakie counties, Wyoming, USA (original hypodigm of Hutchison 1991); Early Eocene (Ypresian-Lutetian), Bridgerian NALMA, Huerfano County, Colorado, USA (holotype of Baltemys velogastros).

Diagnosis. Baltemys staurogastros can be diagnosed as a kinosternid based on the full list of characters provided above for that clade and as a pan-kinosternine by the presence of a single suprapygal. Baltemys staurogastros can be differentiated from all other pan-kinosternines by the presence of a complete neural series and a broad vertebral I, and by lacking an intergular, an anal notch and a transverse epi-hyoplastral suture.

Comments. Baltemys staurogastros is based on a poorly preserved, but near-complete shell from the early Eocene of the Bighorn Basin of Wyoming (Hutchison 1991). Its taxonomic validity has never been questioned. We here refer slightly younger material from the early Bridgerian of Colorado to this taxon as well (see Baltemys velogastros below), thereby extending its range in space and time. Fragmentary remains reminiscent of B. staurogastros have otherwise been documented throughout the Wasatchian and Bridgerian of Wyoming, but these have universally been referred to Baltemys sp. as they are insufficient for species attribution (Hutchison 1991; Holroyd et al. 2001). Additional fragments have been reported from the Chadronian of North America (Hutchison 1992), but no voucher specimens were listed and we therefore cannot reproduce this claim.

Hutchison (1991) integrated Baltemys staurogastros into his densely sampled analysis of fossil and recent kinosternid turtles and retrieved it as the most basal known pan-kinosternine. Many aspects of this analysis were later integrated into the more global phylogenetic analysis of Knauss et al. (2011) and Bourque et al. (2014), who retrieved the same phylogenetic position. However, the combination of the paleontological matrix of Hutchison (1991) with the neontological matrix of Iverson (1991), Bourque (2012a, 2012b) and Bourque and Schubert (2014) retrieved B. staurogastros as a pan-staurotypine. Despite this phylogenetic uncertainty, the placement of B. staurogastros within the crown appears to be unambiguous and this taxon can therefore be used for molecular calibration studies (Joyce et al. 2013).

Staurotypus moschus Cadena et al., 2012

Taxonomic history. Staurotypus moschus Cadena et al., 2012 (new species).

Type material. UF 242076 (holotype), left peripheral II (Cadena et al. 2012, fig. 6). 
Type locality. Near the west side of the Centenario Bridge, Panama Province, Panama (see Figure 8); Cucaracha Formation, early Miocene (Cadena et al. 2012; MacFadden et al. 2014).

Referred material and range. No specimens have been referred to date.

Diagnosis. Staurotypus moschus can be diagnosed as a kinosternid by the presence of musk duct groove. The musk duct groove is well incised (as in Kinosterninae, but unlike Staurotypus) and terminates on the anterior-most peripheral II to the peripheral I-II suture (unlike Kinosterninae and Staurotypus). Nevertheless, this taxon is assigned to Staurotypus on the basis of overall morphological and size similarity as well as geographic considerations, as Staurotypus occurs in part of Central America and is a large-bodied kinosternid.

Comments. Staurotypus moschus is based on a single, left peripheral II from early Miocene sediments exposed in Panama Canal Zone of Panama (Cadena et al. 2012). Although this taxon is based only on a meager single peripheral, Cadena et al. (2012) convincingly elaborate a number of differences between $S$. moschus and the two extant representatives of the group. Staurotypus moschus is notable by having been recovered far outside the currently known range for extant Staurotypus species.

\section{Xenochelys Hay, 1906}

Type species. Xenochelys formosa Hay, 1906.

Comments. Current phylogenies agree that Xenochelys is paraphyletic (Hutchison 1991). We here retain this taxon as we find this solution preferable to naming multiple monotypic genera, but we do not provide a diagnosis given that it is not monophyletic.

\section{Xenochelys bridgerensis Hutchison, 1991}

Taxonomic history. Xenochelys bridgerensis Hutchison, 1991 (new species).

Type material. UCMP 121734, a partial shell consisting of numerous carapacial fragments, a near-complete plastron and an ilium (Hutchison 1991, fig. 8; Bourque 2013, fig. 25.7c).

Type locality. UCMP locality V76186, Uinta County, Wyoming, USA (see Figure 7); Upper Bridger Formation, Twin Buttes Member, Unit D, Bridgerian NALMA (Hutchison 1991), Lutetian, middle Eocene (Woodburne 2004)

Referred material and range. Middle Eocene (Lutetian), Bridgerian NALMA, Uinta County, Wyoming, USA (original hypodigm of Hutchison 1991).

Diagnosis. Xenochelys bridgerensis can be diagnosed as a kinosternid by the full list of characters provided above for that clade and as a pan-kinosternine by the presence of a single suprapygal. Xenochelys bridgerensis can be differentiated from Baltemys staurogastros by the presence of a reduced neural column, narrow vertebral I, an anal notch, a transverse epi-hyoplastral suture and an intergular, from $X$. lostcabinensis by having a broader anterior plastral lobe, from $X$. formosa and $X$. floridensis by having a narrower anterior plastral lobe and from all kinosternines by having an entoplastron and a single pair of humerals.

Comments. Xenochelys bridgerensis is based on a partial skeleton from the middle Eocene Bridger Formation of southwestern Wyoming (Hutchison 1991), of which only the plastron has been figured to date (Hutchison 1991; Bourque 2013). The phylogenetic analysis of Hutchison (1991) revealed that the three then-known Eocene Xenochelys species represent the stem lineage of crown Kinosterninae, a conclusion supported by subsequent analyses (e.g., Knauss et al. 2011; Bourque et al. 2014). Although this indicates that Xenochelys may perhaps be paraphyletic, we agree that it is prudent not to create additional genera, as we herein do not support the notion that genera must be monophyletic. The validity of this taxon is uncontroversial.

\section{Xenochelys floridensis Bourque, 2013}

Taxonomic history. Xenochelys floridensis Bourque, 2013 (new species).

Type material. UF 150006/7 (holotype), associated partial left and right hypoplastra (Bourque 2013, figs. 25.3f); UF 150001 (paratype), right peripheral VIII; UF 150002 (paratype), left costal III; UF 150005 (paratype), left hypoplastron; UF 150008 (paratype), right hyoplastron fragment; UF 150009 (paratype), entoplastron; UF 150017 (paratype), left peripheral I; UF 150018 (paratype), left peripheral III; UF 150019 (paratype), right peripheral V; UF 150020 (paratype), neural I; UF 150021 (paratype), neural; UF 150022 (paratype), left xiphiplastron; UF 150023 (paratype), mandible.

Type locality. Brooksville 2 Site, Hernando County, Florida, USA (see Figure 7); sublocality 1B; early Arikareean NALMA (Bourque 2013), Chattian, late Oligocene (Woodburne 2004).

Referred material and range. No material has been referred to date beyond the original hypodigm of Bourque (2013).

Diagnosis. Xenochelys floridensis can be diagnosed as a kinosternid by the full list of characters provided above for that clade. Xenochelys floridensis can be differentiated from Baltemys staurogastros by the presence of a narrow vertebral I, lack of a femoral-anal notch, a transverse epi-hyoplastral suture and a broader inguinal buttress, from $X$. lostcabinensis and $X$. bridgerensis by lacking a femoral-anal notch, having a deep posterior marginal to visceral step, and from $X$. formosa by having a smaller body size, narrow dorsal femoral-anal margin and by lacking overlap of vertebral I onto peripheral I.

Comments. Xenochelys floridensis is based on a series of fragments from the late Oligocene of central Florida (Bourque 2013). As with any taxon based on fragments, there is legitimate concern that $X$. floridensis could be a chimera. However, given the lack of a second kinosternid taxon at the relevant localities, lack of chelonian diversity from Brooksville 2 (only two taxa represented) and the overall correspondence of 
$X$. floridensis with other Xenochelys species, we herein support the validity of this taxon. Although a phylogenetic analysis is still outstanding, the placement of $X$. floridensis outside crown Kinosterninae is strongly supported by the presence of an entoplastron, anterior position of the humeral-femoral sulcus on the hypoplastron and insertion of the distal costal I rib end into the posterior moiety of peripheral III. The referral of this taxon to the paraphyletic stem taxon Xenochelys is therefore justified.

\section{Xenochelys formosa Hay, 1906}

Taxonomic history. Xenochelys formosa Hay, 1906 (new species).

Type material. AMNH 1097 (holotype), a laterally crushed shell primarily lacking much of the left peripheral series (Hay 1906, figs. 2, 3; Hay 1908a, figs. 355, 356; Bourque 2013, fig. 25.7a, b).

Type locality. Quinn Draw, Oglala Lakota County (formerly Shannon County, previously part of Washington County), South Dakota, USA (see Figure 7); Chadron Formation, Chadronian NALMA (Hutchison 1991), Priabonian, late Eocene (Woodburne 2004)

Referred material and range. Late Eocene (Priabonian), Chadronian NALMA of South Dakota, USA (referred skull of Williams 1952).

Diagnosis. Xenochelys formosa can be diagnosed as a kinosternid by the full list of characters provided above for that clade and as a pan-kinosternine by the presence of a single suprapygal. Xenochelys formosa can be differentiated from Baltemys staurogastros by the presence of a reduced neural column, narrow vertebral I, an anal notch, a transverse epihyoplastral suture and an intergular, from $X$. lostcabinensis and $X$. bridgerensis by having a broader anterior plastral lobe, lacking a femoral-anal notch, and presence of a deep marginal to visceral step, and from $X$. floridensis by having larger body size, broad dorsal femoral-anal margins and an overlap of vertebral I onto peripheral I.

Comments. Xenochelys formosa is based on a slightly crushed, but otherwise well-preserved shell from the late Eocene Chadron Formation of Oglala Lakota County, North Dakota (Hay 1906). As far as we are aware, no additional shell material has ever been referred to this taxon, which underlines the scarcity of Xenochelys remains in Eocene deposits. Williams (1952) later described a turtle skull from the same county and correctly deduced that it represents a kinosternid. Although no shell elements are associated with this find, Williams (1952) referred this skull to X. formosa and all following authors have accepted this assessment (e.g., Hutchison 1991; Joyce 2007; Knauss et al. 2011; Bourque 2013; Bourque et al. 2014). The phylogenetic analysis of Hutchison (1991) implies that $X$. formosa is the most derived representative of the kinosternine stem lineage, a conclusion supported by all following analyses with sufficient sampling (e.g., Joyce 2007; Knauss et al. 2011; Bourque et al. 2014). Given that X. formosa is the type species of Xenochelys, its inclusion in this taxon is unproblematic.
Xenochelys lostcabinensis Hutchison, 1991

Taxonomic history. Xenochelys lostcabinensis Hutchison, 1991 (new species)

Type material. UCMP 112341 (holotype), a nearly complete shell (Hutchison 1991, figs. 2, 7; Bourque 2013, fig. 25.7d).

Type locality. UCMP locality V74133, Natrona County, Wyoming, USA (see Figure 7); Lost Cabin Member, Wind River Formation, late Wasatchian NALMA (Hutchison 1991), Ypresian, early Eocene (Woodburne 2004)

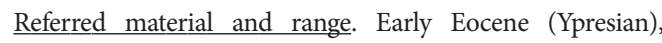
Wasatchian NALMA, Wind River and Green River basins, Wyoming, USA (referred material of Hutchison 1991).

Diagnosis. Xenochelys lostcabinensis can be diagnosed as a kinosternid by the full list of characters provided above for that clade and as a pan-kinosternine by the presence of a single suprapygal. Xenochelys lostcabinensis can be differentiated from Baltemys staurogastros by the presence of a reduced neural column, narrow vertebral I, an anal notch, a transverse epi-hyoplastral suture and an intergular, and from all remaining pan-kinosternines by having a narrow anterior plastral lobe, a residual midline contact of the gulars and thick shell bones.

Comments. Xenochelys lostcabinensis is based on a near-complete shell from the early Eocene (Wasatchian NALMA) of Wyoming that is clearly reminiscent of the holotype of Xenochelys formosa from the late Eocene (Chadronian NALMA) of South Dakota (Hutchison 1991). Additional specimens referable to this taxon were collected in Wasatchian deposits in the Wind River and Green River basins of Wyoming (Hutchison 1991). The phylogenetic analysis of Hutchison (1991) revealed that all then-known Eocene Xenochelys species form the paraphyletic stem lineage leading up to crown Kinosterninae and all sufficiently sampled matrices have confirmed this assertion (e.g., Knauss et al. 2011; Bourque et al. 2014). Although all evidence points toward the paraphyletic nature of Xenochelys, we here retain lostcabinensis within this genus, as we find the explicit paraphyly of select taxa preferable to the proliferation of monotypic genera.

\section{Kinosterninae Lindholm, 1929}

Phylogenetic definition. We herein refer the term Kinosterninae to the clade arising from the last common ancestor of Sternotherus odoratus (Latreille in Sonnini and Latreille, 1801) and Kinosternon scorpioides (Linnaeus, 1766).

Diagnosis. Kinosterninae is currently diagnosed to be part of Kinosternidae by the complete list of characters provided above for that clade. Kinosterninae is differentiated from all other kinosternids by the combined presence of a single suprapygal, a reduced neural column, a narrow cervical and vertebral I, distal costal I terminates in anterior-mid peripheral III, a transverse epi-hyoplastral suture, an anal notch, an intergular, two pairs of humerals and the lack of an entoplastron. 
Comments. Following the rationale outlined by Joyce et al. (2004), we here refer authorship of Kinosterninae to Lindholm (1929), as he was the first to use this name with this exact spelling. Following the rules of the ICZN (1999), however, authorship should be accorded to Agassiz (1857), because he was the first to create a family group taxon typified by Kinosternon (then Cinosternon).

\section{Kinosternon Spix, 1824}

Type species. Testudo scorpioides Linnaeus, 1766.

Diagnosis. Kinosternon is currently diagnosed to be part of Kinosterninae by the complete list of characters provided above for that clade. Kinosternon is currently differentiated from Sternotherus by the development of large anterior and posterior plastral lobes, posterior humeral-femoral sulcus situated posteriorly on the hypoplastron, contact of the axillary and inguinal inframarginals contained on the hyoplastron, anteromedial boundary of the fossa temporalis superior on the parietal reduced to a weakly developed ridge, anterior humeral scutes medially shorter than gular scutes and anterior and posterior plastral lobe kinesis.

\section{Kinosternon arizonense Gilmore, 1923}

Taxonomic history. Kinosternon arizonense Gilmore, 1923 (new species); Kinosternon ( flavescens) arizonense $=$ Kinosternon (flavescens) stejnegeri Iverson, 1979 (senior synonym).

Type material. USNM 10463 (holotype), a skeleton including most of the shell, mandibles and isolated vertebrae and limb bones (Gilmore 1923, figs. 1, 3, 5; pls. 1, 2); USNM 10462 (paratype), a near-complete shell (Gilmore 1923, figs. 2, 4, 6, 7; pls. 3-5).

Type locality. Benson Locality, $3 \mathrm{~km}$ south of Benson, Cochise County, Arizona, USA (Gilmore 1923; see Figure 8); late Blancan NALMA, Piacenzian, late Pliocene (Woodburne 2004; Morgan and White 2005).

Referred material and range. Late Pliocene (Piacenzian), late Blancan NALMA of type locality (Brattstrom 1955a); 111 Ranch, Arizona (McCord 2016).

Diagnosis. Kinosternon arizonense is currently diagnosed to be part of Kinosternon by the complete list of characters provided above for that clade. Kinosternon arizonense is currently differentiated from representatives of Kinosternon flavescens by having a larger adult body size, medial femoral and anal scutes nearly equal in length, gular length nearly half the anterior plastral lobe length and the medial humeral length correspondingly shorter, and a V-shaped anterior plastral forelobe hinge suture.

Comments. Kinosternon arizonense is based on two well-preserved specimens from the late Pliocene Benson Locality of Arizona (Gilmore 1923). Gilmore (1923) noted similarities with the extant taxon $K$. flavescens, but nevertheless felt compelled that sufficient characters were available to establish a new taxon. Iver- son (1979) much later synonymized $K$. arizonense with the extant taxon K. f. stejnegeri because he noted that they broadly overlap in morphology and both occur in Arizona. Although Iverson (1979) classified arizonense as a subspecies of $K$. flavescens, most studies now regard it as a full species, as it appears to be genetically distinct from $K$. flavescens (e.g., Spinks et al. 2014). We nevertheless tentatively accept the recent conclusion of McCord (2016) that the Piazanian material is distinct from the extant $K$. stejnegeri and restrict $K$. arizonense to the Pliocene. A more explicit study using phylogenetic methods will hopefully clarify this persistent taxonomic conundrum.

\section{Kinosternon notolophus Bourque, in press}

Taxonomic history. Kinosternon notolophus Bourque, in press (new species).

Type material. UF 43031 (holotype), a nuchal (Bourque, in press, fig. 8.1,2).

Type locality. Love Bone Bed, Alachua County, Florida, USA (see Figure 8); Alachua Formation, late Clarendonian NALMA (Bourque, in press), Tortonian, late Miocene (Woodburne 2004)

Referred material and range. Late Miocene (Tortonian), late Clarendonian, Alachua County (including type locality) and Hamilton County, Florida, USA (referred material of Bourque, in press).

Diagnosis. Kinosternon notolophus is currently diagnosed to be part of Kinosternon by the complete list of characters provided above for that clade. Kinosternon notolophus is currently differentiated from all other tricarinate representatives of Kinosternon by having a pronounced flat crested medial keel on the nuchal that is more developed than in extant kinosternines, costiform processes short and nublike, posterior marginals thickened with deep visceral step, broad nuchal to neural I contact, more posteriorly situated nuchal horns, lack of an abrupt constriction posterior to the nuchal horns, relatively narrow vertebral I that lacks marginal II contact and broad marginal rim (comprising the marginal I scute set and cervical scute) in relation to the overall width of the nuchal.

Comments. Kinosternon notolophus is known only from a small number of isolated remains from the late Miocene of northern Florida, but it is easily diagnosed from coeval kinosternid turtles by being notably thick shelled and tricarinate (Bourque, in press). Given the fragmentary nature of the available material, Bourque (in press) did not include this taxon in a phylogenetic analysis, but preliminary character analysis indicates a potential affiliation of $K$. notolophus with tricarinate kinosternines that currently live in southern Arizona and northern Mexico $(K$. sonoriense), and is somewhat morphologically intermediate between those taxa and the K. subrubrum group.

\section{Kinosternon pannekollops Bourque, in press}

Taxonomic history. Kinosternon pannekollops Bourque, in press (new species). 
Type material. AMNH FAM12778 (holotype), a nearly complete shell (Bourque, in press, figs. 4-6).

Type locality. Lewis Quarry 7, Donley County, Texas, USA (see Figure 8); Ogallala Formation, Clarendonian NALMA (Bourque, in press), Serravallian-Tortonian, middle-late Miocene (Woodburne 2004).

Referred material and range. No material has been referred to date.

Diagnosis. Kinosternon pannekollops is currently diagnosed to be part of Kinosternon by the complete list of characters provided above for that clade. Kinosternon pannekollops is currently differentiated from all remaining representatives of Kinosternon by vertebrals I-IV being much longer than wide and the vertebral III-IV sulcus crosses costal VI pair, thick anteriorly extensive axillary buttressing on visceral peripherals III-IV (that terminates on peripheral II), deeply incised anterior musk duct groove with its originating foramen on the anterior of peripheral III and its terminus housed by a deep foramen situated on the anterior-most peripheral II. It also possesses a unique combination of symplesiomorphies and synapomorphies with other Kinosternon spp. that distinguish it as a species (Bourque, in press).

Comments. Kinosternon pannekollops is known from a single, well-preserved specimen from the middle-late Miocene of Texas that provides sufficient character information to diagnose it as a valid taxon and to hypothesize a sister group relationship with the extant K. subrubrum group (Bourque, in press). Given the complete nature of the type specimen, the validity of this newly described species will likely not be controversial.

\section{Kinosternon pojoaque Bourque, 2012a}

Taxonomic history. Kinosternon pojoaque Bourque, 2012a (new species).

Type material. AMNH FAM12744 (holotype), a nearly complete subadult skeleton (Bourque 2012a, figs. 4, 5)

Type locality. San Ildefonso Locality, Santa Fe County, New Mexico, USA (see Figure 8); Pojoaque Member, Tesuque Formation, late Barstovian NALMA (Bourque 2012a), Serravallian, middle Miocene (Woodburne 2004).

Referred material and range. A single specimen lacking detailed locality information was referred by Bourque (2012a) to this taxon (see Comments below)

Diagnosis. Kinosternon pojoaque is currently diagnosed to be part of Kinosternon by the complete list of characters provided above for that clade. Kinosternon pojoaque is currently differentiated from all remaining representatives of Kinosternon by a unique combination of characters that include an elevated marginal IX (a synapomorphy of the K. flavescens group), flattened plastral buttresses that lack an inguinal groove, relatively squared plastral forelobe with narrow hyoplastral contact (broad axillary notches) and a small plastron to carapace length ratio.
Comments. Kinosternon pojoaque is based on a beautifully preserved, nearly complete skeleton from the middle Miocene of New Mexico. The specimen clearly displays a number of diagnostic characters, and the most recent phylogenetic analyses place it as sister to the K. flavescens group (Bourque and Schubert 2014). Given the complete nature of the type specimen, the validity of this taxon will likely remain uncontroversial.

Bourque (2012a) referred a single, nearly complete shell to Kinosternon pojoaque, but the attribution of this specimen is somewhat clouded by lacking locality data beyond New Mexico. However, Bourque (2012a) noted that this specimen overlaps with the morphology seen in the holotype, has similar preservation, was encased in similar sediments and is part of the same collection at the AMNH. It therefore appears likely that the referred specimen originated from a locality close in time and space to the type locality.

\section{Kinosternon rincon Bourque, in press}

Taxonomic history. Kinosternon rincon Bourque, in press (new species).

Type material. AMNH FAM13822 (holotype), partial skeleton including much of the shell and skull (Bourque, in press, figs. $2,3)$.

Type locality. Rincon Quarry, Sandoval County, New Mexico, USA (see Figure 8); Cerro Conejo Formation, late Barstovian NALMA (Bourque 2012a), Serravallian, middle Miocene (Woodburne 2004).

Referred material and range. Middle Miocene (Serravallian), late Barstovian NALMA of the type locality (referred material of Bourque, in press)

Diagnosis. Kinosternon rincon is currently diagnosed to be part of Kinosternon by the complete list of characters provided above for that clade. Kinosternon rincon is differentiated by a unique combination of symplesiomorphies and synapomorphies with other species of Kinosternon that include lateral sulci of vertebral I do not extend onto peripheral I (shared with Kinosternon wakeeniense, some of the K. subrubrum group such as Kinosternon steindachneri, and extant Sternotherus), costiform processes moderately developed, axillary buttress contacts posterior peripheral III, marginal IX moderately heightened and obtusely angled in shape (shared with Kinosternon integrum and the Kinosternon scorpioides complex and not as tall or wave-shaped as Kinosternon pojoaque and the extant $K$. flavescens group), crest of marginal IX sulcus intersects peripheral VIII-IX suture (shared with the K. scorpioides complex), femoral scute broadly overlaps approximately $40 \%$ of the hindlobe (shared with Kinosternon arizonense and $K$. wakeeniense), anal scute short, approximately $15 \%$ carapace length (shared with Kinosternon angustipons, Kinosternon dunni, Kinosternon herrerai and Kinosternon sonoriense longifemorale).

Comments. Kinosternon rincon is yet another newly described kinosternid taxon based on a relatively complete fossil skeleton. The type specimen is from the middle Miocene Rincon Quarry locality of New Mexico. Although it possesses a suite 
of diagnostic characters, it is temporally, geographically and in some ways morphologically similar to Kinosternon pojoaque. Phylogenetic placement of $K$. rincon does not affiliate this taxon with any particular extant kinosternine, but rather outside a large clade consisting of the K. scorpioides and K. subrubrum groups, and nested between this clade and stem and crown members of the $K$. flavescens group (Bourque, in press). However, given that the overall topology of this analysis does not conform closely with recent molecular analyses (e.g., Spinks et al. 2014), this result should be viewed with caution for the moment.

\section{Kinosternon skullridgescens Bourque, 2012b}

Taxonomic history. Kinosternon skullridgescens Bourque, 2012b (new species).

Type material. AMNH FAM9090 (holotype), a nearly complete skeleton (Bourque 2012b, figs. 2-4).

Type locality. North of White Operation Wash, Santa Fe County, New Mexico, USA (see Figure 8); Skull Ridge Member, Tesuque Formation, early Barstovian NALMA (Bourque 2012b), Langhian, middle Miocene (Woodburne 2004).

Referred material and range. Middle Miocene (Langhian), early Barstovian NALMA, Santa Fe County, New Mexico, USA (referred material of Bourque 2012b).

Diagnosis. Kinosternon skullridgescens is currently diagnosed to be part of Kinosternon by the complete list of characters provided above for that clade. Kinosternon skullridgescens is differentiated from other representatives of Kinosternon by a unique combination of characters that include a relatively broad and blunt-snouted skull, distal protuberance of the processus trochlearis oticum well developed and highly inflected dorsolaterally (shared with $K$. herrerai), neural I contacts nuchal (shared with other described Miocene Kinosternon and the $K$. subrubrum and $K$. flavescens groups), marginal IX much lower than marginal $\mathrm{X}$ and a narrow step formed by marginals VIII-IX that protrudes laterally from the dorsal carapace (shared with Sternotherus and K. herrerai).

Comments. Kinosternon skullridgescens is based on one wellpreserved partial skeleton and a fragmentary shell from the middle Miocene of New Mexico (Bourque 2012b). This taxon is well diagnosed relative to other kinosternids, and we therefore expect its validity to be uncontroversial. Phylogenetic analyses have placed K. skullridgescens as sister to the slightly younger taxon $K$. pojoaque and the extant $K$. flavescens group (Bourque 2012b), but also as one of the most basal Kinosternon nested between $K$. herrerai and stem and crown members of the $K$. flavescens group (Bourque, in press). On the basis of analyses of Bourque (2012b) and Bourque and Schubert (2014), K. skullridgescens and K. pojoaque form the stem lineage of the $K$. flavescens group radiation and are therefore deeply nested within crown Kinosternon. As the oldest unambiguous representative of the clade, it is therefore possible to utilize K. skullridgescens to date the divergence of crown Kinosternon.

\section{Kinosternon wakeeniense Bourque, in press}

Taxonomic history. Kinosternon wakeeniense Bourque, in press (new species).

Type material. MSU VP771 (holotype), a nuchal and right xiphiplastron (Holman 1975, fig. 2a, a’; Bourque 2011, figs. 1a-d, $2 \mathrm{c}$ and $\mathrm{f}$; Bourque, in press, fig. 7.1,2).

Type locality. WaKeeney Local Fauna, Trego County, Kansas, USA (see Figure 8); Ogallala Formation, middle-late Clarendonian NALMA (Bourque, in press), Tortonian, late Miocene (Woodburne 2004).

Referred material and range. Late Miocene (Tortonian), middle-late Clarendonian NALMA from the type locality; middle Miocene (Serravallian), early Clarendonian NALMA, Nebraska, USA (referred specimens of Bourque, in press).

Diagnosis. Kinosternon wakeeniense is currently diagnosed to be part of Kinosternon by characters provided above for that clade. Kinosternon wakeeniense is currently differentiated from other representatives of Kinosternon by a unique combination of characters that include vertebral I narrow with lateral sulci that do not overlap onto peripheral I, nuchal broadly contacts neural I, nuchal horns reduced, costiform processes diminutive and nublike, only contacting peripheral I viscerally, femoral scute long at the midline and overlaps approximately $40 \%$ of the hindlobe, and plastral hindlobe lobate, lacking distinct caudal notch (Bourque, in press).

Comments. Kinosternon wakeeniense is based on a collection of isolated shell fragments from the late Miocene WaKeeney local fauna of Kansas that are thought to represent a single taxon that shows affinities with the K. flavescens and K. subrubrum groups; however, a phylogenetic analysis was not performed due to the incomplete nature of this taxon (Bourque, in press). The type specimens, a partial nuchal and right xiphiplastron, were originally identified as belonging to the extant stinkpot Sternotherus odoratus (Holman 1975), but were more recently recognized as the Kinosternon lineage (Bourque 2011). We anticipate that future finds will help test the taxonomic validity of $K$. wakeeniense and more firmly establish its phylogenetic relationships.

\section{Sternotherus Gray, 1825}

Type species. Testudo odorata Latreille in Sonnini and Latreille, 1801.

Diagnosis. Sternotherus is currently diagnosed to be part of Kinosterninae by the complete list of characters provided above for that clade. Sternotherus is currently differentiated from Kinosternon by plastron $65-86 \%$ of carapace length, plastral forelobe kinetic to akinetic, midline kinesis present to absent, plastral hindlobe akinetic, moderate to no gular-anterior humeral cusp along the outer margin of the epiplastron, perimeter length of nuchal longer to about equal to longest peripheral, inguinal plastral buttress terminates in anterior one-third of peripheral VII, extensive interplastral scute skin sometimes 
present, plastral bridges relatively narrow, gular scutes with narrow contact at the midline, anterior humeral scutes with broad midline contact, posterior humeral-femoral sulci situated approximately midway on the hypoplastra and highly angled posteriorly toward the midline, converging posteriorly near the hypo-xiphiplastral sutures.

\section{Sternotherus bonevalleyensis \\ Bourque and Schubert, 2014}

Taxonomic history. Sternotherus bonevalleyensis Bourque and Schubert, 2014 (new species).

Type material. UF TRO1964 (holotype), a left hyoplastron (Bourque and Schubert 2014, figs. 9bb). Paratypes: UF 102655, nuchal; UF TRO1934, right hypoplastron; UF TRO1939, left peripheral III; UF TRO1946, left hypoplastron; UF TRO1947, left hypoplastron; UF TRO1953, pygal; UF TRO1958, right hypoplastron; UF TRO1963, pygal; UF TRO1967, right hyoplastron; UF TRO1968, right hyoplastron; UF TRO1990, right hyoplastral bridge fragment; UF TRO1991, left hypoplastron; UF TRO1992, pygal; UF TRO1996, partial carapace comprising left peripheral VII-IX and right peripheral VIII; UF TRO2000, left peripheral X; UF TRO2001, right peripheral IX; UF TRO2004, left peripheral II; UF TRO2009, left peripheral III; UF TRO2014, worn peripheral; UF TRO2068, left peripheral II; UF TRO2073, left peripheral IV; UF TRO2094, right peripheral IV; UF TRO3794, right peripheral I; UF TRO3796, right xiphiplastron; UF TRO3797, left hypoplastron; UF TRO3799, right hyoplastron; UF TRO25800, left epiplastron; UF 293900, partial left hyoplastron (Bourque and Schubert 2014, fig. 9).

Type locality. Central Florida Phosphate District, Polk County, Florida, USA (see Figure 8); Bone Valley Formation, late Hemphillian NALMA (Bourque and Schubert 2014), Messinian, late Miocene (Woodburne 2004).

Referred material and range. No material has been referred to date beyond the original hypodigm of Bourque and Schubert (2014).

Diagnosis. Sternotherus bonevalleyensis is currently diagnosed to be part of Sternotherus by characters provided above for that clade. Sternotherus bonevalleyensis is currently differentiated from all remaining representatives of Sternotherus by having the narrowest axillary notch among congeners. It is further diagnosed by a unique combination of synapomorphies and symplesiomorphies with other Sternotherus (Bourque and Schubert 2014)

Comments. Sternotherus bonevalleyensis is based on a collection of isolated shell elements from the late Miocene Bone Valley Formation of central Florida (Bourque and Schubert 2014). The majority of shell elements are represented in the original hypodigm, and the shell morphology of this taxon is therefore relatively well understood. Although $S$. bonevalleyensis was not included in a phylogenetic analysis, Bourque and Schubert (2014) note more similarities of S. bonevalleyensis with the extant Sternotherus minor complex and Sternotherus depressus than to the similarly aged $S$. palaeodorus from nearby Tennessee. It is therefore plausible that this taxon represents a pro- genitor of the Sternotherus minor group, while S. palaeodorus is more basally positioned on the stem of the Sternotherus lineage. We are optimistic that more complete future finds will be able to test these assertions, but until the phylogenetic position of this taxon has been further tested, we recommend that it not be used to date the divergence of crown Sternotherus.

\section{Sternotherus palaeodorus \\ Bourque and Schubert, 2014}

Taxonomic history. Sternotherus palaeodorus Bourque and Schubert, 2014 (new species).

Type material. ETMNH 13912 (holotype), a nearly complete shell lacking most of the right half of the plastron (Bourque and Schubert 2014, figs. 2, 3); ETMNH 3595 (paratype), partial carapace and associated fragments (Bourque and Schubert 2014, fig. 4); ETMNH 4687 (paratype), nearly complete shell (Bourque and Schubert 2014, fig. 5); ETMNH 4867 (paratype), a partial shell (Bourque and Schubert 2014, fig. 6); ETMNH 10000 (paratype), nearly complete carapace and anterior plastral lobe (Bourque and Schubert 2014, fig. 7).

Type locality. Gray Fossil Site, Washington County, Tennessee, USA (see Figure 8); late Hemphillian NALMA (Bourque and Schubert 2014), Messinian, late Miocene (Woodburne 2004).

Referred material and range. No material has been referred to date beyond the original hypodigm of Bourque and Schubert (2014).

Diagnosis. Sternotherus palaeodorus is currently diagnosed to be part of Sternotherus by the complete list of characters provided above for that clade. Sternotherus palaeodorus is currently differentiated from all other representatives of Sternotherus in having an enlarged intergular scute, wide vertebral I that is broadly pointed to roundly squared (shared with S. odoratus and Kinosternon) posteriorly at the vertebral I-II sulcus and overlaps peripheral set I, posteriorly extensive hypoplastron-peripheral VII contact, elongate anal scute (approximately $22 \%$ of carapace length) that is lobate along the posterior-most margin and a posteriorly situated inguinal musk duct pore.

Comments. Sternotherus palaeodorus is based on beautifully preserved partial to nearly complete shells from the late Miocene Gray Fossil Site in eastern Tennessee. Phylogenetic analysis places this taxon as sister to all extant Sternotherus, which is consistent with the relatively recent diversification of the group (Bourque and Schubert 2014). This taxon should therefore not be used to date the divergence of crown Sternotherus. Given the complete nature of the type material, the validity of this taxon is likely to remain uncontroversial.

\section{Invalid and Problematic Taxa}

Agomphus masculinus Wieland, 1905 nomen invalidum

(junior synonym of Agomphus pectoralis (Cope, 1868)) 
Taxonomic history. Agomphus masculinus Wieland, 1905 (new species); Agomphus pectoralis $=$ Adocus petrosus $=$ Agomphus masculinus $=$ Agomphus tardus $=$ Emys turgidus Hutchison and Weems, 1998 (junior synonym).

Type material. YPM VP 000671 (holotype), a partial shell consisting of a nuchal, fragmentary costals and peripherals, and a complete plastron (Wieland 1905, fig. 8; Hay 1908a, fig. 319).

Type locality. West Jersey Marl Pits, Barnsboro, Gloucester County, New Jersey, USA (Wieland 1905); Hornerstown Formation, Danian, early Paleocene (Miller 1955; Sugarman et al. 1995)

Comments. For an extensive discussion of all New Jersey Agomphus material, see Agomphus pectoralis (above).

\section{Adocus petrosus Cope, 1868 nomen invalidum}

(junior synonym of Agomphus pectoralis (Cope, 1868))

Taxonomic history. Adocus petrosus Cope, 1868 (new species); Emys petrosus Cope, 1869/70 (new combination); Agomphus petrosus Cope, 1871 (new combination); Agomphus pectoralis = Adocus petrosus $=$ Agomphus masculinus $=$ Agomphustardus $=$ Emys turgidus Hutchison and Weems, 1998 (junior synonym).

Type material. AMNH 1482 (holotype), a fragmentary skeleton consisting of four costals, five peripherals, a right hyo- and hypoplastron and a pelvic fragment (Hay 1908a, figs. 311-313, pls. $36.4,37.6,7)$.

Type locality. West Jersey Marl Pits, Barnsboro, Gloucester County, New Jersey, USA; Hornerstown Formation, Danian, early Paleocene (Gallagher 1993, not Campanian sensu Miller 1955).

Comments. For an extensive discussion of all New Jersey Agomphus material, see Agomphus pectoralis (above).

\section{Agomphus tardus Wieland, 1905} nomen invalidum

(junior synonym of Agomphus pectoralis (Cope, 1868))

Taxonomic history. Agomphus tardus Wieland, 1905 (new species); Agomphus petrosus Cope, 1871 (new combination); Agomphus pectoralis $=$ Adocus petrosus $=$ Agomphus masculinus $=$ Agomphus tardus = Emys turgidus Hutchison and Weems, 1998 (junior synonym).

Type material. YPM VP 000774 (holotype), a partial shell consisting of the partial nuchal, two neurals, five costal fragments, eight peripherals, the left hyoplastron and the right hypoplastron (Wieland 1905, figs. 1-7; Hay 1908a, figs. 314-318).

Type locality. Pemberton Marl Pits, Birmingham, Burlington County, New Jersey, USA (Wieland 1905); Hornerstown
Formation, Danian, early Paleocene (Miller 1955; Sugarman et al. 1995).

Comments. For an extensive discussion of all New Jersey Agomphus material, see Agomphus pectoralis (above).

\section{Baena ponderosa Cope, 1873 nomen invalidum}

(junior synonym of Baptemys wyomingensis

$$
\text { (Leidy, 1869)) }
$$

Taxonomic history. Baena ponderosa Cope, 1873 (new species); Baptemys wyomingensis = Baena ponderosa Hay, 1908a (junior synonym); Baptemys wyomingensis = Baena ponderosa $=$ Baptemys fluviatilis Bourque et al., 2014 (senior synonym).

Type material. USNM 4056 (holotype), a highly fragmentary shell (Cope 1884, pl. 17.3-8; Hay 1908a, fig. 345).

Type locality. Hams Fork, Green River Basin, Wyoming, USA; unknown age, likely Eocene (Cope 1873, see Comments below).

Comments. Baena ponderosa is based on a highly fractured shell collected along Hams Fork in the Green River Basin of Wyoming. In the type description, Cope (1873) already noted similarities with Baptemys wyomingensis, but he nevertheless referred this taxon to Baenidae, because he believed vertebral $\mathrm{V}$ to contribute to the posterior margin of the shell, a character still used to diagnose the group (Joyce and Lyson 2015). After restudying the holotype, Hay (1908a) noted that the margin of the shell appears to be malformed, but that the fragments in question actually document a complete marginal series. Hay (1908a) therefore referred this taxon to Baptemys wyomingensis, and we agree with this assessment.

Baltemys velogastros Lichtig and Lucas, 2015 nomen invalidum

(junior synonym of Baltemys staurogastros Hutchison, 1991)

Taxonomic history. Baltemys velogastros Lichtig and Lucas, 2015 (new species).

Type material. UCM 32796 (holotype), a partial shell consisting of neurals II-IV, parts of costals III-V, right peripherals I-IV, $\mathrm{V}-\mathrm{X}$, left peripherals I, $\mathrm{V}-\mathrm{X}$, part of the nuchal and pygal and part of the hyo- and hypoplastra (Lichtig and Lucas 2015, figs. $5,6 a)$.

Type locality. UCM locality 77032, E1/2, Section 3, T 26 S, R 70 W, Huerfano County, Colorado, USA; early Bridgerian NALMA (Lichtig and Lucas 2015), Ypresian-Lutetian, early Eocene (Woodburne 2004).

Comments. Baltemys velogastros was recently described based on a relatively complete shell from Colorado. The type locality is early Bridgerian in age and therefore only slightly younger than the late Wasatchian type material of Baltemys staurogastros from nearby Wyoming. Lichtig and Lucas listed three charac- 
ters to diagnose their taxon: (1) a narrower plastron with a wide bridge; (2) a posteriorly pointing hypo-xiphiplastral suture; and (3) contact of pleural IV with marginal XI. We are unable to see any substantial differences in plastral lobe and bridge dimensions between the type material of B. velogastros and B. staurogastros and therefore disregard the first character. Additionally, bridge width is sexually dimorphic for extant kinosternids, with males having more narrow bridges across taxa (Iverson 1991). The hypoplastral-xiphiplastral suture of Baltemys indeed appears to be straight in ventral aspect when the hypoplastron and xiphiplastron are articulated, but once the xiphiplastron is removed, visceral processes formed by the hypoplastron, which are normally covered by the xiphiplastron, create the illusion of an oblique contact. These processes are also apparent in the type material of B. velogastros, and we therefore disregard this second character as a preservational artifact. The third character, once again, appears to be substantial at first sight, but this appeal is specious once again. Lichtig and Lucas (2015) clearly document that pleural IV of the Colorado Baltemys broadly articulates with marginal XI, and this indeed contrasts the condition reconstructed by Hutchison (1991) for B. staurogastros. However, Hutchison (1991) clearly states that the type specimen of $B$. staurogastros lacks both peripherals $\mathrm{X}$, and we are unaware of any peripheral $\mathrm{X}$ having since been reported. The only element that could document the contact in question is therefore not known for B. staurogastros, and this character therefore lacks any basis. Given that we otherwise agree that the Colorado material displays the diagnostic characters of $B$. staurogastros, we here synonymize these two taxa.

\section{Baptemys fluviatilis Hay, 1908a nomen invalidum \\ (junior synonym of Baptemys wyomingensis} (Leidy, 1869))

Taxonomic history. Baptemys fluviatilis Hay, 1908a (new species); Baptemys wyomingensis = Baptemys fluviatilis Lucas et al., 1989 (junior synonym); Baptemys wyomingensis = Baena ponderosa = Baptemys fluviatilis Bourque et al., 2014 (senior synonym)

Type material. AMNH 4913 (holotype), a shell consisting of a near-complete carapace and the imprint of the plastron (Hay 1908a, figs. 350, 351, pl. 42.1, 2).

Type locality. Rocky Mountains Region, USA; unknown age, likely Eocene (Hay 1908a, see Comments below).

Comments. Hay (1908a) named Baptemys fluviatilis based on a relatively complete shell that had been donated to the AMNH in the late 19th century. The specimen had purportedly been collected from Colorado, but Hay (1908a) already noted that this locality information was highly dubious and that the shell may very well have originated from a different state. Baptemys wyomingensis has so far only been reported from the Green River Basin of Wyoming (see above), but given the wide distribution of the pan-dermatemydid lineage in other Eocene deposits, this is likely a preservational artifact. Given that the morphology of B. fluviatilis broadly corresponds to that of B. wyomingensis, we agree with Lucas et al. (1989) and Bourque et al. (2014) that these taxa are synonymous, although the uncertain locality information of $B$. fluviatilis prevents us from expanding the spatial range of $B$. wyomingensis.

\section{Baptemys tricarinata Hay 1908 a nomen invalidum \\ (junior synonym of Baptemys garmanii} (Cope, 1872))

Taxonomic history. Baptemys tricarinata Hay 1908a (new species); Notomorpha garmanii $=$ Baptemys tricarinata $=$ Dermatemys costilata Lucas et al., 1989 (junior synonym); Notomorpha garmanii $=$ Baptemys tricarinata $=$ Dermatemys costilata $=$ Notomorpha gravis Bourque et al., 2014 (junior synonym).

Type material. AMNH 6109 (holotype), a shell consisting of the central portion of the carapace and most of the plastron (Hay 1908a, figs. 346, 347; Bourque et al. 2014, fig. 7a).

Type locality. The mouth of Alkali Creek, Fremont County, Wyoming, USA (Hay 1908a); Wind River Formation, Wasatchian NALMA (Bourque et al. 2014), Ypresian, early Eocene (Woodburne 2004)

Comments. See Baptemys garmanii above for a more extensive discussion regarding this taxon.

\section{Dermatemys costilata Cope, 1875 \\ nomen invalidum \\ (junior synonym of Baptemys garmanii}

(Cope, 1872))

Taxonomic history. Dermatemys costilata Cope, 1875 (new species); Baptemys costilatus Hay, 1902 (new combination); Kallistira costilata Hay, 1908a (new combination); Baptemys garmanii $=$ Baptemys tricarinata $=$ Dermatemys costilata Lucas et al., 1989 (junior synonym); Notomorpha garmanii = Baptemys tricarinata $=$ Dermatemys costilata $=$ Notomorpha gravis Bourque et al., 2014 (junior synonym and lectotype designation).

Type material. USNM 1152, in part (lectotype), a costal fragments (Cope 1877, figs. 21-22; Hay 1908a, fig. 330). The remainder of USNM 1152 represents the polyphyletic paralectotype series (Bourque et al. 2014).

Type locality. San Juan Basin, New Mexico, USA; San Jose Formation, Wasatchian NALMA (Bourque et al. 2014), Ypresian, early Paleocene (Woodburne 2004)

Comments. Cope (1875) based this taxon on a purported assemblage of six individuals. Bourque et al. (2014) note that all available material is now catalogued under the number USNM 1152 and it is not possible to rigorously reproduce the original estimate of individuals reported by Cope (1875). However, Bourque et al. (2014) were able to clarify that USNM 1152 consists of a mixture of testudinoid and pan-dermatemydid remains, and they designated one fragment as the paralectotype to clarify the taxonomic application of the name. The selected fragment is a costal 
that clearly shows the keels diagnostic for the coeval Baptemys garmanii from Wyoming. We therefore agree with Bourque et al. (2014) that these two taxa are synonymous.

\section{Emys turgidus Cope, 1869/70} nomen invalidum

(junior synonym of Agomphus pectoralis (Cope, 1868))

Taxonomic history. Emys turgidus Cope, 1869/70 (new species); Agomphus turgidus Cope, 1871 (new combination); Agomphus pectoralis $=$ Adocuspetrosus $=$ Agomphus masculinus $=$ Agomphus tardus = Emys turgidus Hutchison and Weems, 1998 (junior synonym).

Type material. AMNH 1481 (holotype), partial shell consisting of neural IV, medial portions of left costals III-VI and right costals III-VI, several peripherals, the entoplastron and both hyoplastra (Hay 1908a, fig. 310, pl. 37.1-5).

Type locality. Mount Holly, Burlington County, New Jersey, USA; Hornerstown Formation, Danian, early Paleocene (Miller 1955; Sugarman et al. 1995).

Comments. For an extensive discussion of all New Jersey Agomphus material, see Agomphus pectoralis (above).

\section{Hoplochelys bicarinata Hay, 1911 nomen invalidum}

(junior synonym of Hoplochelys crassa (Cope, 1888))

Taxonomic history. Hoplochelys bicarinata Hay, 1911 (new species); Hoplochelys crassa $=$ Hoplochelys bicarinata $=$ Hoplochelys laqueata Hutchison and Holroyd, 2003 (junior synonym); Hoplochelys crassa $=$ Hoplochelys bicarinata $=$ Hoplochelys elongata $=$ Hoplochelys laqueata $=$ Hoplochelys paludosa $=$ Hoplochelys saliens Knauss et al., 2011 (junior synonym).

Type material. USNM 6549 (holotype), a partial shell consisting of two neurals, one costal, eleven peripherals and the central portion of the plastron (Hay 1911, figs. 20-23, pl. 12).

Type locality. Near Ojo Alamo, San Juan County, New Mexico, USA (Hay 1911); Nacimiento Formation, Puercan NALMA (Gilmore 1919b), Danian, early Paleocene (Woodburne 2004).

Comments. Hoplochelys bicarinata is based on a partial shell from the early Paleocene of New Mexico (Hay 1911), and Gilmore (1919b) later referred additional, more complete material from equivalent strata in New Mexico to this taxon. For a complete discussion regarding the validity of Hoplochelys taxa from the early Paleocene of New Mexico, see Hoplochelys crassa (above).

\section{Hoplochelys elongata Gilmore, 1919b} nomen invalidum

(junior synonym of Hoplochelys crassa (Cope, 1888))
Taxonomic history. Hoplochelys elongata Gilmore, 1919b (new species); Hoplochelys crass $a=$ Hoplochelys bicarinata $=$ Hoplochelys elongata $=$ Hoplochelys laqueata $=$ Hoplochelys paludosa $=$ Hoplochelys saliens Knauss et al., 2011 (junior synonym).

Type material. USNM 8553 (holotype), a partial shell lacking much of the nuchal and pygal region and the tips of the anterior and posterior plastral lobes (Gilmore 1919b, figs. 21, 22, pl. 16)

Type locality. $13 \mathrm{~km}$ northeast of Kimbetoh, Section 17, T $23 \mathrm{~N}$, R 8 W, San Juan County, New Mexico, USA; Nacimiento Formation, Torrejonian NALMA (Gilmore 1919b), Danian, early Paleocene (Woodburne 2004).

Comments. For a complete discussion regarding the validity of Hoplochelys taxa from the early Paleocene of New Mexico, see Hoplochelys crassa (above).

\section{Hoplochelys laqueata Gilmore, 1919b nomen invalidum}

(junior synonym of Hoplochelys crassa

(Cope, 1888))

Taxonomic history. Hoplochelys laqueata Gilmore, 1919b (new species); Hoplochelys crassa $=$ Hoplochelys bicarinata $=$ Hoplochelys laqueata Hutchison and Holroyd, 2003 (junior synonym); Hoplochelys crassa $=$ Hoplochelys bicarinata $=$ Hoplochelys elongata $=$ Hoplochelys laqueata $=$ Hoplochelys paludosa $=$ Hoplochelys saliens Knauss et al., 2011 (junior synonym).

Type material. USNM 8527 (holotype), a highly fractured shell missing many small bits and pieces, but representing most elements (Gilmore 1919b, figs. 19, 20, pl. 15).

Type locality. 6 km east of Kimbetoh, Section 35, T 23 N, R 9 W, San Juan County, New Mexico, USA; Nacimiento Formation, Puercan NALMA (Gilmore 1919b), Danian, early Paleocene (Woodburne 2004).

Comments. See Hoplochelys crassa above for a complete discussion regarding the validity of Hoplochelys taxa from the early Paleocene of New Mexico.

\section{Hoplochelys paludosa Hay, 1908a nomen invalidum \\ (junior synonym of Hoplochelys crassa (Cope, 1888))}

Taxonomic history. Hoplochelys paludosa Hay, 1908a (new species); Hoplochelys crassa $=$ Hoplochelys bicarinata $=$ Hoplochelys elongata $=$ Hoplochelys laqueata $=$ Hoplochelys paludosa $=$ Hoplochelys saliens Knauss et al., 2011 (junior synonym).

Type material. AMNH 6079 (holotype), a peripheral (Hay 1908a, fig. 328).

Type locality. Escavada Wash, Rio Arriba County, New Mexico, USA (Hay 1908a); Nacimiento Formation, Torrejonian 
NALMA (Gilmore 1919b), Danian, early Paleocene (Woodburne 2004)

Comments. For a complete discussion regarding the validity of Hoplochelys taxa from the early Paleocene of New Mexico, see Hoplochelys crassa (above).

\section{Hoplochelys saliens Hay, 1908a} nomen invalidum

(junior synonym of Hoplochelys crassa (Cope, 1888))

Taxonomic history. Hoplochelys saliens Hay, 1908a (new species); Hoplochelys crassa $=$ Hoplochelys bicarinata $=$ Hoplochelys elon gata $=$ Hoplochelys laqueata $=$ Hoplochelys paludosa $=$ Hoplochelys saliens Knauss et al., 2011 (junior synonym).

Type material. AMNH 1200 (holotype), a crushed shell primarily lacking portions of the anterior and posterior neurals and costals and of the plastral lobes (Hay 1908a, figs. 326, 327).

Type locality. At the head of Escavada Wash, Rio Arriba County, New Mexico, USA (Hay 1908a); Nacimiento Formation, Torrejonian NALMA (Gilmore 1919b), Danian, early Paleocene (Woodburne 2004)

Comments. Hoplochelys saliens is based on a crushed partial shell from the early Paleocene of New Mexico (Hay 1911) to which Gilmore (1919b) referred additional, more complete material from equivalent strata in New Mexico. For a complete discussion regarding the validity of Hoplochelys taxa from the early Paleocene of New Mexico, see Hoplochelys crassa (above).

Notomorpha gravis Cope, 1872 nomen dubium

Taxonomic history. Notomorpha gravis Cope, 1872 (new species); Notomorpha gravis = Notomorpha garmanii Hay, 1908a (senior synonym); Notomorpha garmanii = Baptemys tricarinata $=$ Dermatemys $\quad$ costilata $=$ Notomorpha gravis Bourque et al., 2014 (junior synonym).

Type material. The type material is lost and has never been figured (Hay 1908a).

Type locality. Near Bear River, $10 \mathrm{~km}$ north of Evanston, Uinta County, Wyoming, USA; Wasatch Formation (Hay 1908a), Wasatchian NALMA, Ypresian, early Eocene (Woodburne 2004).

Comments. We consider this taxon to be a nomen dubium, because the type material is lost and was never figured and because the characters provided by Cope (1872) are insufficient to diagnose a valid taxon. For a more extensive discussion, see Baptemys garmanii above.

\section{Acknowledgments}

We would like to thank Carl Mehling (AMNH) and Michael Brett-Surmann (USNM) for helping us locate type specimens. Richard Hulbert and Roger Portell (UF) provided pertinent literature. We finally would like to thank Don Brinkman, Tyler Lyson, Natasha Vitek and an anonymous reviewer for providing us with insightful comments that helped improve the quality of this paper.

Received 13 November 2015; revised and accepted 29 January 2016.

\section{Appendix 1 \\ Institutional Abbreviations}

$\mathrm{AMNH}$

American Museum of Natural History, New York, New York, USA

ANSP Academy of Natural Sciences, Philadelphia, Pennsylvania, USA

ETMNH East Tennessee State University Museum of Natural History, Gray, Tennessee, USA

GSG

KU

Geological Survey of Georgia, Atlanta, Georgia, USA

University of Kansas Natural History Museum, Lawrence, Kansas, USA

MSU Michigan State University Museum, East Lansing, Michigan, USA

PTRM Pioneer Trails Regional Museum, Bowman, North Dakota, USA

UCM University of Colorado Natural History Museum, Boulder, Colorado, USA

UCMP University of California Museum of Paleontology, Berkeley, California, USA

UF Florida Museum of Natural History, University of Florida, Gainesville, Florida, USA

USNM National Museum of Natural History, Smithsonian Institution, Washington, DC, USA

YPM VP Vertebrate Paleontology, Peabody Museum of Natural History, Yale University, New Haven, Connecticut, USA

\section{Appendix 2}

\section{Named Fossil Pan-Kinosternoid Genera}

Agomphus Cope, 1871 (type species: Emys turgidus Cope, 1869/70)

Amphiemys Cope, 1877 (type species: Amphiemys oxysternum Cope, 1877)

Baltemys Hutchison, 1991 (type species: Baltemys staurogastros Hutchison, 1991) 
Baptemys Leidy, 1870 (type species: Emys wyomingensis Leidy, 1869)

Emarginachelys Whetstone, 1978 (type species: Emarginachelys cretacea Whetstone, 1978)

Gomphochelys Bourque et al., 2014 (type species: Gomphochelys nanus Bourque et al., 2014)

Hoplochelys Hay, 1908a (type species: Chelydra crassa Cope, 1888)

Kallistira Hay, 1908a (type species: Dermatemys costilata Cope, 1875)

Tullochelys Hutchison, 2013 (type species: Tullochelys montana Hutchison, 2013)

Planetochelys Weems, 1988 (type species: Planetochelys savoiei Weems, 1988)

Xenochelys Hay, 1906 (type species: Xenochelys formosa Hay, 1906)

\section{Appendix 3 \\ Biogeographic Summary of Fossil Pan-Kinosternoidea}

Numbers in brackets reference Figures 7 and 8 . Holocene records and literature lacking vouched specimens are omitted. Abbreviation: TL, Type locality.

\section{Canada}

[1] Early Eocene, Wasatchian NALMA, Ypresian; Ellesmere Island; Pan-Kinosterninae indet. (Kinosterninae indet. of Estes and Hutchison 1980)

\section{Colombia}

[2] Late Pleistocene; Department of Cundinamarca; Kinosternon indet. (Cadena et al. 2007)

\section{El Salvador}

[3] Pleistocene; Kinosternon indet. (Cisneros 2005)

\section{Honduras}

[4] Late Miocene, early Hemphillian NALMA; Kinosternon indet., cf. K. scorpioides group (Bourque 2012b)

\section{Mexico}

[5] Late Cretaceous, Campanian; Coahuila; Hoplochelys indet. (Rodriguez-de la Rosa and Cevallos-Ferriz 1998; Brinkman and Rodriguez de la Rosa 2006), Pan-Kinosternidae indet. (Kinosternidae of Brinkman and Rodriguez de la Rosa 2006)

[6] Pleistocene; Aguascalientes; Kinosternon indet. (Kinosternon scorpioides integrum of Mooser 1980)

\section{Panama}

[7] Early Miocene; Panama Province; Staurotypus moschus (TL) (Cadena et al. 2012; MacFadden et al. 2014)

\section{United States of America}

[8] Late Cretaceous, Campanian; Utah; Pan-Kinosternidae indet. (Kinosternidae of Hutchison et al. 2013)

[9] Late Cretaceous, Campanian; New Mexico; PanKinosternidae indet. (Kinosternoidea of Sullivan et al. 2013)

[10] Late Cretaceous, Maastrichtian; Montana; PanKinosternoidea indet. (Kinosternoidea indet. of Holroyd and Hutchison 2002), Emarginachelys cretacea (TL) (Whetstone 1978), Hoplochelys clark (Knauss et al. 2011), Tullochelys montana (Hutchison 2013)

[11] Late Cretaceous, Maastrichtian; North Dakota; Pan-Kinosternoidea indet. (Kinosternoidea indet. of Holroyd and Hutchison 2002), Hoplochelys clark (TL) (Knauss et al. 2011)

[12] Late Cretaceous, Maastrichtian; Wyoming; PanKinosternoidea indet. (Kinosternoidea indet. of Holroyd and Hutchison 2002)

[13] Late Cretaceous, Maastrichtian; San Juan Basin, New Mexico; Hoplochelys indet. (Knauss et al. 2011)

[14] Early Paleocene, Puercan NALMA, Danian; Montana; Tullochelys montana (TL) (Hutchison 2013)

[15] Early Paleocene, Puercan NALMA, Danian; Colorado; Hoplochelys indet. (Hoplochelys crassa of Hutchison and Holroyd 2003)

[16] Early Paleocene, Puercan-Torrejonian NALMAs, Danian; San Juan Basin, New Mexico; Hoplochelys crassa (TL) (Cope 1888; Hay 1908a, 1911; Gilmore 1919b; Knauss et al. 2011; including H. paludosa and H. saliens of Hay 1908a, H. bicarinata of Hay 1911 and H. elongata and H. laqueata of Gilmore 1919b)

[17] Early Paleocene, Danian; Texas; Hoplochelys indet. (Tomlinson 1997)

[18] Early Paleocene, Danian; New Jersey; Agomphus pectoralis (TL) (Cope 1868; Wieland 1905; Hutchison and Weems 1998; including Emys turgidus of Cope 1869/70, Adocus petrosus of Cope 1868 and Agomphus tardus and Agomphus masculinus of Wieland 1905)

[19] Late Paleocene, Thanetian; Virginia; Planetochelys savoiei (TL) (Weems 1988)

[20] Early Paleocene, Danian; Alabama; “Agomphus" alabamensis (TL) (Gilmore 1919a)

[21] Early Paleocene, Danian; Georgia; Agomphus oxysternum (TL) (Cope 1877)

[22] Paleocene; South Carolina; Pan-Kinosternoidea, Pan-Kinosternidae indet., Agomphus indet. (Kinosternoid A + B, Kinosternidae indet., and Agomphus pectoralis, Agomphus alabamensis of Hutchison and Weems 1998, respectively)

[23] Early Eocene, Wasatchian NALMA, Ypresian; North Dakota; Baptemys garmanii (Baptemys tricarinata of Estes 1988)

[24] Late Eocene, Chadronian NALMA, Priabonian; South Dakota; Xenochelys indet. (Hutchison 1991), Xenochelys formosa (TL) (Hay 1906; Williams 1952)

[25] Early Eocene, Wasatchian NALMA, Ypresian; Wyoming, Bighorn Basin; Baltemys staurogastros 
(TL), Baltemys indet. (Hutchison 1991; Holroyd et al. 2001), Baptemys garmanii (Bourque et al. 2014; Baptemys indet. of Holroyd et al. 2001), Baptemys nanus (TL) (Bourque et al. 2014), Planetochelys dithyros (Holroyd et al. 2001; Hutchison 2013)

[26] Early Eocene, Bridgerian NALMA, Ypresian/Lutetian; Wyoming, Bighorn Basin; Baltemys indet. (Kinosterninae indet. of Hutchison 1991)

[27] Early Eocene, Wasatchian NALMA, Ypresian; Wyoming, Wind River Basin; Baltemys indet., Xenochelys indet., Xenochelys lostcabinensis (TL) (Hutchison 1991), Baptemys garmanii (Bourque et al. 2014; Baptemys tricarinata of Hay 1908a), Planetochelys dithyros (Hutchison 2013)

[28] Early Eocene, Wasatchian NALMA, Ypresian; Wyoming, Powder River Basin; Pan-Kinosternidae indet. (Kinosterninae indet. of Hutchison 1991)

[29] Early Eocene, Wasatchian NALMA, Ypresian; Wyoming, Green River Basin; Baltemys indet., Xenochelys indet., Xenochelys lostcabinensis (Hutchison 1991), Baptemys garmanii (TL) (Cope 1872; Bourque et al. 2014), Planetochelys dithyros (TL) (Hutchison 2013)

[30] Early Eocene, Bridgerian NALMA, Ypresian/Lutetian; Wyoming, Green River Basin; Baltemys indet., Xenochelys indet., Xenochelys bridgerensis (TL) (Hutchison 1991), Baptemys wyomingensis (Leidy 1869; Hay 1908a; Zonneveld et al. 2000; Bourque et al. 2014; Baena ponderosa of Cope 1873; West and Hutchison 1981)

[31] Late Eocene, Chadronian NALMA, Priabonian; Colorado; Xenochelys indet. (Hutchison 1991)

[32] Early Eocene, Bridgerian NALMA, Ypresian/Lutetian; Colorado; Baltemys staurogastros (Baltemys velogastros of Lichtig and Lucas 2015)

[33] Early Eocene, Wasatchian NALMA, Ypresian; San Juan Basin, New Mexico; Pan-Kinosterninae indet. (Kinosterninae indet. of Hutchison 1991), Baptemys garmanii (Dermatemys costilata of Cope 1875)

[34] Early Eocene, Wasatchian NALMA, Ypresian; central New Mexico; Baptemys indet. (Lucas et al. 1989)

[35] Middle Eocene, Uintan NALMA, Lutetian; Texas; Xenochelys indet. (Hutchison 1991)

[36] Middle Eocene, Uintan NALMA, Lutetian; Arkansas; Xenochelys indet. (Hutchison 1991)

[37] Late Oligocene, early Arikareean NALMA, Chattian; Florida; Xenochelys floridensis (TL) (Bourque 2013; Kinosternidae indet. of Hayes et al. 2000)

[38] Middle Miocene, early-late Barstovian NALMA, Langhian-Serravallian; north-central New Mexico; Kinosternon pojoaque (TL) (Bourque 2012a); Kinosternon skullridgescens (TL) (Bourque 2012b); Kinosternon rincon (TL) (Bourque, in press)

[39] Early-middle Miocene, late Hemingfordian-early Clarendonian NALMA, Burdigalian-Serravallian; northwestern Nebraska; Kinosternon indet. (Hutchison 1991), Kinosternon wakeeniense (Bourque, in press)
[40] Late Miocene, late Hemphillian NALMA; northeastern Nebraska; Kinosternon indet. (K. flavescens of Parmley 1992)

[41] Late Miocene, middle/late Clarendonian NALMA, Tortonian; central Kansas; Kinosternon wakeeniense (TL) (Bourque, in press; Kinosternon indet. of Wilson 1968; Sternotherus indet. of Holman 1975)

[42] Late Miocene, late Hemphillian NALMA, Messinian; southwestern Kansas; Kinosternon indet. (K. flavescens and K. subrubrum of Fichter 1969)

[43] Middle-late Miocene, Clarendonian NALMA, Serravallian/Tortonian; Texas panhandle; Kinosternon pannekollops (TL) (Bourque, in press)

[44] Early Miocene, late Arikareean, Aquitanian; southeastern Texas; Pan-Dermatemys indet. (Dermatemys indet. of Albright 1994)

[45] Late Miocene/early Pliocene, late Hemphillian, Messinian/Zanclean; Tennessee; Sternotherus palaeodorus (TL) (Bourque 2011, 2012a; Bourque and Schubert 2014)

[46] Early Miocene, early Hemingfordian, Burdigalian/ Langhian; Delaware; Kinosternidae indet. (Bourque, in press; Kinosternon of Holman 1998 and Weems and George 2013)

[47] Early-late Miocene, late Hemingfordian-early Hemphillian, Burdigalian-Messinian; northern Florida; Kinosternidae indet., Kinosternon indet., Sternotherus indet., Kinosternon notolophus (TL) (Becker 1985; Bryant 1991; Bourque 2013, in press) (see Bourque 2013, in press for great detail)

[48] Late Miocene, late Hemphillian NALMA, Messinian; central Florida; Kinosternon indet., Sternotherus bonevalleyensis (TL) (Bourque 2012b; Bourque and Schubert 2014)

[49] Late Pliocene, late Blancan NALMA, Piacenzian; Arizona; Kinosternon arizonense (TL) (Gilmore 1923)

[50] Pliocene, Blancan NALMA; Nebraska; Kinosternon indet. (K. flavescens of Holman and Schloeder 1991)

[51] Late Pliocene, late Blancan NALMA, Piacenzian; southwestern Kansas; Kinosternon indet. (K. flavescens of Fichter 1969)

[52] Pliocene, Blancan NALMA; Texas; Kinosternon indet. (K. flavescens of Rogers 1976)

[53] Late Pliocene, late Blancan NALMA, Piacenzian; Florida; Sternotherus indet. (Bourque and Schubert 2014)

[54] Pleistocene; Nebraska; Kinosternon indet. (K. flavescens of Fichter 1969)

[55] Pleistocene; central Kansas; Kinosternon indet. (K. flavescens of Preston 1979), Sternotherus indet. (S. odoratus of Holman 1972)

[56] Pleistocene; southwestern Kansas; Kinosternon indet. (K. flavescens of Preston 1979), Sternotherus indet. (S. odoratus of Preston 1979; Holman 1987)

[57] Pleistocene; Oklahoma; Kinosternon indet. (K. flavescens of Preston 1979), Sternotherus indet. (S. odoratus of Preston 1979) 
[58] Pleistocene; Texas panhandle; Kinosternon indet. (K. flavescens of Johnson 1974)

[59] Pleistocene; north-central Texas; Sternotherus indet. (S. odoratus of Holman 1963)

[60] Pleistocene; central Texas; Kinosternon indet. (K. flavescens of Holman and Winkler 1987)

[61] Pleistocene; southern Texas; Kinosternon indet. (K. flavescens of Preston 1979)

[62] Pleistocene; Missouri; Sternotherus indet. (S. odoratus of Parmalee and Oesch 1972)

[63] Pleistocene; Indiana; Sternotherus indet. (Sternotherus odoratus of Holman and Richards 1993)

[64] Pleistocene; South Carolina; Kinosternon indet. and Sternotherus indet. (K. subrubrum and S. odoratus of Bentley and Knight 1998)

[65] Pleistocene; northern Florida; Kinosternon indet. (Meylan 1995; K. baurii and K. subrubrum of Bourque 2013)

[66] Pleistocene; central Florida; Kinosternon indet. (K. subrubrum and K. baurii of Weigel 1962), Sternotherus indet. (S. odoratus and S. minor of Weigel 1962)

\section{Appendix 4 Hierarchical Taxonomy of Pan-Kinosternoidea}

Pan-Kinosternoidea Joyce et al., 2004

Emarginachelys cretacea Whetstone, 1978

Planetochelys dithyros Hutchison, 2013

Planetochelys savoiei Weems, 1988

Tullochelys montana Hutchison, 2013

Kinosternoidea Hutchison and Weems, 1998

Pan-Dermatemys Joyce et al., 2004

“Agomphus" alabamensis Gilmore, 1919a

Agomphus oxysternum (Cope, 1877)

Agomphus pectoralis (Cope, 1868)

Hoplochelys clark Knauss et al., 2011

Hoplochelys crassa (Cope, 1888)

Baptemys garmanii (Cope, 1872)

Baptemys nanus (Bourque et al., 2014)

Baptemys wyomingensis (Leidy, 1869)

Pan-Kinosternidae Joyce et al., 2004

Kinosternidae Hay, 1892

Staurotypus moschus Cadena et al., 2012

Baltemys staurogastros Hutchison, 1991

Xenochelys bridgerensis Hutchison, 1991

Xenochelys floridensis Bourque, 2013

Xenochelys formosa Hay, 1906

Xenochelys lostcabinensis Hutchison, 1991

Kinosterninae Lindholm, 1929

Kinosternon arizonense Gilmore, 1923

Kinosternon notolophus Bourque, in press
Kinosternon pannekollops Bourque, in press

Kinosternon pojoaque Bourque, 2012a

Kinosternon rincon Bourque, in press

Kinosternon skullridgescens Bourque, 2012b

Kinosternon wakeeniense Bourque, in press

Sternotherus bonevalleyensis Bourque and Schubert, 2014

Sternotherus palaeodorus Bourque and Schubert, 2014

\section{Literature Cited}

Agassiz, L. 1857. Contributions to the Natural History of the United States of America. Boston: Little, Brown. 643 pp.

AlBRECHT, P.W. 1967. The cranial arteries and cranial arterial foramina of the turtle genera Chrysemys, Sternotherus, and Trionyx: a comparative study with analysis of possible evolutionary implications. Tulane Studies in Zoology 14:81-99.

AlBRIGHT, L.B. 1994. Lower vertebrates from an Arikareean (earliest Miocene) fauna near the Toledo Bend Dam, Newton County, Texas. Journal of Paleontology 68:1131-1145.

ANQUETIN, J. 2012. Reassessment of the phylogenetic interrelationships of basal turtles (Testudinata). Journal of Systematic Paleontology 10:3-45.

BArley, A.J., P.Q. Spinks, R.C. Thomson And H.B. ShafFer. 2010. Fourteen nuclear genes provide phylogenetic resolution for difficult nodes in the turtle tree of life. Molecular Phylogenetics and Evolution 55:1189-1194.

BAUR, G. 1888. Osteologische Notizen über Reptilien. Fortsetzung IV. Zoologischer Anzeiger 11:592-597.

-1893 . Notes on the classification of the Cryptodira. American Naturalist 27:672-675.

BECKER, J.J. 1985. Fossil herons (Aves: Ardeidae) of the late Miocene and early Pliocene of Florida. Journal of Vertebrate Paleontology 5:24-31.

Bentley, C.C. AND J.L. KNIGHT. 1998. Turtles (Reptilia: Testudines) of the Ardis Local Fauna late Pleistocene (Rancholabrean) of South Carolina. Brimleyana 25:3-33.

BEvER, G.S. 2009. Postnatal ontogeny of the skull in the extant North American turtle Sternotherus odoratus (Cryptodira: Kinosternidae). Bulletin of the American Museum of Natural History 330:1-97.

BIEnZ, A. 1895. Dermatemys mavii Gray: eine osteologische Studie mit Beiträgen zur Kenntniss vom Baue der Schildkröten. Revue Suisse de Zoologie 3:61-135.

Boulenger, G.A. 1889. Catalogue of Chelonians, Rhynchocephalians and Crocodiles in the British Museum (Natural History). London: Taylor and Francis. 311 pp.

BOURQUE, J.R. 2011. Reassessment of a putative fossil stinkpot (Kinosternidae: Sternotherus) from the late Miocene (Clarendonian) of Kansas. Journal of Herpetology 45: 234-237.

-2012a. An extinct mud turtle of the Kinosternon flavescens group (Testudines, Kinosternidae) from the middle Miocene (late Barstovian) of New Mexico. Journal of Vertebrate Paleontology 32:68-81.

-2012b. A fossil mud turtle (Testudines, Kinosternidae) from the early middle Miocene (early Barstovian) of New Mexico. Journal of Vertebrate Paleontology 32:836-853. 
-2013. Fossil Kinosternidae from the Oligocene and Miocene of Florida, USA. In: D.B. Brinkman, P.A. Holroyd and J.D. Gardner, eds. Morphology and Evolution of Turtles. Vertebrate Paleobiology and Paleoanthropology Series. Dordrecht, Netherlands: Springer. pp. 459-475.

-New mud turtles (Kinosternidae, Kinosternon) from the middle-late Miocene of the United States. Journal of Paleontology. In press.

Bourque, J.R., J.H. Hutchinson, P.A. Holroyd AND J.I. BLOCH. 2014. A new dermatemydid (Testudines, Kinosternoidea) from the Paleocene-Eocene Thermal Maximum, Willwood Formation, southeastern Bighorn Basin, Wyoming. Journal of Vertebrate Paleontology 35:e905481.

Bourque, J.R. AND B.W. SCHUBERT. 2014. Fossil musk turtles (Kinosternidae, Sternotherus) from the late Miocene-early Pliocene (Hemphillian) of Tennessee and Florida. Journal of Vertebrate Paleontology 35:e885441.

Bramble, D.M., J.H. Hutchison and J.M. Legler. 1984 Kinosternid shell kinesis: structure, function and evolution. Copeia 1984:456-475.

Brattstrom, B.H. 1955A. Pliocene and Pleistocene amphibians and reptiles from southeastern Arizona. Journal of Paleontology 29:150-154.

-1955b. Records of some Pliocene and Pleistocene reptiles and amphibians from Mexico. Bulletin of the Southern California Academy of Sciences 54:1-4.

BRINKMAN, D.B. 2003. A review of nonmarine turtles from the Late Cretaceous of Alberta. Canadian Journal of Earth Sciences 40:557-571.

BRINKMAN, D. AND R. RoRdiguez DE LA Rosa. 2006. Nonmarine turtles from the Cerro del Pueblo Formation (Campanian), Coahuila State, Mexico. New Mexico Museum of Natural History and Science Bulletin 35:229-233.

BRYANT, J.D. 1991. New early Barstovian (middle Miocene) vertebrates from the upper Torreya Formation, eastern Florida panhandle. Journal of Vertebrate Paleontology 11:472-489.

Cadena, E., J.R. Bourque, A.F. Rincon, J.I. Bloch, C.A JARAMILLO AND B.J. MACFADDEN. 2012. New turtles (Chelonia) from the late Eocene through late Miocene of the Panama Canal Basin. Journal of Paleontology 86:539-557.

Cadena, E.R., C.M. Jaramillo and M. Paramo. 2007. The first late Pleistocene record of Kinosternon (Cryptodira: Kinosternidae) turtles for northern South America, Pubenza locality, Colombia. South American Journal of Herpetology 2:201-205.

CARroll, R.L. 1988. Vertebrate Paleontology and Evolution. New York: Freeman. 698 pp.

CisNEROS, J.C. 2005. New Pleistocene vertebrate fauna from El Salvador. Revista Brasileira de Paleontologia 8:239-255.

Cope, E.D. 1868. On some Cretaceous Reptilia. Proceedings of the Academy of Natural Sciences of Philadelphia 20: 233-242.

$-1869 / 70$. Synopsis of the extinct Batrachia, Reptilia and Aves of North America. Transactions of the American Philosophical Society 14:1-248.

-1871. Supplement to the "Synopsis of the Extinct Batrachia and Reptilia of North America." Proceedings of the American Philosophical Society 12:41-52.

-1872 . On a new genus of Pleurodira from the Eocene of Wyoming. Proceedings of the American Philosophical Society $12: 472-477$
-1873. On the extinct Vertebrata of the Eocene of Wyoming observed by the Expedition of 1872, with notes on the geology. In: F.V. Hayden, ed. Sixth Annual Report of the United States Geological Survey of the Territories. Washington, DC: Government Printing Office. pp. 545-649.

-1875. Systematic Catalogue of Vertebrata of the Eocene of New Mexico Collected in 1874. Washington, DC: Govern ment Printing Office. 37 pp.

-1877. On a new species of Adocidae from the Tertiary of Georgia. Proceedings of the American Philosophical Society 17:82-84.

-1882. The reptiles of the American Eocene. American Naturalist 16:979-993.

-1884. The Vertebrata of the Tertiary Formations of the West. Report of the United States Geological Survey of the Territories, Volume 3. Washington, DC: Government Printing Office. $1001 \mathrm{pp}$

-1888. Synopsis of the vertebrate fauna of the Puerco Series. Transactions of the American Philosophical Society $16: 298-361$.

Crawford, N.G., J.F. Parham, A.B. Sellas, B.C. Faircloth, T.C. Glenn, T.J. Papenfuss, J.B. Henderson, M.H. Hansen AND W.B. Simison. 2015. A phylogenomic analysis of turtles. Molecular Phylogenetics and Evolution 83:250-257.

DobiE, J.L. 1980. The musculus retrahens capitis collique complex in some cryptodiran turtles: phylogenetic significance [abstract]. Presented at: American Society of Ichthyologists and Herpetologists, 60th Annual Meeting. 1980 June 15-20. Fort Worth, TX: Texas Christian University.

ERnst, C.H. AND R.W. BARBour. 1989. Turtles of the World. Washington, DC: Smithsonian Institution Press. 290 pp.

ESTES, R. 1988. Lower vertebrates from the Golden Valley Formation, early Eocene of North America. Acta Zoologica Cracoviensia 31:541-562.

ESTES, R. AND J.H. HuTCHISON. 1980. Eocene lower vertebrates from Ellesmere Island, Canadian Arctic Archipelago. Palaeogeography, Palaeoclimatology, Palaeoecology 30: 325-347.

FICHTER, L.S. 1969. Geographical distribution and osteological variation in fossil and Recent specimens of two species of Kinosternon (Testudines). Journal of Herpetology 3: 113-119.

GAFFNEY, E.S. 1975. A phylogeny and classification of the higher categories of turtles. Bulletin of the American Museum of Natural History 155:387-436.

-1979. Comparative cranial morphology of Recent and fossil turtles. Bulletin of the American Museum of Natural History 164:65-376.

GaffneY, E.S. AND P.A. MeYlan. 1988. A phylogeny of turtles. In: M.J. Benton, ed. The Phylogeny and Classification of the Tetrapods, Volume 1. Oxford: Clarendon Press. pp. 157-219.

Gallagher, W.B. 1993. The Cretaceous/Tertiary mass extinction event in the Northern Atlantic Coastal Plain. Mosasaur 5:75-154.

Gilmore, C.W. 1919a. New fossil turtles, with notes on two described species. Proceedings of the United States National Museum 56:113-132.

-1919b. Reptilian faunas of the Torrejon, Puerco, and underlying Upper Cretaceous formations of San Juan County, New Mexico. United States Geological Survey Professional Paper 119:1-68. 
-1923. A new fossil turtle, Kinosternon arizonense, from Arizona. Proceedings of the United States National Museum 62:1-8.

GrAY, J.E. 1825. A synopsis of the genera of reptiles and Amphibia, with a description of some new species. Annals of Philosophy 10:193-217.

-1831. A specimen of a tortoise regarded as the type of a new genus in the family Emydidae. Proceedings of the Zoological Society of London 1831:106-107.

-1847. Description of a new genus of Emydae. Proceedings of the Zoological Society of London 1847:55-56.

-1869 . Notes on the families and genera of tortoises (Testudinata), and on the characters afforded by the study of their skulls. Proceedings of the Zoological Society of London 1869:165-223.

HAY, O.P. 1892. The batrachians and reptiles of the State of Indiana. Annual Report of the Indiana Department of Geology and Natural Resources 17:409-602.

-1902. Bibliography and catalogue of the fossil vertebrata of North America. Bulletin of the United States Geological Survey 179:1-868.

-1905. The fossil turtles of the Bridger Basin. American Geologist 35:327-342.

-1906. Descriptions of two new genera (Echmatemys and Xenochelys) and two new species (Xenochelys formosa and Terrapene putnami) of fossil turtles. Bulletin of the American Museum of Natural History 22:27-31.

-1908a. The Fossil Turtles of North America. Washington, DC: Carnegie Institution of Washington. (Publications 75.) $568 \mathrm{pp}$.

-1908b. Descriptions of five new species of North American fossil turtles, four of which are new. Proceedings of the United States National Museum 35:161-169.

-1911. Descriptions of eight new species of fossil turtles from west of the one hundredth meridian. Proceedings of the United States National Museum 38:307-326

HAYES, F.G. 2000. The Brooksville 2 Local Fauna (Arikareean, latest Oligocene): Hernando County, Florida. Bulletin of the Florida Museum of Natural History 43:1-47.

Holman, J.A. 1963. Late Pleistocene amphibians and reptiles of the Clear Creek and Ben Franklin local faunas of Texas. Journal of the Graduate Research Center, Southern Methodist University 31:152-167.

-1972. Herpetofauna of the Kanapolis local fauna (Pleistocene: Yarmouth) of Kansas. Michigan Academician 5: 87-98.

-1975. Herpetofauna of the WaKeeney local fauna (lower Pliocene: Clarendonian) of Trego County, Kansas. University of Michigan Papers on Paleontology 12:49-66.

-1987. Climatic significance of a late Illinoian herpetofauna from southwestern Kansas. Contributions from the Museum of Paleontology, University of Michigan 27:129141.

-1998. Reptiles of the lower Miocene (Hemingfordian) Pollack Farm Fossil Site, Delaware. Delaware Geological Survey, Special Publication 21:141-147.

Holman, J.A. AND R.L. Richards. 1993. Herpetofauna of the Prairie Creek Site, Davies County, Indiana. Proceedings of the Indiana Academy of Science 102:115-131.

Holman, J.A. AND M.E. SCHLOEDER. 1991. Fossil herpetofauna of the Lisco C Quarries (Pliocene: early Blancan) of
Nebraska. Transactions of the Nebraska Academy of Sciences 18:19-29.

Holman, J.A. AND A.J. WinkLER. 1987. A mid-Pleistocene (Irvingtonian) herpetofauna from a cave in south-central Texas. Pearce-Sellards Series, Texas Memorial Museum 44:1-17.

Holroyd, P. AND J.H. HuTCHISON. 2002. Patterns of geographic variation in latest Cretaceous vertebrates: evidence from the turtle component. Geological Society of America Special Papers 361:177-190.

Holroyd, P.A., J.H. Hutchison and S.G. STRAit. 2001. Turtle diversity and abundance through the lower Eocene Willwood Formation of the southern Bighorn Basin. University of Michigan Papers on Paleontology 33:97-107.

Holroyd, P.A., G.P. Wilson AND J.H. HutChISON. 2014. Temporal changes within the latest Cretaceous and early Paleogene turtle faunas of northeastern Montana. Geological Society of America Special Papers 503:299-312.

Huddlestun, P.E., W.E. MARSALIS AND S.M. PicKerING. 1974 Tertiary stratigraphy of central Georgia coastal plain. Georgia Geological Survey Guidebook 12(2):1-35.

Hutchison, J.H. 1991. Early Kinosterninae (Reptilia: Testudines) and their phylogenetic significance. Journal of Vertebrate Paleontology 11:145-167.

-1992. Western North American reptile and amphibian record across the Eocene/Oligocene boundary and its climatic implications. In: D.R. Prothero and W.A. Berggren, eds. Eocene-Oligocene Biotic and Climatic Evolution. Princeton, NJ: Princeton University Press. pp. 451-463.

-1996. Testudines. In: D.R. Prothero and R.J. Emry, eds. The Terrestrial Eocene-Oligocene Transition in North America. Cambridge: Cambridge University Press. pp. 337-353.

-2013. New turtles from the Paleogene of North America. In: D.B. Brinkman, P.A. Holroyd and J.D. Gardner, eds. Morphology and Evolution of Turtles. Dordrecht, Netherlands Springer. pp. 477-497.

HutChison, J.H. AND D.M. BRAMBLE. 1981. Homology of the plastral scales of the Kinosternidae and related turtles. Herpetologica 37:73-85.

Hutchison, J.H. AND P.A. Holroyd. 2003. Late Cretaceous and early Paleocene turtles of the Denver Basin, Colorado. Rocky Mountain Geology 38:121-142.

Hutchison, J.H., M.J. Knell and D.B. Brinkman. 2013. Turtles from the Kaiparowits Formation, Utah. In: A.L. Titus and M.A. Loewen, eds. At the Top of the Grand Staircase: The Late Cretaceous of Southern Utah. Bloomington, IN: Indiana University Press. pp. 295-318.

Hutchison, J.H. AND R.E. WeEms. 1998. Paleocene turtle remains from South Carolina. Transactions of the American Philosophical Society 88:165-195.

[ICZN] INTERNATIONAL COMMISSION ON ZOOLOGICAL NOMENCLATURE. 1999. International Code of Zoological Nomenclature, 4th ed. London: International Trust for Zoological Nomenclature. $306 \mathrm{pp}$

IVERSON, J.B. 1979. On the validity of Kinosternon arizonense Gilmore. Copeia 1979:175-177.

-1991. Phylogenetic hypotheses for the evolution of modern kinosternine turtles. Herpetological Monographs 5: $1-27$.

-1998. Molecules, morphology, and mud turtle phylogenetics (Family Kinosternidae). Chelonian Conservation and Biology 3:113-117. 
IVERSON, J.B., M. LE AND C. InGRAM. 2013. Molecular phylogenetics of the mud and musk turtle family Kinosternidae. Molecular Phylogenetics and Evolution 69:929-939.

JoHnson, E. 1974. Zooarcheology and the Lubbock Lake Site. Museum Journal (West Texas Museum Association) 15:107-122.

JOYCE, W.G. 2007. A phylogeny of Mesozoic turtles. Bulletin of the Peabody Museum of Natural History 48:3-102.

-2016. A review of the fossil record of turtles of the clade PanChelydridae. Bulletin of the Peabody Museum of Natural History 57(1):21-56.

JoyCE, W.G. AND J.A. GauTHIER. 2004. Paleoecology of Triassic stem turtles sheds new light on turtle origins. Proceedings of the Royal Society of London, Series B, Biological Sciences 271:1-5.

JoYCE, W.G. AND T.R. LYSON. 2011. New material of Gilmoremys lancensis nov. comb. (Testudines: Trionychidae) from the Hell Creek Formation and the diagnosis of plastomenid turtles. Journal of Paleontology 85:442-459.

-2015. A review of the fossil record of turtles of the clade Baenidae. Bulletin of the Peabody Museum of Natural History 56:147-183.

Joyce, W.G., J.F. PARHAM AND J.A. GaUthier. 2004. Developing a protocol for the conversion of rank-based taxon names to phylogenetically defined clade names, as exemplified by turtles. Journal of Paleontology 78:989-1013.

JOYCE, W.G., J.F. PARHAM, T.R. LYSON, R.C.M. WARNOCK AND P.C.J. Donoghue. 2013. A divergence dating analysis of turtles using fossil calibrations: an example of best practices. Journal of Paleontology 87:612-634.

Knauss, G.E., W.G. Joyce, T.R. Lyson and D. Pearson. 2011. A new kinosternoid from the Late Cretaceous Hell Creek Formation of North Dakota and Montana and the origin of the Dermatemys mawii lineage. Paläontologische Zeitschrift 85:125-142.

KrenZ, J.G., G.J.P. NAYlor, H.B. Shaffer and F.J. JanZen. 2005. Molecular phylogenetics and evolution of turtles. Molecular Phylogenetics and Evolution 37:178-191.

KuHn, O. 1964. Fossilium Catalogus, Volume 1: Animalia, Pars 107, Testudines. The Hague: Junk. 299 pp.

Legler, J. ANd R.C. Vogt. 2013. The Turtles of Mexico, Land and Freshwater Forms. Berkeley, CA: University of California Press. 416 pp.

LEIDY, J. 1856. Notices of remains of extinct turtles of New Jersey, collected by Prof. Cook, of the State Geological Survey, under the direction of Dr. W. Kitchell. Proceedings of the Academy of Natural Sciences of Philadelphia 8:303-304.

-1869 . Notice of some extinct vertebrates from Wyoming and Dakota. Proceedings of the Academy of Natural Sciences of Philadelphia 21:63-67.

-1870 . [Remarks on some fossils.] Proceedings of the Academy of Natural Sciences of Philadelphia 1870:3-5.

-1873 . Contributions to the extinct vertebrate fauna of the Western Territories. Washington, DC: Government Printing Office. 358 pp

LICHTIG, A.J. AND S.G. LUCAS. 2015. Turtles of the Eocene Huerfano Formation, Raton Basin, Colorado. New Mexico Museum of Natural History and Science Bulletin 67:153-160.

LINDHOLM, W.A. 1929. Revidiertes Verzeichnis der Gattungen der rezenten Schildkröten nebst Notizen zur Nomenklatur einiger Arten. Zoologischer Anzeiger 81:275-295.
LinNaEus, C. 1766. Systema Naturae, Volume 1. 12th ed. Stockholm: Laurentius Salvius. 532 pp.

Lucas, S.G., S.M. Cather, P. Sealey and J.H. Hutchison. 1989. Stratigraphy, paleontology, and depositional systems of the Eocene Cub Mountain Formation, Lincoln County, New Mexico-a preliminary report. New Mexico Geology 11:11-17.

LYSON, T.R. AND W.G. JOYCE. 2011. Cranial anatomy and phylogenetic placement of the enigmatic turtle Compsemys victa. Journal of Paleontology 85:789-801.

MacFadden, B.J., J.L. Bloch, H. Evans, D.A. Foster, G.S. Morgan, A. Rincon AND A.R. Wood. 2014. Temporal calibration and biochronology of the Centenario Fauna, early Miocene of Panama. Journal of Geology 122:113-135.

MCCORD, R.D. 2016. What is Kinosternon arizonense? Historical Biology 28:310-315.

MCDoweLL, S.B. 1961. On the major arterial canals in the earregion of testudinoid turtles and the classification of the Testudinoidea. Bulletin of the Museum of Comparative Zoology 125:23-39.

-1964. Partition of the genus Clemmys and related problems in the taxonomy of the aquatic Testudinidae. Proceedings of the Zoological Society of London 143:239-279.

MeYLan, P.A. 1995. Pleistocene amphibians and reptiles from the Leisey Shell Pit, Hillsborough County, Florida. Bulletin of the Florida Museum of Natural History 37:273-297.

MeYlan, P.A. and E.S. Gaffney. 1989. The skeletal morphology of the Cretaceous Cryptodiran turtle, Adocus, and the relationships of the Trionychoidea. American Museum Novitates 2941:1-60.

MiLLER, H.W. 1955. A check-list of the Cretaceous and Tertiary vertebrates of New Jersey. Journal of Paleontology 29: 903-914.

MLYNARSKI, M. 1976. Handbuch der Paläoherpetologie, Part 7: Testudines. Stuttgart: Gustav Fischer Verlag. 130 pp.

MoOser, O. 1980. Pleistocene fossil turtles from Aguascalientes, State of Aguascalientes. Universidad Nacional Autónoma de México, Instituto de Geología, Revista 4:63-66.

Morgan, G.S. AND R.S. White. 2005. Miocene and Pliocene vertebrates from Arizona. New Mexico Museum of Natural History and Science Bulletin 29:115-136.

ParmaleE, P.W. and R.D. Oesch. 1972. Pleistocene and recent faunas from the Brynjulfson Caves, Missouri. Illinois State Museum, Reports of Investigations 25:1-52

PARmley, D. 1992. Turtles from the late Hemphillian (latest Miocene) of Knox County, Nebraska. Texas Journal of Science 44:339-348.

PreSTON, R.E. 1979. Late Pleistocene cold-blooded vertebrate faunas from the mid-continental United States, I. Reptilia; Testudines, Crocodylia. University of Michigan Papers on Paleontology 19:1-53.

Pritchard, P.C.H. and P. Trebbau. 1984. The Turtles of Venezuela. Ithaca, NY: Society for the Study of Amphibians and Reptiles. 403 pp.

Rabi, M., V. SuKhanov, V. Egerova, I.G. Danilov and W.G. JOYCE. 2014. Osteology, relationships, and ecology of Annemys (Testudines, Eucryptodira) from the Late Jurassic of Shar Teg, Mongolia, and phylogenetic definitions for Xinjiangchelyidae, Sinemydidae, and Macrobaenidae. Journal of Vertebrate Paleontology 34:327-352. 
RodrigueZ-DE LA Rosa, R. AND S.R.S. CEVAllos-FerRIZ. 1998. Vertebrates of the El Pelillal locality (Campanian, Cerro del Pueblo Formation), southeastern Coahuila, Mexico. Journal of Vertebrate Paleontology 18:751-764.

RoGERS, J.S. 1972. Measures of genetic similarity and genetic distance. University of Texas Publication 7213:145-153.

Rogers, K.L. 1976. Herpetofauna of the Beck Ranch local fauna (Upper Pliocene: Blancan) of Texas. Publications of the Museum, Michigan State University, Biological Series 1:163-200.

ROMER, A.S. 1956. Osteology of Reptiles. Chicago: University of Chicago Press. 772 pp.

SEIDEL, M.E., J.B. IVERSON AND M.D. AdKIns. 1986. Biochemical comparisons and phylogenetic relationships in the family Kinosternidae (Testudines). Copeia 1986:285-294.

Shaffer, H.B., P. MeYlan AND M.L. McKNIGHT. 1997. Tests of turtle phylogeny: molecular, morphological, and paleontological approaches. Systematic Biology 46:235-268.

SiEBENROCK, F. 1909. Synopsis der rezenten Schildkröten mit Berücksichtigung der in historischer Zeit ausgestorbenen Arten. Zoologische Jahrbücher Supplement 10:427-618.

Sonnini, C.S. AND P.A. LATREILLE. 1801. Histoire naturelle des reptiles, avec figures dessine¥es d’apre`s nature, Tome premier. Premie 're partie: Quadrupe'des et Bipe'des Ovipares. Paris: Deterville. 280 pp.

SPINKs, P.Q., R.C. Thomson, M. GIDIS AND H.B. SHAFFER. 2014. Multilocus phylogeny of the New-World mud turtles (Kinosternidae) supports the traditional classification of the group. Molecular Phylogenetics and Evolution 76:254-260.

SPIX, J.B. von. 1824. Animalia Nova sive Species Novae Testudinum et Ranarum, quas in Itinere per Brasiliam Annis 1817-1820 Jussu et Auspiciis Maximiliani Josephi I. Bavariae Regis. Münich: F.S. Hübschmann. 53 pp.

STERLI, J., D. POL AND M. LAURIN. 2013. Incorporating phylogenetic uncertainty on phylogeny-based palaeontological dating and the timing of turtle diversification. Cladistics 29:233-246.

Sugarman, P.J., K.G. Miller, D. Bukry and M.D. Feigenson. 1995. Uppermost Campanian-Maestrichtian strontium isotopic, biostratigraphic, and sequence stratigraphic framework of the New Jersey Coastal Plain. Geological Society of America Bulletin 107:19-37.

SUlLIVAN, R.M., S.E. JasinSKI AND S.G. LuCAS. 2013. Re-Assessment of late Campanian (Kirtlandian) turtles from the Upper Cretaceous Fruitland and Kirtland Formations, San Juan Basin, New Mexico, USA. In: D.B. Brinkman, P.A. Holroyd and J.D. Gardner, eds. Morphology and Evolution of Turtles. Dordrecht, Netherlands: Springer. pp. 337-387.

TomLinson, S.L. 1997. Late Cretaceous and Early Tertiary turtles from the Big Bend region, Brewster County, Texas [dissertation]. Lubbock, TX: Texas Tech University. 194 pp.
Weems, R.E. 1988. Paleocene turtles from the Aquia and Brightseat Formations, with a discussion of their bearing on sea turtle evolution and phylogeny. Proceedings of the Biological Society of Washington 101:109-145.

WeEMS, R.E. AND R.A. GEORGE. 2013. Amphibians and nonmarine turtles from the Miocene Calvert Formation of Delaware, Maryland, and Virginia (USA). Journal of Paleontology 87:570-588.

WeIgEL, R.D. 1962. Fossil vertebrates of Vero, Florida. Florida Geological Survey, Special Publication 10:1-59.

WEST, R.M. AND J.H. HUTCHISON. 1981. Geology and paleontology of the Bridger Formation, southern Green River Basin, southwestern Wyoming. Part 6: The fauna and correlation of Bridger E. Milwaukee Public Museum Contributions in Biology and Geology 46:1-8.

Westgate, J.W. 1989. Lower vertebrates from an estuarine facies of the middle Eocene Laredo Formation (Claiborne Group), Webb County, Texas. Journal of Vertebrate Paleontology 9:282-294.

Whetstone, K.N. 1978. A new genus of cryptodiran turtles (Testudinoidea, Chelydridae) from the Upper Cretaceous Hell Creek Formation of Montana. University of Kansas Science Bulletin 51:539-563.

WiegmanN, A.F. 1828. Beyträge zur Amphibienkunde. Isis 21:364-383.

Wieland, G.R. 1905. Structure of the Upper Cretaceous turtles of New Jersey: Agomphus. American Journal of Science 10:430-444.

WiLliAms, E.E. 1950. Variation and selection in the cervical central articulations of living turtles. Bulletin of the American Museum of Natural History 94:511-561.

-1952. A staurotypine skull from the Oligocene of South Dakota (Testudinata, Chelydridae). Breviora 2:1-16.

WILSON, R.L. 1968. Systematics and faunal analysis of a lower Pliocene vertebrate assemblage from Trego County, Kansas. Contributions from the Museum of Paleontology, University of Michigan 22:75-126.

Woodburne, M.O. 2004. Late Cretaceous and Cenozoic Mammals of North America. Biostratigraphy and Geochronology. New York: Columbia University Press. 391 pp.

Zonneveld, J.-P., G.F. GunNELl AND W.S. BARTELS. 2000. Early Eocene fossil vertebrates from the southwestern Green River Basin, Lincoln and Uinta counties, Wyoming. Journal of Vertebrate Paleontology 20:369-386.

ZUG, G.R. 1966. The penial morphology and the relationships of cryptodiran turtles. Occasional Papers of the Museum of Zoology, University of Michigan 647:1-24.

-1971. Buoyancy, locomotion, morphology of the pelvic girdle and hindlimb, and systematics of cryptodiran turtles. Miscellaneous Publications, Museum of Zoology, University of Michigan 142:1-98.

Editor's note: This article is intended to be included with others in a forthcoming book being coordinated by Walter G. Joyce to elucidate the fossil record of turtles. The individual articles that will form the components of this book are being published separately in the next several volumes of the Bulletin of the Peabody Museum of Natural History. 